\title{
Marine Complex Adaptive Systems: Theory, Legislation and Management Practices
}

Emanuele Bigagli 


\section{Thesis committee}

\section{Promotor}

Prof. Dr A.K. Bregt

Professor of Geo-information Science and Remote Sensing

Wageningen University \& Research

\section{Co-promotor}

Dr M. Craglia

Scientific Officer

European Commission Joint Research Centre, Ispra, Italy

\section{other members}

Prof. Dr J. P. M. Van Tatenhove, Wageningen University \& Research

Dr A. Fischer, Intergovernmental Oceanographic Commission of UNESCO, Paris, France Dr P. C. Smits, European Commission Joint Research Centre, Ispra, Italy Dr W. Bonne, JPI-Oceans, Brussels, Belgium

This research was conducted under the auspices of the C.T. de Wit Graduate School of Production Ecology \& Resource Conservation (PE\&RC) 


\title{
Marine Complex Adaptive Systems: Theory, Legislation and Management Practices
}

\author{
Emanuele Bigagli
}

\section{Thesis}

submitted in fulfilment of the requirements for the degree of doctor at Wageningen University by the authority of the Rector Magnificus

Prof. Dr A.P.J. Mol

in the presence of the

Thesis Committee appointed by the Academic Board to be defended in public on Wednesday 22 March 2017 at 1:30 p.m. in the Aula. 
Emanuele Bigagli

Marine Complex Adaptive Systems: Theory, Legislation and Management Practices. 161 pages.

$\mathrm{PhD}$ thesis, Wageningen University, Wageningen, the Netherlands (2017) With references, with summary in English and Italian

ISBN: 978-94-6343-125-5

DOI: $10.18174 / 408737$ 


\section{Table of Contents}

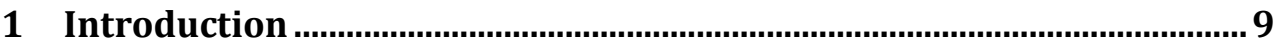

1.1 Background ............................................................................................ 10

1.1.1 Scientific research on marine complex adaptive systems ............................11

1.1.2 Legal frameworks for marine complex adaptive systems............................15

1.1.3 Management practices of marine complex adaptive systems .....................16

1.2 Research gaps ............................................................................................ 17

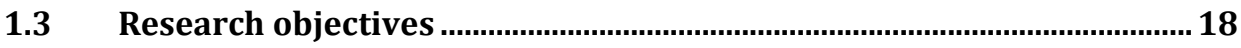

$1.4 \quad$ Structure of the thesis.............................................................................. 19

2 A framework for the assessment and management of marine complex

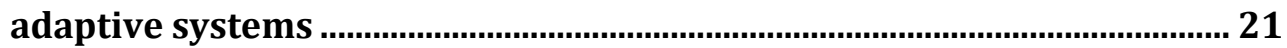

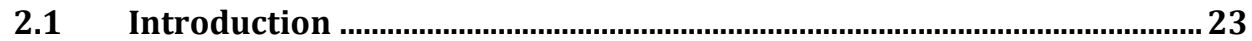

2.2 Adaptive Management and Transition Management …............................ 24

2.2.1 Adaptive Management........................................................................................

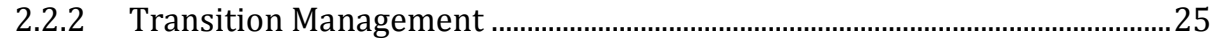

2.2.3 Similarities and differences...............................................................................26

2.2.4 Limitations of AM and TM and reasons for their combination ...................28

2.3 A framework for marine complex adaptive systems...............................29

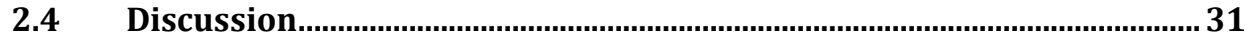

3 The EU legal framework for the management of marine complex

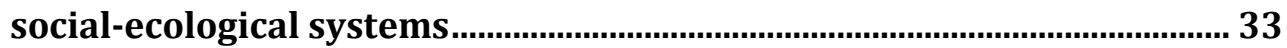

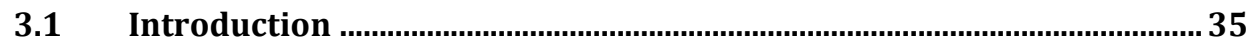

3.2 A complex systems approach for marine social-ecological systems ... 36

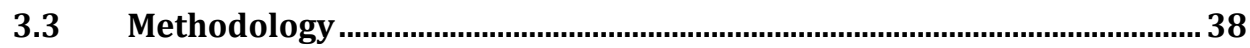

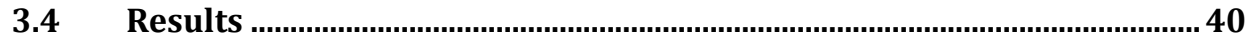

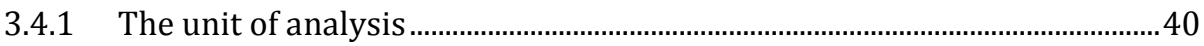

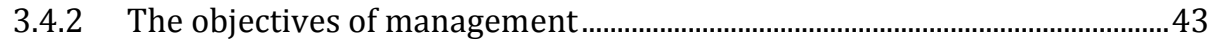

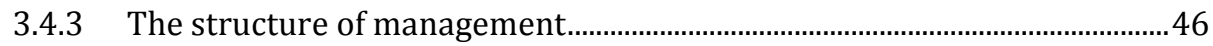

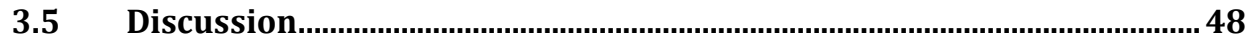

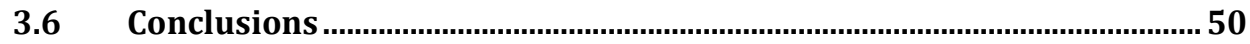

Appendix

4 The international legal framework for the management of the global

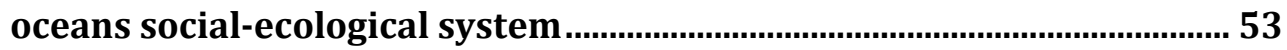

$4.1 \quad$ Introduction 
4.2 A framework for the assessment and management of ocean complex

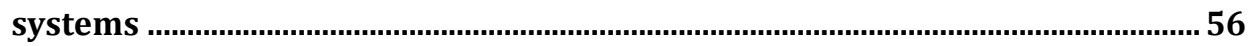

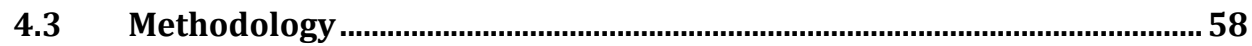

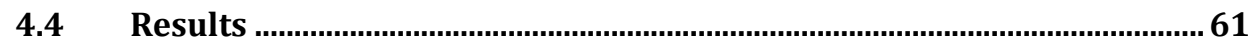

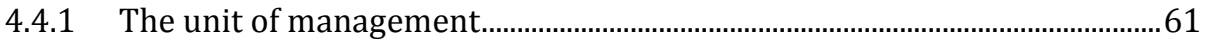

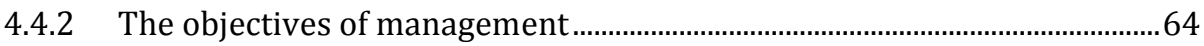

4.4.3 The structure of management..............................................................................

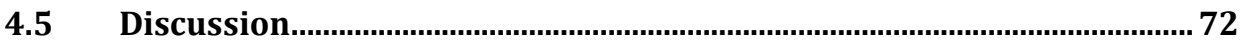

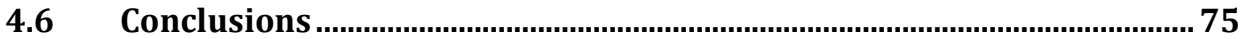

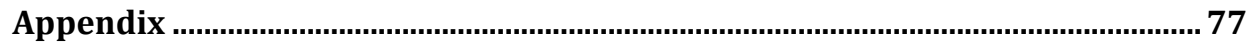

5 The role of the Marine Strategy Framework Directive for marine integrated management in Europe. Lessons from the Adriatic Sea ........ 79

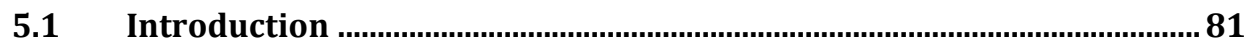

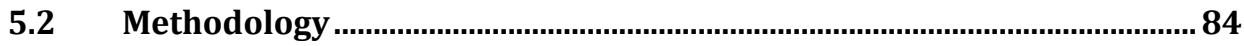

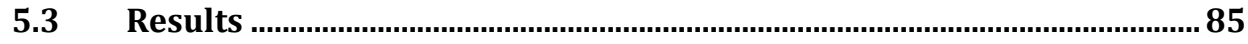

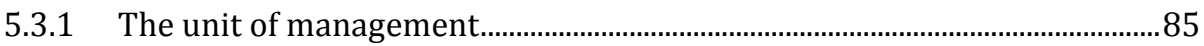

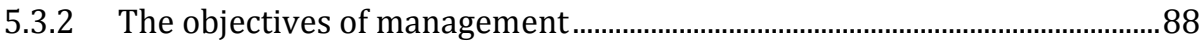

5.3.3 The structure of management........................................................................ 92

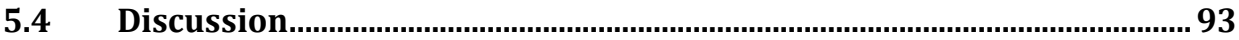

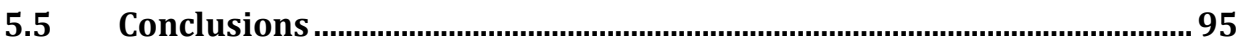

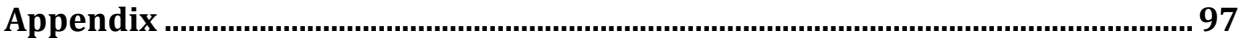

6 Marine monitoring in the European Union: how to fulfil the requirements for the Marine Strategy Framework Directive in an efficient

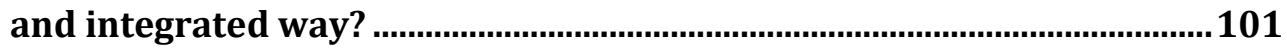

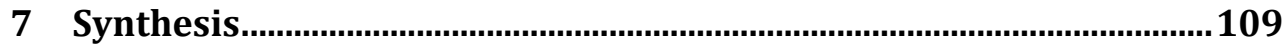

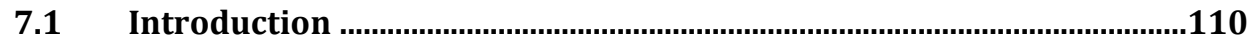

7.2 Research findings .......................................................................110

7.3 Overall reflection ......................................................................................114

7.3.1 Understanding marine Complex Adaptive Systems .....................................114

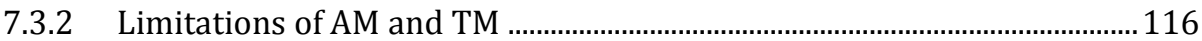

7.3.3 Synergies between AM and TM: are they really possible? ........................117

7.4 Improving legal frameworks and management practices ....................122

7.5 Further research ...........................................................................128

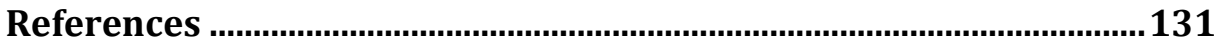

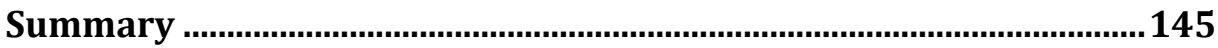




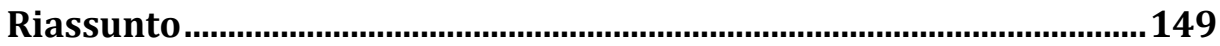

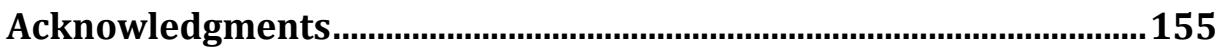

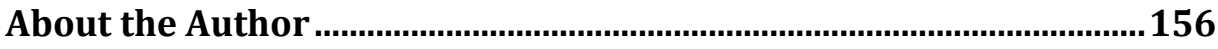

List of Publications .................................................................................... 157

PE\&RC Training and Education Statement ............................................159 



\section{Chapter}

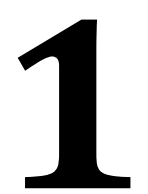

Introduction 


\subsection{Background}

Oceans cover about $71 \%$ of the Earth surface, and hold about $97 \%$ of all water on our planet. They play a major role in global material and energy cycles (Costanza, 1999). Their interactions with atmospheric and terrestrial systems contribute to the regulation of global weather and climate, where water, carbon, and oxygen cycles determine the transfer of heat and energy throughout the globe.

Oceans are unique, critical habitats for feeding, reproduction or juvenile maturation of thousands of species of flora and fauna (Hattam et al., 2015). Moreover, they provide a wide range of services to human communities. They are an essential source of food for millions of people around the globe, especially in low-latitude developing countries (Golden et al., 2016). In 2008, nearly 80 million tonnes of fish were caught or farmed, with an estimated value of 80 billion USD and employing about 35 million people around the globe (TEEB, 2012). Genetic material extracted from marine flora and fauna is used to develop new medicines, while a wide variety of raw materials are extracted for various uses, like weed for industry and fertiliser (Beaumont et al., 2007). Oceans are the dumping ground for million tonnes of waste. Petroleum hydrocarbons and nutrients are detoxified by ocean microbial communities, while other waste such as nuclear waste, heavy metals and artificial organic pollutants like dioxins and DDT are sequestrated far from humans (Peterson and Lubchenko, 1997). Oceans also provide opportunities for tourism, recreation and leisure like coastal tourism, boating, recreational diving and whale-watching. Finally, they have an important "non-use" value especially among indigenous communities, where people benefit from the knowledge that marine ecosystems simply exist of will be around for future generations (Barbier, 2012).

Currently, anthropogenic and climate-related stressors challenge the health of nearly every part of the oceans, from intertidal to coastal and oceanic zones (Halpern et al., 2008). Global warming and increasing anthropogenic pressures alter physical, chemical and biological properties of the ocean, impacting on their capacity to regulate global weather and climate, on ocean productivity and food services, and contributing to the loss or degradation of marine habitats and biodiversity (IOC/UNESCO, 2011; Moomaw and Blankenship, 2014). This in turn has negative impacts not only in the economy of maritime sectors like fisheries, aquaculture, coastal tourism and transportation, but also on the social welfare and the health of dependent coastal populations. 
Traditional practices approached the management of marine environmental and human systems from a sector-based perspective, developing blueprint strategies for the management of specific sectors and related environmental and socio-economic problems. However, scientific literature pointed to how these sector-based, centralised, "command and control" approaches do not have the capacity to solve complex, ill-structured, persistent problems of unsustainability, also called 'wicked' problems (Berkes et al., 2003; Guerry, 2005; Rotmans, 2006; Van den Brugge and van Raak, 2007; Loorbach, 2010; Curtin and Prellezo, 2010; Katsanevakis et al., 2011). The dramatic decline of coastal and oceanic fish stocks caused by overfishing (Lotze et al., 2006); biodiversity losses and transformed food webs, such as phase shifts on coral reefs and in kelp forests (Hughes et al., 2005); and increasing marine pollution and decline in the provision of ecosystem services (Crowder et al., 2006) have been largely attributed to a failure of ocean governance (Crowder and Norse, 2008).

\subsubsection{Scientific research on marine complex adaptive systems}

In order to address this failure, scientific research focused on developing conceptual and methodological frameworks to understand the complexity of coupled environmental and human systems, conceived as Complex Adaptive Systems (CAS). CAS are open systems in which different elements interact dynamically to exchange information, self-organise around one of several possible dynamic equilibrium states, and create many different feedback loops; relationships between causes and effects are nonlinear, and the systems as a whole show path dependency and have emergent properties that cannot be understood by reference to the component parts (Barnes et al., 2003 cited by Grus et al., 2010). CAS are identified by key features and behaviours, which are listed in the first column of Table 1.1.

The so-called Ecosystem Approach, or Ecosystem-Based Management (EBM), emerged as one of the most promising conceptual frameworks to overcome traditional approaches and introduce CAS theory into management practices. In fact, whereas traditional natural resource management had taken an anthropocentric approach, with nature existing to serve human needs, EBM takes a bio/eco-centric perspective, focusing on key ecological, management and social aspects, such as: the emphasis of ecological protection as an essential component of sustainability; the recognition of humans as key elements of the ecosystem; the acknowledgment of complex linkages between ecosystems and social and economic components; the need to consider crossscale interactions; the need to improve management through systematic evaluation, 
and to promote shared responsibility across stakeholders; and the application of a precautionary approach (Grumbine, 1994; Arkema et al., 2006).

Central to EBM is the vision of coupled environmental and human systems as CAS through the notion of social-ecological systems (Berkes, 2003). Social-ecological systems are a particular type of CAS; they are defined as bio-geophysical units and their associated social actors and institutions (Glaser et al. 2008). Table 1.1 depicts the main features and behaviours of social-ecological systems as CAS, including the key features and behaviours of marine systems as social-ecological systems.

Social-ecological systems are delimited by more or less open spatial or functional boundaries, surrounding particular ecosystems and their problem context (Glaser et al. 2008). They show emergent patterns, i.e. large scale structures or regularities that arise due to interactions at smaller scales (Levin, 1998). Impacted by change, socialecological systems tend to adapt and shape in non-linear, unpredictable ways, with lock-in and feedback loop mechanisms, and unpredictable effects also across scales. This implies inherent uncertainty on the capacity to predict system behaviour, because of the organisation of the system around one of several possible equilibrium states (Berkes et al. 2003). Social-ecological systems are not isolated, but are nested in space and time into a system of hierarchies, called panarchy (Holling, 2001). According to this theorisation, change can be transmitted across scales with two types of processes: the so-called 'revolt' process, where fast, small events overwhelm large, slower phenomena at higher scales; and the so-called 'remember' process, where the potential accumulated and stored in larger, slow levels influence the reorganisation of lower scales (a process called 'remember') (Gunderson and Holling, 2002).

Social-ecological systems are characterised by a certain degree of resilience (Holling, 1973). Resilience is defined as the ability of a system to withstand shocks, maintain stability during disturbances and rebuild itself when required (Carpenter et al. 2001). When social-ecological resilience diminishes, regime shifts may occur. Regime shifts are defined as abrupt, high-amplitude and low-frequency changes events that occur over large spatial scales and that are evident in multiple bio-physical attributes over a range of trophic levels (Lees et al., 2006). They are characterised by multiple causality, scale-dependent patterns and multiple possible final states (Levin and Möllmann, 2015). 
Table 1.1: Key features and behaviours of marine social-ecological systems as CAS (adapted from van der Lei et al., 2009 and Grus et al., 2010; based on Hughes et al., 2005, Halpern et al. 2008, Perry et al., 2010 and Hagstrom and Levin, 2016).

\begin{tabular}{|c|c|c|}
\hline $\begin{array}{l}\text { CAS features } \\
\text { and } \\
\text { behaviours }\end{array}$ & Social-ecological systems & Marine social-ecological systems \\
\hline \multicolumn{3}{|l|}{ Features } \\
\hline Components & $\begin{array}{l}\text { Biophysical components: } \\
\text { ecological structures and } \\
\text { functions; } \\
\text { Human components: social } \\
\text { systems; economic systems; } \\
\text { cultural, political and ethical } \\
\text { aspects }\end{array}$ & $\begin{array}{l}\text { Biophysical components: } \\
\text { oceanographic and physico-chemical } \\
\text { features; ecological structures and } \\
\text { functions (marine biodiversity and } \\
\text { food webs) } \\
\text { Human components: maritime } \\
\text { sectors (e.g. fisheries, } \\
\text { transportation, coastal tourism, } \\
\text { energy extraction) and dependent } \\
\text { communities and institutions }\end{array}$ \\
\hline $\begin{array}{l}\text { Path } \\
\text { dependency }\end{array}$ & $\begin{array}{l}\text { Social-ecological systems } \\
\text { may exhibit hysteresis, i.e. } \\
\text { the time-based dependence } \\
\text { of the output of a system } \\
\text { based on present and past } \\
\text { inputs. }\end{array}$ & $\begin{array}{l}\text { Examples of path dependency and } \\
\text { hysteresis include the failed } \\
\text { recovery of fish stocks even though } \\
\text { fishing bans and reduction of } \\
\text { overfishing have been implemented } \\
\text { (Hughes et al., 2005) }\end{array}$ \\
\hline $\begin{array}{l}\text { Emergent } \\
\text { patterns }\end{array}$ & $\begin{array}{l}\text { Social-ecological systems } \\
\text { show large-scale structures } \\
\text { or regularities that arise } \\
\text { due to interactions at } \\
\text { smaller scales }\end{array}$ & $\begin{array}{l}\text { Ocean emergent patterns emerge } \\
\text { e.g. at microbial level, such as the } \\
\text { Sheldon Spectrum }^{1} \text { and Margalef's } \\
\text { Mandala }^{2} \text { (Hagstrom and Levin, } \\
\text { 2016) }\end{array}$ \\
\hline Openness & $\begin{array}{l}\text { Social-ecological systems } \\
\text { are delimited by open } \\
\text { spatial or functional } \\
\text { boundaries }\end{array}$ & $\begin{array}{l}\text { Marine social-ecological systems are } \\
\text { open to interactions with the global } \\
\text { oceans and at lower scales, and with } \\
\text { atmospheric and freshwater systems }\end{array}$ \\
\hline $\begin{array}{l}\text { Scale } \\
\text { independence }\end{array}$ & $\begin{array}{l}\text { Social-ecological systems } \\
\text { have scale independent } \\
\text { properties; they are nested } \\
\text { into hierarchies, called }\end{array}$ & $\begin{array}{l}\text { Oceans have scale independent } \\
\text { properties (e.g. currents, pH and } \\
\text { salinity); cross-scale influences exist }\end{array}$ \\
\hline
\end{tabular}




\begin{tabular}{|c|c|c|}
\hline & $\begin{array}{l}\text { panarchy, with cross-scale } \\
\text { influences ('revolt' and } \\
\text { 'remember') }\end{array}$ & $\begin{array}{l}\text { with global, regional and local } \\
\text { oceans and seas. }\end{array}$ \\
\hline \multicolumn{3}{|l|}{ Behaviours } \\
\hline Adaptability & $\begin{array}{l}\text { The degree of resilience of } \\
\text { the system determines its } \\
\text { capacity to adapt to change } \\
\text { and maintain its structure } \\
\text { and functions }\end{array}$ & $\begin{array}{l}\text { Oceans adapt to anthropogenic } \\
\text { stressors and climate change } \\
\text { through phenomena and processes } \\
\text { such as ocean acidification and } \\
\text { warming and increased carbon } \\
\text { uptake }\end{array}$ \\
\hline $\begin{array}{l}\text { Self- } \\
\text { organisation }\end{array}$ & $\begin{array}{l}\text { Social-ecological systems } \\
\text { have no single centralised } \\
\text { mechanism that governs } \\
\text { them; they organise around } \\
\text { one of several possible } \\
\text { states }\end{array}$ & $\begin{array}{l}\text { Overall ocean behaviour derives } \\
\text { from the interactions of its } \\
\text { components, without central } \\
\text { steering mechanisms. }\end{array}$ \\
\hline $\begin{array}{l}\text { Nonlinear } \\
\text { behaviour }\end{array}$ & $\begin{array}{l}\text { The passing of thresholds to } \\
\text { specific functions or } \\
\text { components of social- } \\
\text { ecological systems may lead } \\
\text { to cumulative, multiplied } \\
\text { effects and trigger regime } \\
\text { shifts }\end{array}$ & $\begin{array}{l}\text { Multiple anthropogenic and climatic } \\
\text { drivers and stressors at various } \\
\text { scales have a cumulative effect on } \\
\text { oceans ecosystems and services and } \\
\text { may trigger local regime shifts }\end{array}$ \\
\hline $\begin{array}{l}\text { Feedback loop } \\
\text { mechanisms }\end{array}$ & $\begin{array}{l}\text { Social-ecological systems } \\
\text { may exhibit positive or } \\
\text { negative feedback loops } \\
\text { among ecological systems, } \\
\text { and with associated human } \\
\text { components }\end{array}$ & $\begin{array}{l}\text { Examples of positive feedback loop } \\
\text { mechanisms in marine social- } \\
\text { ecological systems are the link } \\
\text { between phosphorus discharges, } \\
\text { algal blooms and eutrophication, } \\
\text { and the link between overfishing, } \\
\text { food web distortions, macro-algae } \\
\text { blooms and corals replacement } \\
\text { (Hughes et al., 2005). }\end{array}$ \\
\hline
\end{tabular}

\footnotetext{
1 The Sheldon spectrum describes a regularity in aquatic ecosystems, where there are equal amounts of biomass in each logarithmically spaced size class.

2 The Margaref's Mandala accurately predicts the cell-size and motility of phytoplankton as a function of the level of nutrients and turbulence in their environment.
} 
The purpose of management of social-ecological systems is no longer to control and prevent change, but to enhance the capacity of the system to cope with, adapt to and shape change (Ostrom, 2007). As stated by McLeod et al. (2005), the goal of management should be to maintain ecosystems in a healthy, productive and resilient condition so that they can sustain human uses and provide the goods and services humans want and need. This should be based on a comprehensive understanding of the social-ecological system and its resilience, and a characterisation of regime shifts with suitable indicators and risk analyses (Levin and Möllmann, 2015). Deliberate experiments and learning processes should be supported, where the periodic formulation, implementation and revision of policy is based on the results of system monitoring (Walters, 1986).

\subsubsection{Legal frameworks for marine complex adaptive systems}

In the last decade, the principles of EBM started to be introduced into the texts of international agreements, especially in relation to the protection of the marine environment and the regulation of maritime activities. The United Nations Convention on Biological Diversity (CBD), a multilateral agreement on the conservation of biodiversity, the sustainable use of its components and the fair and equitable sharing of benefits arising from genetic resources, defined EBM as "a strategy for the integrated management of land, water and living resources that promotes conservation and sustainable use in an equitable way". Chapter 17 of the Agenda 21, devoted to the protection of the oceans, their rational use and development of their living resources, identifies global oceans as an "integrated whole that is an essential component of the global life-support system" (Rothwell, 2010). More recently, the Regional Seas Programme (RSP) of the United Nations Environment Programme (UNEP) stated the necessity to apply an ecosystem approach for healthy, productive and resilient oceans (UNEP, 2013). More in general, hundreds of international agreements are today in place, regulating these issues at global, regional seas and local levels.

Several voices in literature point to the fact that this legal framework is fragmented (Rothwell and Stephens, 2010; Freestone, 2011; Scott, 2011) and inadequate to tackle the challenges of managing the ocean complex system (Vidas, 2011). This view is shared also by the United Nations Secretary General, who raised the need for a better horizontal and vertical integration among levels of ocean governance, in order to foster the implementation of an ecosystem approach to the global oceans (UN Secretary General Report, 2006). 
In the European Union (EU), the principles of EBM have been introduced in 2000 with the approval of the Water Framework Directive (WFD; 2000/60/EC) for continental freshwater systems, including transitional and coastal waters. This process has been extended in 2008 with the Marine Strategy Framework Directive (MSFD; 2008/56/EC), targeted at the achievement of the Good Environmental Status (GES) of European seas and oceans by 2020. These Directives are part of a legal framework composed of more than 12,000 legal acts, which is perceived as deeply fragmented, with several levels of management (from municipalities to regions, Member States and European institutions) sharing competences and objectives in different sectors and in different ways inside each Member State. Fragmentation is reflected also in the production, use and sharing of knowledge required to support marine European policies. As noted by the European Commission, marine knowledge in the EU is very scattered and costineffective (European Commission, 2009), with overlaps and gaps in data availability (Meiner, 2010). Most data collection activities are focused on meeting the needs of a single purpose, be it part of a regulatory requirement, operational purposes or further scientific understanding (European Commission, 2010). This aspect has been identified as one of the primary obstacles towards an effective implementation of marine environment protection and management policies (Cicin-Sain and Belfiore, 2005). Also maritime stakeholders highlighted the concern for a more clear-cut legal framework on maritime affairs (European Commission, 2008). In order to tackle these issues, the European institutions launched in 2007 the Integrated Maritime Policy (IMP). One of the declared objectives of the IMP is to promote the integration of governance and to improve the quality of sector-based maritime policies through "an active search for synergies and increased coherence across sectors" (European Commission, 2007). This was accompanied by the recognition of the need to reduce operational costs and delays for marine data users, to increase competition and innovation amongst users and reusers of marine data, by providing wider access to high quality, rapidly available and coherent marine data; and to reduce uncertainty in knowledge (European Commission, 2010). However, the IMP has been criticised for lacking a coherent strategy for sustainable fisheries, and failing to integrate major sectors impacting of marine ecological health, like agriculture (Salomon, 2009).

\subsubsection{Management practices of marine complex adaptive systems}

Driven by legal developments, marine EBM recently started to be applied to the practice of management of marine social-ecological systems all around the world. A first example of application of an EBM approach is the promotion of the use of networks of Marine Protected Areas (MPAs) to support marine resilience in the USA, with special 
focus on certain species, like highly migratory species, and on certain pressures, like climate warming and disease and non-indigenous species (Ruckelshaus et al., 2008). In Canada, marine management strategies have been developed for the harmonisation of the activities of maritime sectors, in order to achieve agreed management goals, by engaging stakeholders into a cooperative environment (Curtin and Prellezo, 2010). In Australia, the Great Barrier Reef Marine Park Authority applied long since an ecosystem-based approach, emphasising aspects like management at the ecosystem level, public participation and monitoring and performance evaluation (Curtin and Prellezo, 2010). Ruckelshause et al. (2008) identify the Great Barrier Reef experience as "the current gold standard for EBM in the oceans", mainly because of its capacity to integrate environmental and human systems.

The implementation of a public policy is in general a non-straightforward process, especially in the EU where multiple decision points and opportunities for national governments to deviate from the understanding of legislators (Dimitrakopoulos and Richardson, 2001). As for marine EBM, its implementation has been acknowledged as a significant hurdle, as demonstrated by recent scientific literature (Arkema et al., 2006; Levin et al., 2009; Tallis et al., 2010; Katsanevakis et al., 2011). In fact, several voices in literature point to the difficulties in translating EBM into practice. Arkema et al. (2006) highlighted how different approaches between scientists and managers on system characterisation and the formulation of management priorities may lead to the result that critical ecological and human factors are missing into management plans. Levin et al. (2009) pointed to the lack of practical advice to inform management authorities on how to select specific management measures to achieve EBM goals. Katsanevakis et al. (2011) pointed to the existence of major science and knowledge gaps, especially on the dynamics and resilience of populations, biological communities and ecosystems, the dynamics of human uses of marine ecosystems and their cumulative impacts on the marine environment, the effectiveness of management and governance systems, and how to conduct fully integrated assessments across environmental, economic, and social dimensions of marine systems. Finally, Tallis et al. (2010) showed that managers may have a "difficulty bias", i.e. they may perceive that the implementation of EBM is complicated and expensive, with prohibitive data requirements and lacking testing with long-term applications.

\subsection{Research gaps}

Several analyses have been conducted in literature, investigating both the international (Kimball, 2001; Gjerde et al., 2008; Freestone, 2011; Gjerde et al., 2013; Ban et al., 2014; Rochette et al., 2014; Warner et al., 2014; Mahon et al., 2015) and EU (Nixon et al., 1996; 
Borja et al., 2008; De Santo, 2010) legal frameworks for the protection of the marine environment. However, none of them evaluated these legal frameworks from the perspective of complex adaptive systems, resilience and social-ecological systems. In 1996, the European Environment Agency (EEA) required to conduct a study, which identified and reviewed the monitoring requirements of existing and proposed EU legislation, policy and international agreements regarding the EU water policy (Nixon et al, 1996). Although this study gathered details on the data collection and monitoring required by the international conventions applying to the EU, however this study covered legislation about all types of water (e.g. freshwater, drinking water) that is now old and, for the most part, repealed. Borja et al. (2008) identified a list of recent legislative instruments approved worldwide, to address the need to assess the ecological status of, and pressures and impacts on the marine environment. This list, however, is not exhaustive, as it covers only two legal acts, the WFD and MSFD. De Santo, 2010 lists the qualitative measures included in Annex I of the MSFD, which overlap with the requirements under other EU legislation (e.g. the Habitats Directive, the WFD and the Common Fisheries Policy). This analysis is focused on this particular legal act, and no details about monitoring activities are provided (De Santo, 2010).

\subsection{Research objectives}

The main objective of this thesis is to fill these gaps in literature, and evaluate if a complex systems approach is in place for the assessment and management of marine complex adaptive systems. To this purpose, it is necessary to review current scientific approaches to marine complex systems assessment and management and provide for the first time a comprehensive evaluation of the legal frameworks and policy practices against these scientific requirements. Finally, as mentioned in Section 1.3, legislation must be evaluated also 'on the field', as the way it is implemented may considerably affect its effectiveness. Hence, there is the need to integrate the evaluation of the performance of the legal frameworks with an investigation of how legal acts are translated into policy practices.

The main research objective is divided into four sub-objectives:

1. Sub-objective 1: Develop a framework for marine complex adaptive systems assessment and management;

2. Sub-objective 2: Evaluate the entire European Union (EU) legal framework against the framework developed;

3. Sub-objective 3: Evaluate the international legal framework for the assessment and management of the global oceans against the framework developed; and 
4. Sub-objective 4: Evaluate the implementation of the EU and global legal frameworks into practice.

\subsection{Structure of the thesis}

This thesis is structured into 7 chapters, as illustrated in Figure 1.1.

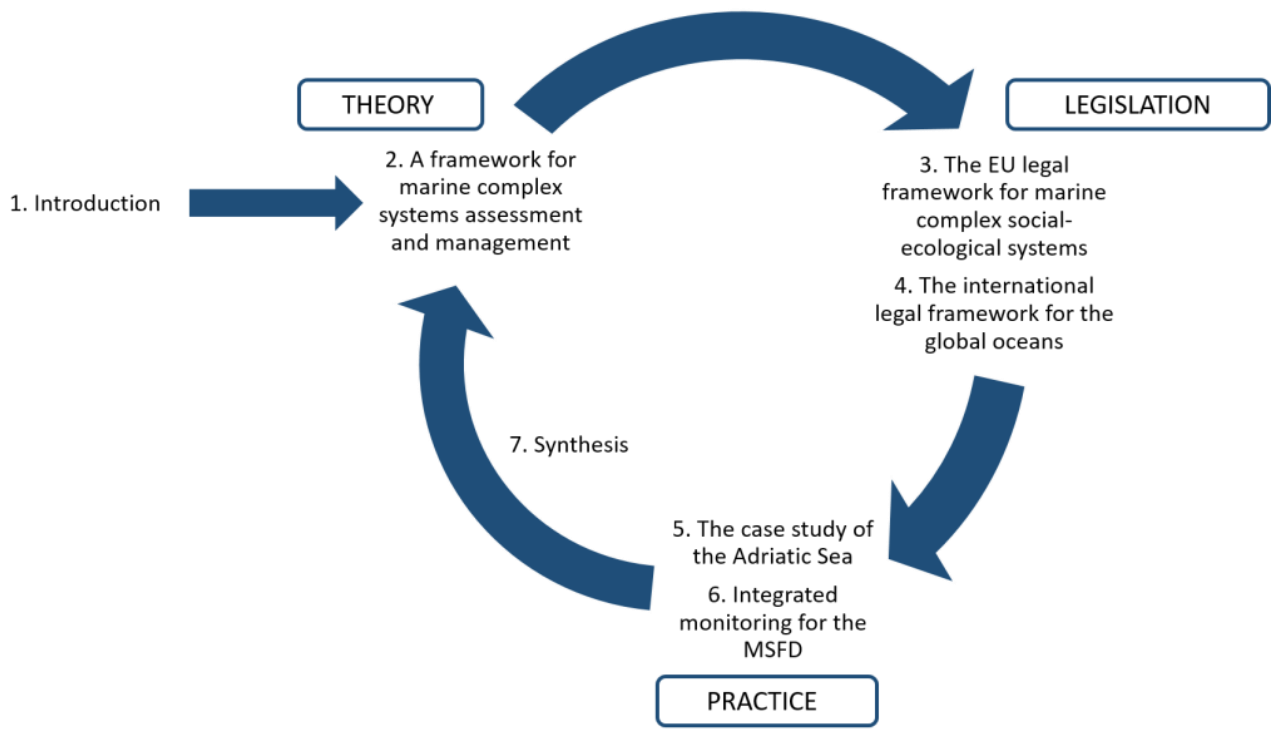

Figure 1.1: Overview of the chapters of the thesis.

Chapter 2 reviews the theoretical frameworks in place for the assessment and management of marine complex adaptive systems. It focuses on two promising approaches, partially based on the EBM: Adaptive Management (AM) and Transition Management (TM), and suggests their combination into a framework for the assessment and management of marine social-ecological systems. Chapters 3 and 4 evaluate two parallel legal regimes for marine assessment and management against the framework developed in Chapter 2. Chapter 3 focuses on the EU legal framework, while Chapter 4 evaluates the international agreements applied to the global oceans. Chapter 5 evaluates the implementation of the EU and global legal frameworks into the practice of assessment and management of a case-study area, the Adriatic Sea. Chapter 6 builds on the findings of Chapter 5 and suggests ways to integrate the monitoring activities required by the MSFD, also across borders. Finally, Chapter 7 synthesizes the major findings of this thesis. Lessons are derived on the possibility and usefulness of 
combining the theoretical approaches identified and of using them to evaluate the legal frameworks and management practices. Obstacles and opportunities to support their implementation are discussed, including suggestions for further research. 


\section{Chapter}

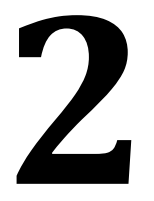

A framework for the assessment and management of marine complex adaptive systems

Emanuele Bigagli 


\begin{abstract}
Adaptive Management (AM) and Transition Management (TM) have emerged as promising frameworks for managing change and achieving sustainability of complex environmental and human systems. However, when it comes to their implementation into practice, each approach shows limitations. On the one hand, AM theory and practices do not pay enough attention to micro-level socio-economic components and their complex interactions with ecological resilience. On the other hand, TM has been criticised for its relative isolation, and for giving ecological aspects only a general value, without incorporating them into the sustainability assessment. This paper suggests to combine AM and TM into a framework for marine complex adaptive systems assessment and management, in order to overcome these limitations. The proposed framework is articulated intro three components: (i) the unit of management - socialecological and connected socio-technical systems; (ii) the objectives of management ecological resilience and transitions of unsustainable socio-technical systems; and (iii) the structure of management - iterative, learning- and science-based policy cycles, coordinated across sectors. The proposed framework has three benefits. First, it is possible to overcome AM's limitations and better characterise micro-level socioeconomic components through TM's view of socio-technical systems, actors and institutions. Second, it is possible to improve TM's consideration of environmental aspects into system assessment and management through the systematic inclusion of AM managers into the transition arena. Third, and more in general, by linking the two strands of management it is possible to reduce current fragmentation and support the implementation of an integrated approach to marine systems assessment and management.
\end{abstract}

Keywords: Adaptive management; Transition Management; social-ecological systems; integrated management; ecological resilience; transitions. 


\subsection{Introduction}

Over the past decades, complex, ill-structured, persistent problems of un-sustainability of environmental and human systems (Rotmans, 2006; Loorbach, 2010) triggered a shift both in scientific theorisation and management practices, from a sectorial, centralised, "command and control" approach (van der Brugge and van Raak, 2007), towards a new paradigm. This new paradigm is rooted in the consideration of environmental and human systems as Complex Adaptive Systems (CAS). CAS are considered as open, self-organizing systems, composed of multiple variables, interacting in complex, non-linear and often path-dependent ways, with feedback loops and emergent properties that cannot be understood by reference to specific components (Cumming et al., 2005; Rotmans and Loorbach, 2008) or to single disciplines (Liu et al., 2007).

Two theoretical approaches, in particular, emerged as promising conceptual and methodological frameworks to manage change and achieve sustainability in complex environmental and human systems: Adaptive Management (AM) and Transition Management (TM) (Foxon et al., 2009). Similarities and differences between the two approaches, as well as possibilities and potential benefits of their combination of crossfertilisation, have already been reviewed in literature (van der Brugge and van Raak 2007; Foxon et al. 2009; Smith and Stirling 2010; Voss and Bornemann, 2011). However, these investigations did not give enough attention to the analysis of important limitations of both approaches. Depending on the thematic and geographic area, authorities implementing AM practices tend to focus mainly on ecological aspects, using frameworks for analysis and conceptualisation that may not fully take into account the complexity of social systems and their dynamics, and their interactions with ecological systems (Binder et al., 2013). Moreover, they often lack the political strength to support environmental considerations in cases of conflict with economic and social ones. At the same time, TM strategies tend to be applied to a particular area, or sector, in isolation, with little or no connection with other initiatives or systems. In addition to this, concerns have been expressed in the literature, about transitions not always taking into account environmental consideration into system assessment (Dryzek, 2013; Olsson et al., 2014; Pereira et al., 2015).

This paper suggests a way to combine AM and TM into a framework for the assessment and management of marine complex adaptive systems, which is based on the assumption that each approach has the potential to overcome the limitations of the other. Section 2.2 presents AM and TM and illustrates their similarities and differences. Section 2.3 focuses on the limitations of the two approaches and the potential for their 
combination. Then, Section 2.4 presents a framework for marine complex adaptive systems assessment and management, based on the positive contributions of AM and TM. Finally, Section 2.5 briefly discusses the potential benefits and limitations of the proposed framework.

\subsection{Adaptive Management and Transition Management}

\subsubsection{Adaptive Management}

Adaptive Management emerged in the last decades in the field of ecosystem studies and theory of management, as a natural progression of earlier ecosystem approaches. AM focuses on social-ecological systems, defined as bio-geophysical units and their associated social actors and institutions (Glaser et al., 2008). Social-ecological systems are delimited by (more or less open) spatial or functional boundaries surrounding particular ecosystems and their problem context (Glaser et al., 2008). Impacted by change, they tend to adapt and shape in non-linear, unpredictable ways; this implies inherent uncertainty on the capacity to predict system behaviour, because of the organisation of the system around one of several possible equilibrium states (Berkes et al., 2003).

The objective of AM is to maintain and enhance the resilience of the social-ecological system. Resilience is defined as the ability of a system to withstand shocks, maintain stability during disturbances and rebuild itself when required (Carpenter et al., 2001). In this perspective, the purpose of management is not to control change in stable systems, but to enhance the capacity of social-ecological systems to cope with, adapt to and shape change (Ostrom, 2007). Resilience is often measured through the identification of thresholds assigned to key system components and interactions. Such thresholds are considered as hypotheses on the status of the system (Garmestani and Harm Benson, 2013) to be continuously challenged and updated through data and learning.

Social-ecological systems are not isolated, but are nested in space and time. Such hierarchies, called 'panarchy' (Holling, 2001), are adaptive and sensitive; they operate in multiple directions, transmitting change across levels. For this reason, socialecological systems should be managed in a multi-scale approach. Finally, AM recognizes the need to base management practices in sound data and information. Such management needs to follow an iterative, learning-based cycle of policy formulation, implementation, and revision of policy based on the results of monitoring. 
AM is considered as an emerging scientific paradigm for integrated, sustainable management of marine social-ecological systems (Crowder and Norse, 2008; Levin et al., 2009; Perry et al., 2010; Katsanevakis et al., 2011). Legal frameworks and management practices recently introduced AM principles (e.g. the Convention on Biological Diversity; the Bergen Declaration for the North Sea; and countries like Australia, Canada and the United States of America, and the European Union), with results still unclear in relation to their efficacy. Science and knowledge gaps; constraints in policies and legislation; institutional fragmentation; and difficulties in coupling environmental protection and sustainable use of resources with stakeholders, are some of the limitations identified in the application of AM strategies (Arkema et al., 2006; Katsanevakis et al., 2011).

\subsubsection{Transition Management}

Transition Management has been developed in the Netherlands by the Dutch Scientific Network on Transitions (KSI; Fischer-Kowalski and Rotmans, 2009). The point of departure of TM is the notion of 'wicked' problems, problems which are deeply embedded in our societal structures, fraught with structural uncertainty and difficult to interpret and manage (Fischer-Kowalski and Rotmans, 2009). Wicked problems affect socio-technical systems (Smith and Stirling, 2010), i.e. the linkages between elements necessary to fulfil societal functions, such as transport, communication and nutrition (Geels, 2004). Socio-technical systems are articulated along the production, distribution and consumption of a good or service, and the corresponding level of technology required in order to fulfil such functions. By nature, socio-technical systems are not place-based, but operate across multiple spatial domains.

Socio-technical systems interact on a reciprocal basis with two other components: actors and regimes. Actors are the social groups who maintain and refine the elements of a socio-technical system; these include not only firms and engineers, but also scientists, users, policy makers and societal groups. Regimes are defined as the semicoherent sets of rules and norms that guide and orient activities of social groups. These three elements influence each other, reciprocally. Rules and norms guide the perceptions and interactions between actors, and are embedded in production practices and product characteristics. At the same time, socio-technical systems shape the perceptions of actors, their behavioural patterns and activities (Geels, 2004), as well as the rules of the system. 
Transition research aims at understanding how sustainable regimes may emerge and be established over time. Unsustainable socio-technical systems require transitions, i.e. fundamental changes in physical, economic and institutional structures, culture and practices (Rotmans and Loorbach, 2008). According to TM, change happens at first in niches, emerging structures with different characteristics from the incumbent regime. Niches are incubators of novelty, like new technologies or new rules and legislation, which, if successful, may trigger the transition of the whole socio-technical system. Socio-technical systems are not isolated, but they are included into the so-called landscape, consisting of social values, political cultures, economic development and trends, and which defines room and direction of potential change.

Management for transitions should follow a cyclical, participatory process, called Integrated Sustainability Assessment (ISA) (Rotmans, 2006). The first step of the ISA process is the analysis of the system and the identification of the 'wicked' problem to solve, including the setting of 'transition arenas' composed of all relevant stakeholders. The outcome of debate into the arena is the formulation of a shared vision of sustainability for the socio-technical system, which should then be implemented. Finally, results should be monitored and used to inform a new policy cycle.

Unlike AM, TM has not been applied to the marine domain. Existing studies focused on the energy and waste sectors (Kern and Smith, 2008; Loorbach et al., 2003), on local or corporate governance (Loorbach and Rotmans, 2010) or on historical analyses (Rotmans and Loorbach, 2008). The only study on water issues related to the Dutch water system and the main impediments to the transition towards an Integrated Water Resource Management (Van der Brugge and Rotmans, 2007).

\subsubsection{Similarities and differences}

The two theoretical approaches presented above have already been reviewed in literature (Foxon et al., 2009; Smith and Stirling, 2010; Voss and Bornemann, 2011). Table 2.1 summarises the major similarities and differences between the two approaches.

The first point of similarity between the two approaches is the adoption of the conceptual lens of complexity. Iteration of policies and learning are advocated by both $\mathrm{AM}$ and TM as the key strategies to reduce the inherent and irreducible uncertainty in the knowledge of a complex system (for AM, see e.g. Walters, 1986; Mee, 2005; Levin et al., 2009; for TM, see e.g. Rotmans, 2006). Moreover, both approaches share a multi- 
scale view: in AM it is called panarchy, while in TM it is referred to as 'multi-level framework', and relates to three functional levels (niche, regime and landscape) and the way change spreads from lower to higher levels (Rip and Kemp, 1998).

Table 2.1: Similarities and differences between, and limitations of Adaptive Management and Transition Management. Extended from Smith and Stirling, 2010.

\begin{tabular}{|c|c|c|}
\hline Criteria & Adaptive Management & Transition Management \\
\hline \multirow{2}{*}{$\begin{array}{l}\text { Unit of } \\
\text { management }\end{array}$} & Social-ecological system & Socio-technical system \\
\hline & $\begin{array}{l}\text { Rooted in a spatial context (e.g. } \\
\text { watershed, region) }\end{array}$ & $\begin{array}{l}\text { Not place-bound; it operates } \\
\text { simultaneously across multiple } \\
\text { loci }\end{array}$ \\
\hline $\begin{array}{l}\text { Objectives of } \\
\text { management }\end{array}$ & $\begin{array}{l}\text { Achieve or maintain system } \\
\text { resilience }\end{array}$ & $\begin{array}{l}\text { Stimulate transition of the } \\
\text { system towards sustainability }\end{array}$ \\
\hline $\begin{array}{l}\text { Structure of } \\
\text { management }\end{array}$ & $\begin{array}{l}\text { Iterative, participatory policy } \\
\text { cycle in four phases: } \\
\text { 1. Initial assessment of the } \\
\text { system and definition of the } \\
\text { problems; } \\
\text { 2. Elaboration and choice of } \\
\text { management alternatives, and } \\
\text { related indicators; } \\
\text { 3. Implementation of policy; } \\
\text { 4. Monitoring to verify } \\
\text { effectiveness of policy and for } \\
\text { learning }\end{array}$ & $\begin{array}{l}\text { Iterative, participatory policy } \\
\text { cycle in four phases: } \\
\text { 1. Scoping - definition of wicked } \\
\text { problems and integrated analysis } \\
\text { of the system; } \\
\text { 2. Envisioning - building of } \\
\text { vision and formulation of policy } \\
\text { options; } \\
\text { 3. Implementing - } \\
\text { implementation of policy } \\
\text { measures; } \\
\text { 4. Monitoring - social learning } \\
\text { through process monitoring }\end{array}$ \\
\hline Limitations & $\begin{array}{l}\text { Focus on ecological aspects; } \\
\text { low attention to micro-level } \\
\text { socio-economic components, } \\
\text { their interactions and } \\
\text { influences on ecological } \\
\text { resilience }\end{array}$ & $\begin{array}{l}\text { Focus on socio-economic aspects; } \\
\text { not always taking into account } \\
\text { ecological components }\end{array}$ \\
\hline
\end{tabular}

At the same time, major differences exist between the two approaches. First, AM and TM have a focus on different systems: social-ecological systems for AM, and sociotechnical systems for TM. Second, the objectives of management are different. The 
purpose of AM is not to control change in stable systems, but to enhance system resilience, i.e. the capacity to cope with, adapt to and shape change (Ostrom, 2007). On the contrary, the purpose of TM is to address and solve the 'wicked' problems, through the building of institutions and practices that would trigger transitions of unsustainable socio-technical systems.

\subsubsection{Limitations of AM and TM and reasons for their combination}

As briefly stated in the Introduction, both AM and TM have limitations; they are highlighted in Table 2.1.

Depending on thematic and geographic area, AM strategies tend to focus mainly on ecological aspects, using frameworks for analysis and conceptualisation of socialecological systems that may not fully take into account the complexity of human systems, their dynamics and their interactions with ecological systems (Binder et al., 2013). This is particularly true for marine social-ecological systems, whose characterisation is generally done through either of two conceptual frameworks: DPSIR (Drivers, Pressures, State, Impact, Response), and/or the Ecosystem Services frameworks (Atkins et al. 2011; de Jonge et al., 2012; Kelble et al., 2013; Tett et al., 2013). The major limitation of these two conceptual frameworks is that the 'social' side of social-ecological systems is characterised at macro level, i.e. considering systemscale variables such as economic added value, or employment, while not giving enough attention to micro-level social and economic aspects, their complex internal dynamics as well as their interactions with the 'ecological' side.

At the same time, TM strategies tend to be applied to a particular area, or sector, in isolation, with little or no connection with other initiatives or systems (Foxon et al., 2009). Moreover, they assign a primary role to a concerted view of sustainability, built with the active participation and contribution of all stakeholders into the transition arena. The issue of who to include in the transition arena is crucial, as participants need to contribute with their own knowledge, values and interests to frame a shared vision of sustainability for the socio-technical system. In this respect, concerns have been expressed in the literature, about transitions not always taking into account ecological aspects in the system assessment (Dryzek, 2013; Olsson et al., 2014; Pereira et al., 2015).

This paper suggests that each approach has the potential to overcome the limitations of the other. On the one side, AM can incorporate TM's perspective of micro-level socio- 
economic components in the characterisation of social-ecological systems. At the same time, the limitation of TM identified above could be addressed by an explicit inclusion of the consideration of ecological resilience into the transition arena. Section 2.3 presents a framework for marine complex adaptive systems assessment and management, based on these assumptions.

\subsection{A framework for marine complex adaptive systems}

Building from the considerations exposed, we can delineate the building blocks of a framework for the assessment and management of marine complex adaptive systems, which would overcome the limitations of AM and TM, and combine their positive insights. The framework is illustrated in Table 2.2.

Table 2.2: A framework for marine assessment and management.

\begin{tabular}{ll}
\hline $\begin{array}{l}\text { Unit of } \\
\text { management }\end{array}$ & $\begin{array}{l}\text { Social-ecological system (AM), including connected socio- } \\
\text { technical systems (TM) }\end{array}$ \\
\hline $\begin{array}{l}\text { Objectives of } \\
\text { management }\end{array}$ & $\begin{array}{l}\text { Achieve or maintain the ecological resilience (AM), in } \\
\text { coordination with transitions of unsustainable socio-technical } \\
\text { systems (TM) }\end{array}$ \\
\hline $\begin{array}{l}\text { Structure of } \\
\text { management }\end{array}$ & $\begin{array}{l}\text { Iterative, learning-based policy cycle, based on thorough } \\
\text { knowledge and understanding of the system (AM and TM) }\end{array}$ \\
\hline
\end{tabular}

According to AM, the objective of management should be to achieve or maintain the general resilience of the social-ecological system, defined as the resilience of any and all parts of a social-ecological system to all kind of shock (Folke et al., 2010). However, this aspect cannot be directly tackled by management. As acknowledged by both AM and TM, a pure command and control approach to all complex interactions and outcomes, also across scale, among human systems and ecosystems is impossible to realise. A way to overcome this obstacle is to consider general resilience as maintained when any and all parts of a social-ecological system manifest resilience (Cumming et al., 2005), that is, when both ecological and human resilience are maintained.

Ecological resilience is a well-studied concept in AM literature, also in relation to marine social-ecological systems. It is determined by key processes undertaken by functional groups (Hughes et al., 2005). For example, there may be carnivorous species regulating the abundance of prey species, where there are no other species that may replace them. Or there may be ecological functions, the loss of which would lead to irreversible change, possibly involving unacceptable consequences and triggering 
regime shifts. These key processes are strongly related to ecological features, such as diversity, variability and redundancy (Berkes et al., 2003), also at various scales. In turn, given the complexity of interactions between human systems and ecosystems, such ecological features may be better characterised by the consideration of sociotechnical systems, actors and regimes.

But what does 'human resilience' mean? Given the complex nature of environmental systems, human systems must be prepared for the unexpected, have the ability to capture the emergent ecosystem patterns that may anticipate future ecosystem change and possible regime shifts. Adaptability and transformability of ecosystems must be accompanied by the capacity of human systems to develop and maintain their own adaptive capacity, i.e. their capacity to adapt to change and, if needed, to perform radical transformations (i.e. transitions) of their systems. This translates into iterative, learning-based and participatory management strategies for the ecological resilience. Transitions may be considered as are a way to improve such adaptive capacity, as their aim is to trigger radical change towards more desirable states.

How can this be realised? Clearly, the two sets of management frameworks and practices should be linked, in order to create the required synergy. This synergy should be articulated along the three dimensions, or components of the framework: the unit of management; the objectives of management; and the structure of management.

The first dimension relates to the unit of management. The two sets of connected systems (social-ecological and socio-technical systems) must be identified, and the complex interactions and influences between socio-economic patterns of production and consumption, actors and institutions on the one side, and ecological components on the other side, must be assessed. This includes the assessment of how current patterns of production and consumption and technology impact on ecological resilience. Lights would be shed on, for example, on the impacts of rising sea temperatures to fishermen and fish consumers, through the displacement of fish resources towards northern latitudes and cooler waters. This may be realised through the identification of higher and lower scale influences, and the establishment of thresholds and tipping points on key processes and interactions. Thresholds and tipping points would also help in identifying emerging behaviour of the system and the possibility of regime shifts, so that management may adopt measures for preventing, or for adapting to, such shifts.

The second dimension of synergy relates to the objectives of management. The identification of the persistent sustainability problem, and the vision of sustainability 
for the socio-technical system, should be done by reference to the effects of the system on the ecological conditions and resilience of connected social-ecological systems: i.e. a socio-technical system is unsustainable if the pressures it generates on the ecological resilience of a connected social-ecological system push it beyond its environmental boundaries and towards a regime shift. A way to achieve this objective would include fostering the inclusion into the transition arena of actors and institutions (e.g. public bodies, stakeholders and interest groups, and citizens' associations) involved in the implementation of AM strategies for connected social-ecological systems. These actors would highlight the potential consequences on ecological resilience of the transition options at stake, and monitor the effects of adopted management measures into the status and the ecological resilience of connected social-ecological systems. These actors may already be known in existing transition arenas, but not sufficiently involved in the participatory process. The added value of our suggestion lays in their systematic inclusion into all transition arenas, as this would foster the consideration of ecological resilience considerations into the shaping of transitions.

Finally, the third dimension of synergy relates to the structure of management. Both $\mathrm{AM}$ and TM require managers to have an iterative, learning-based approach, where the knowledge of the system is at the basis of the development of a vision, policy options and management measures, whose effectiveness should be monitored in order to 'learn' from results and inform a new phase of vision and objectives setting. Such policy cycles should be fundamentally connected, or aligned, in order to solve potential problems of overlaps, duplication of efforts and misalignment in the temporal scale of activities. In this way, it would be possible to improve the efficiency and effectiveness of managers and avoid potential conflicts, and reduce the relative isolation of sectorbased management.

\subsection{Discussion}

This paper presented a framework for the assessment and management of marine complex, adaptive social-ecological systems. This framework is based on the combination of two theoretical approaches: Adaptive Management (AM) and Transition Management (TM). The framework is based on the idea that AM and TM have the potential to overcome each other's limitations. It suggests a way to create synergies between the theory and practice of the two approaches, and is based on two parallel assumptions. First, AM theory and practices should incorporate the attention to micro-level socio-economic components and their complex interactions with ecological resilience. Second, TM should improve the attention to ecological aspects and environmental limits, in order to trigger transitions with a clear direction, 
contributing to the objectives of ecological resilience of connected social-ecological systems.

The benefits of this framework are threefold. First, by adopting TM's characterisation of human systems as composed of socio-technical systems, actors and institutions, it is possible to strengthen AM's characterisation of ecological resilience. The types of analyses that this objective implies are not new; they may include environmental impact assessments of specific activities or policies, or life cycle assessments of specific products. The added value of this suggestion is that their use would be streamlined into ecological resilience assessment. Second, by systematically including AM managers into established transition arenas, the inclusion of ecological considerations into TM would be enhanced. In this way, there is potential for ecological resilience to play a role in the transition, as stakeholders will debate whether to take it into account, and to what extent. Third, and more in general, by linking transition arenas with AM practices, it is possible to reduce the current fragmentation of management. This may take the form of a coordinating committee at the scale of the social-ecological system, whose objective would be to coordinate management across sectors in all phases: i.e. the identification of the systems and the assessment of ecological resilience; the discussion and choice of policy options and transitions to trigger; the implementation of measures; and the monitoring and learning. This committee would include representatives of all stakeholders of established TM arenas.

This framework has the potential to enhance our understanding of, as well as our management practices for the sustainability of marine complex adaptive systems. However, it has to be tested against the reality of legal frameworks and management practices in place for marine complex adaptive systems, which should be the object of further research. 


\section{Chapter}

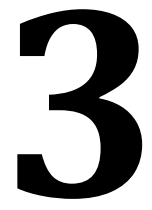

\section{The EU legal framework for the management of marine complex social-ecological systems}

Emanuele Bigagli 


\begin{abstract}
This paper evaluates the European Union (EU) legal framework for the management of marine complex, adaptive systems. The entire EU legal framework, consisting of 12,421 Directives, Regulations and Decisions, is reviewed against a framework of reference, grounded on the theoretical approaches of Adaptive Management and Transition Management. According to this framework, marine complex systems management should: (1) be calibrated at the scale of social-ecological systems; (2) aim to achieve or maintain their ecological resilience; and (3) implement iterative, learning-based management strategies, supported by periodical assessments and monitoring. The results show that the EU legislation does not provide a fully coherent framework for the implementation of a complex systems approach to the management of EU marine social-ecological systems. Although the Marine Strategy Framework Directive (MSFD) is a major step towards this purpose, the present research highlights three major limitations: (1) the limited capacity of the MSFD to support the coordination between Member States sharing the same marine region or sub-region; (2) the insufficient characterisation of marine ecological resilience, in particular in relation to socioeconomic elements, ecosystem services, human benefits and cross-scale interactions; and (3) the limited capacity of the MSFD to tackle the fragmentation of the EU legal framework and prioritise complexity and ecological resilience over sectorial approaches.
\end{abstract}

Keywords: European Union law; Complex systems; Marine social-ecological systems; Ecological resilience; MSFD. 


\subsection{Introduction}

In the last decades, marine conservation and management science moved gradually away from sectorial, "command and control" approaches, towards the appreciation of the complexity of coupled environmental-human systems (Van der Brugge and Van Raak, 2007; Foxon et al., 2009). Several approaches emerged (e.g. ecosystem approach and ecosystem-based management), sharing the consideration of marine ecological and human systems as interacting in non-linear, path dependent ways, with feedback loops and unpredictable effects also across multiple scales (Hughes et al., 2005; Mee, 2005; Levin et al., 2009; Perry et al., 2010; Atkins et al., 2011).

At the same time, these concepts started to be translated into the practice of management of marine and coastal systems (for a review, see Arkema et al., 2006). In the European Union (EU), this process dates back to 2000, with the approval of the Water Framework Directive (WFD; 2000/60/EC), which introduces for the first time in Europe a geographical, complexity-based approach to the management of continental freshwater systems, including transitional and coastal waters. Some years later, this approach was introduced to the marine waters with the approval of the Marine Strategy Framework Directive (MSFD; 2008/56/EC), targeted at the achievement of the Good Environmental Status (GES) of European seas and oceans by 2020.

The WFD and MSFD represent the last step of a long legislative process, which dates back to the 1970s, when the first Directives and Regulations were produced by the European Community, regulating specific aspects of the marine environment, or specific sectors like fisheries and maritime transportation. Over the decades, a considerable amount of legal acts was produced, often without a real coherence or coordination, and which must be taken into account in the implementation of the WFD and the MSFD. This lack of coherence and coordination was recently acknowledged also by the European institutions, which launched in 2007 the Integrated Maritime Policy (IMP). One of the declared objectives of the IMP is to promote the integration of governance and to improve the quality of sectorial maritime policies through "an active search for synergies and increased coherence across sectors" (European Commission, 2007).

A comprehensive evaluation of all $\mathrm{EU}$ legal acts in place for the protection of the marine environment and the management of maritime activities has never been done until now. The purpose of this paper is to present the results of such analysis, and assess whether the EU legal framework for the protection of the marine environment and the management of maritime activities requires a complex systems approach. 


\subsection{A complex systems approach for marine social- ecological systems}

For the purposes of this evaluation, the paper proposes a framework for the management of marine complex systems based on the combination of two scientific approaches, Adaptive Management (AM) and Transition Management (TM). The framework is presented in Table 3.1.

Table 3.1: A framework for the management of marine complex systems.

\begin{tabular}{ll}
\hline $\begin{array}{l}\text { Unit of } \\
\text { management }\end{array}$ & $\begin{array}{l}\text { Social-Ecological System, including the Socio-Technical Systems } \\
\text { located there }\end{array}$ \\
\hline $\begin{array}{l}\text { Objectives of } \\
\text { management }\end{array}$ & $\begin{array}{l}\text { Achieve or maintain the ecological resilience, including transitions } \\
\text { of unsustainable Socio-Technical Systems, if necessary }\end{array}$ \\
\hline $\begin{array}{l}\text { Structure of } \\
\text { management }\end{array}$ & $\begin{array}{l}\text { Iterative, learning- based policy cycle, based on thorough } \\
\text { knowledge and understanding of the system }\end{array}$ \\
\hline
\end{tabular}

Though developed in different contexts and for different purposes, AM and TM emerged as promising conceptual and methodological frameworks for managing change and achieving sustainability of complex, adaptive systems (Foxon et al., 2009). Taken individually, both AM and TM have limitations (see Chapter 2), which may be overcome by combining the two approaches into the framework presented in Table 3.1.

The concepts of social-ecological system (SES) and ecological resilience are the first two components of the framework. The notion of SES was developed by the Adaptive Management literature (Berkes et al., 2003). It is defined as a bio-geophysical unit and its associated social actors and institutions (Glaser et al., 2008). Examples of marine SESs in the scientific literature include marine reserves (Pollnac et al., 2010) and the notion of Large Marine Ecosystems (LMEs), developed in the USA in the 1990s (Sherman, 1991) and still used until today by UNEP and other international bodies as the theoretical foundation for global marine assessment and management.

Ecological resilience is defined by AM as the ability of a system to withstand shocks, maintain stability during disturbances and rebuild itself when required (Carpenter and Gunderson, 2001). It is determined by specific groups of species, whose functions, such as their role in the trophic web, support essential processes and sustain ecosystem services (Hughes et al., 2005). To characterise ecological resilience, it is necessary to identify key system components and interactions, such as diversity, variability and redundancy of biological communities (Berkes et al., 2003), and assign thresholds to 
them. These thresholds can be seen as stability limits; their exceedance leads to a regime shift, or a substantial re-organisation of the SES around a completely different configuration (Folke et al., 2010). Given the complexity of the system, and the impossibility to have a complete understanding of it, these thresholds must be considered as hypotheses on the status of the system (Garmestani and Harm Benson, 2013). Such hypotheses must be continuously challenged and updated with new data, covering the whole spectrum of SES components, especially humans and ecosystems, and their complex, non-linear interactions, also across different scales.

The first limitation that the framework overcomes is related to the capacity of AM to include complexity in the theorisation of marine SESs. Even if humans are included as integral components of SESs, the complexity of their interactions with ecosystems is reduced by AM into a two-way relationship, with humans as providers of pressures to ecosystems, and deriving benefits from ecosystem services (for example, see Atkins et al., 2011, and the work of TEEB, 2010). The framework overcomes this limitation, by considering human systems as the complex interactions between socio-technical systems (STSs), actors and regimes. STSs are defined by TM as socio-economic systems of production, distribution and consumption of a good or service, necessary to fulfil societal functions (Geels, 2004). Examples of STSs include the transportation and the fisheries sectors. Actors are an integral component of STSs; at the same time, their perceptions are shaped by current systems of production and consumption. In a parallel way, the behaviour of actors and the structure and functioning of STSs is influenced by regimes, or the rules and norms that guide and orient activities of social groups.

At the same time, STSs are not place-bound, but stretch along multiple locations and ecosystems. Consequently, their management is generally not tailored to the scale of one SES. For example, the adoption of a ban of fishing of a certain fish species may have positive effects on the ecological resilience of some SESs located inside national borders and on the sustainability of the fisheries sector. However, this could determine an overpopulation of that species in other adjacent SESs, triggering unbalances in the trophic webs and, ultimately, to a deterioration of their ecological resilience. This limitation of the TM approach is overcome by the framework, through the requirement to set the management of human systems at the level of the SESs where these are located. In this way, transitions of unsustainable STSs, that is fundamental changes in physical, economic and institutional structures, cultures and practices (Rotmans, 2006), are given a clear spatial context. Moreover, they are re-framed as one of the possible management options to achieve or maintain SES ecological resilience. 
Finally, the third component of our framework is more procedural, and relates to the structure of management. As shared by both adaptive management and transition management, management of complex systems acknowledge at the outset the impossibility to have a full knowledge of the system, and develop iterative strategies, where learning from the effects of the measures implemented is fundamental to update the system assessment and build management objectives in a participatory way. Thus, management should be articulated into four phases:

1. Scoping - the system to manage is defined, and an initial assessment is performed;

2. Envisioning - targets and objectives of management are set, indicators are developed to measure their attainment, and a management strategy is chosen;

3. Implementing - the management strategy is implemented; and

4. Evaluating - monitoring of the effects of the management strategy on the system and in relation to the achievement of the objectives; results of monitoring will be the basis for a new initial assessment for the next cycle of policy.

\subsection{Methodology}

This paper analyses the binding secondary legislation produced by the EU, i.e. Regulations, Directives and Decisions. Other types of secondary legislation produced by the EU, such as recommendations and opinions, are beyond the scope because not binding upon Member States. A database of all existing, valid, binding legislation of EU was received in September 2012 from Eur-Lex, the portal for the access to EU law and other public documents. This Excel database listed 12,421 records. The database was analysed to identify the legal acts requiring the assessment and management of marine social-ecological systems. A summary of the different steps in the processing of the legal acts is given in Table 2; numbers in italics refer to legal acts excluded from the analysis, while the initial and final number of legal acts is highlighted in bold.

Table 3.2: Summary of the methodology used for filtering EU legal acts.

\begin{tabular}{lr}
\hline \multicolumn{1}{c}{ Category } & $\begin{array}{r}\text { Number of } \\
\text { acts }\end{array}$ \\
\hline EU binding secondary legislation & $\mathbf{1 2 , 4 2 1}$ \\
\hline $\begin{array}{l}\text { Acts removed because they had a specific addressee (e.g. Member } \\
\text { State, company) }\end{array}$ & 3,435 \\
\hline
\end{tabular}




\begin{tabular}{|c|c|}
\hline Results of keywords search & 2,561 \\
\hline \multicolumn{2}{|l|}{ Acts discarded because: } \\
\hline Irrelevant with the research topic & 604 \\
\hline Ratifying international agreements on behalf of the EU & 83 \\
\hline Only amending or repealing other acts & 65 \\
\hline $\begin{array}{l}\text { Only prohibiting fishing in specific areas and time } \\
\text { periods }\end{array}$ & 796 \\
\hline Records discarded because duplicated & 238 \\
\hline Total number of acts investigated & 774 \\
\hline $\begin{array}{l}\text { Acts containing marine complex systems assessment and } \\
\text { management requirements }\end{array}$ & 133 \\
\hline
\end{tabular}

Because the objective of the research is to analyse legal requirements erga omnes, i.e. binding on all Member States without discrimination, 3,435 acts were eliminated, because they addressed a specific Member State or a private body. A keywords search was applied to the 8,986 acts remaining, which was then repeated in January 2014 in the website of Eur-Lex (www.eur-lex.eu), in order to update the results. The keywords used are related to specific components and interactions of marine social-ecological systems (e.g. 'heritage'; 'ship'; 'beach'; 'fish'; 'water'; 'ocean'; 'marine'). The complete list of keywords, together with the number of acts retrieved, and the detailed results of filtering according to the categories aforementioned, is enclosed in Appendix A. This resulted in a total of 2,561 legal acts likely to be related to the assessment and management of marine complex systems.

An additional filtering was then applied to these results. Some categories of acts were identified and discarded from the analysis. They are: 604 acts, considered to be irrelevant to the topic of the investigation, retrieved by the keywords search (e.g. acts about 'sealing' retrieved with the keyword 'sea*', with the asterisk standing for a wildcard character); 83 acts, whose objective is to ratify international agreements on behalf of the EU; 65 acts providing only amendments or repeals of other legislation; and 796 acts related to prohibitions for fishing in specific areas and for specified periods. The list was then cleaned, eliminating 238 results that were duplicated, that is acts showing up for two or more keywords at the same time. 774 acts were investigated for requirements contained in the text, related to marine complex systems assessment and management. A total of 133 acts contain such requirements; they are listed in Appendix B. 
Details were gathered from the text of these legal acts, related to the components of the framework presented in Section 3.2. The specific research questions for each component of the framework are:

1) Unit of analysis-What is the unit of analysis, i.e. the spatial location where the legal act applies?

2) Objectives of management-What are the objectives of the legal act?

3) Structure of management-Does the legal act have an iterative, learning-based approach, based upon a thorough knowledge of the system?

Section 3.4 presents the results of the analysis. It is divided into three sub-sections, following the three specific research questions highlighted above.

\subsection{Results}

\subsubsection{The unit of analysis}

Two legal acts have a complex systems approach to the management of the marine environment and maritime activities, the WFD and the MSFD. The WFD targets the management of freshwater systems along river basins and including transitional and coastal waters. The MSFD applies to marine and coastal waters; it divides all EU marine areas into four marine regions, determined by hydrological, oceanographic and biogeographic considerations. They are: the North-East Atlantic Ocean; the Baltic Sea; the Mediterranean Sea; and the Black Sea. More into detail, the North-East Atlantic and the Mediterranean Sea may be divided into marine sub-regions, such as the North Sea and the Macaronesian biogeographic region for the North-East Atlantic, and the Adriatic Sea and Aegean-Levantine Sea for the Mediterranean, among others. As such, the MSFD contains the most extended and comprehensive spatial scope for the management of marine social-ecological systems in Europe.

This study has identified a limitation in the approach of the MSFD that relates to the difference in spatial scale between its requirements and the activities implemented by the single Member States. On the one hand, the MSFD clearly identifies marine socialecological systems as the spatial scope for its implementation. On the other hand, Member States must implement the MSFD in relation to their marine waters, which are defined as the waters, the seabed and the subsoil where a Member State has and/or exercises jurisdiction rights (art. 3(1)). It is true that the MSFD requires Member States to coordinate with other Member States, using existing Regional Sea Conventions cooperation structures (art. 6(1)), and extending where appropriate to Member States 
located in the catchment areas of a marine region or sub-region (art. 6(2)). However, the MSFD does not contain details on how to enforce these requirements. This represents a limitation of the MSFD, as the realisation of a social-ecological systems approach relies only on the capacity and goodwill of the Member States sharing the same marine region or sub-region to collaborate.

A second aspect to consider as potentially limiting the SES-based approach is the spatial overlap of marine regions with river basins, identified following the WFD, and the consequent need to clearly define the borders between these two complex systems. As illustrated in Fig. 1, the WFD includes transitional and coastal waters inside the river basin, but extends to territorial waters (up to $12 \mathrm{~nm}$ offshore) for chemical aspects. At the same time, the coverage of MSFD includes coastal waters, but only in relation to aspects not already addressed through the WFD, e.g. physical and biodiversity aspects, and the coastal subsoil.

\begin{tabular}{|c|c|c|c|c|}
\hline & $\begin{array}{c}\text { Coastal waters } \\
(0-1 \mathrm{~nm})\end{array}$ & $\begin{array}{c}\text { Territorial waters } \\
(0-6 / 12 \mathrm{~nm})\end{array}$ & $\begin{array}{c}\text { Exclusive Economic } \\
\text { Zone (EEZ) / } \\
\text { Continental Platform }\end{array}$ & High seas \\
\hline \multicolumn{5}{|l|}{$\begin{array}{l}\text { Surface } \\
\text { water }\end{array}$} \\
\hline \multicolumn{5}{|l|}{$\begin{array}{l}\text { Water } \\
\text { column }\end{array}$} \\
\hline \multicolumn{5}{|l|}{ Seabed } \\
\hline \multicolumn{5}{|l|}{ Subsoil } \\
\hline \multicolumn{5}{|c|}{ LEGEND } \\
\hline & \multicolumn{4}{|c|}{ Water Framework Directive } \\
\hline & \multicolumn{4}{|c|}{ Marine Strategy Framework Directive } \\
\hline & No EU legislation a & & & \\
\hline
\end{tabular}

Fig. 3.1: Spatial overlaps between the Water Framework Directive and the Marine Strategy Framework Directive. 
Spatial overlaps occur not only with the WFD but also with other acts applying to specific spatial locations or socio-economic activities. For example, the legislation on industrial installations and infrastructures (e.g. Seveso II 96/82/EC; Environmental Impact Assessment (EIA) 85/337/EEC; Integrated Pollution Prevention and Control (IPPC) 2008/1/EC; and Carbon Capture and Storage (CCS) 2009/31/EC Directives; and E-PRTR Regulation 166/2006) or on waste water from urban and industrial sources (UWWT Directive, 91/271/EEC) applies to specific point- or diffuse-source pollution, which may be located anywhere in marine and coastal areas. As another example, the Atlantic marine biogeographic region, which the Habitats Directive (92/43/EC) identifies, together with other four regions, as the basis to assess and report on the adequacy of protected areas, has a partial overlap with MSFD Atlantic marine subregions. Other examples include the Common Fisheries Policy (CFP), which applies to all EU marine waters, including the Exclusive Economic Zones (EEZ), and the continental shelf; and the Bathing Waters Directive (BWD, 2006/7/EC), which requires Member States to designate coastal bathing waters and monitor their microbiological quality.

A further potential obstacle to a social-ecological approach is related to the regulation in the EU of maritime sectors at continental scale, i.e. for all EU marine SESs. As a matter of fact, all legislation regulating sectors like maritime transport, fisheries, tourism and material and energy extraction, applies in a homogeneous way at continental scale, without specificities for one or more marine SESs. Partial exceptions are provided by the CFP, where Regulations are in place for the management of certain fish species in some marine regions, e.g. for cod in the North and Baltic Seas, and for the Mediterranean. However, the coverage of such legislation is neither homogeneous nor exhaustive, both in terms of species and marine SESs.

A final consideration is more general, and relates to the intrinsic characteristics of national and supra-national jurisdiction. No country in the world, party to the UNCLOS (United Nations International Convention on the Law of the Sea), can exert jurisdiction over the part of the oceans referred to as 'high seas'. A partial exception to this regime is provided by the regulation of ships flying the flag of a state. In the EU, this applies especially to the legislation on maritime transportation safety and security (e.g. Port State Control Directive, 2009/16/EC; and Flag State Requirements Directive, 2009/21/EC), and to the CFP, whose provisions are applicable to all ships flying the flag of any EU Member State, anywhere in the world. Consequently, a consistent part of marine social-ecological systems falls outside the spatial coverage of management. 


\subsubsection{The objectives of management}

Marine ecological resilience is explicitly mentioned by the MSFD, where it is stated that the structure, functions and processes of marine ecosystems, together with related hydro-morphological, physical and chemical properties, must support the resilience of marine ecosystems to human-induced environmental change (art. 3). This concept is operationalised through the notion of Good Environmental Status (GES), which means "ecologically diverse and dynamic oceans and seas which are clean, healthy and productive, and where the use of the marine environment is sustainable". GES are articulated into 11 descriptors, covering ecological features such as habitats and species and food webs, and anthropogenic pressures and impacts like contaminants in fish, marine litter and underwater noise. GES must be clearly identified, and indicators must be set and monitored by identifying qualitative or quantitative thresholds. Their identification should be based on the outcomes of an initial assessment, including an analysis of the essential physico-chemical, hydro-morphological and biological features and characteristics; an analysis of the predominant pressures and impacts on the marine environment, including their 'main cumulative and synergistic effects'; and an economic and social analysis of the use of these waters and of the cost of degradation of the marine environment (art. 8).

As such, the data required by MSFD to support the characterisation of marine ecological resilience focus on: ecological variables; anthropogenic pressures; and impacts of these to ecosystems. Ecosystem services and benefits that humans derive from them (e.g. food and materials provision and recreational services) are not given explicit coverage. The same applies to cross-scale effects, which are not even mentioned. Finally, the complexity of the inter-relations between marine SES components is the target of a general formulation, where the 'main cumulative and synergistic effects' of the predominant pressures and impacts on the marine environment should be assessed (art. 8(1)).

Other EU legal acts include requirements for the collection of data on several human activities and marine ecological features. The CFP contains obligations for data collection on the fisheries and aquaculture sectors (e.g. catches; landings; fishing effort; production; and selling prices). The legislation on maritime transportation includes requirements for monitoring traffic (through the Vessel Monitoring System, VMS), and the collection of statistical data on aspects such as the quantity and type of goods transported and the routes. Moreover, statistical data must be collected on aspects such as the status of reserves, and the amount of extraction of hydrocarbons and materials, and the production of renewable energy from off-shore wind facilities. The full list of 
data requirements is displayed in Appendix C. These data requirements overlap to a certain extent with MSFD requirements, and can provide a positive contribution to the characterisation of ecological resilience. However, in a similar way as for the MSFD, there is no data coverage on ecosystem services and human benefits, and on cross-scale interactions and effects. The only exception is provided by the Floods Directive (2007/60/EC) and the Birds Directive (2009/147/EC). The Floods Directives has an obligation to assess the consequences of past and future floods on human health, cultural heritage, economic activities, industrial installations and protected areas. The Birds Directive requires Member States to consider cultural and recreational aspects in the protection of European birds.

A second aspect to consider is that none of these legal acts provide a link between such data and the concept of ecological resilience. In fact, the EU legal framework is fragmented into several acts, each setting a specific objective and, overall, providing potential synergies or conflicts with the objective of the MSFD. The most important example is the WFD. The WFD sets the achievement by 2015 of the good ecological and chemical status of transitional and coastal waters, which is related to a very low or inexistent level of human pressures to water ecosystems. On the one hand, the WFD does not mention ecological resilience and does not cover several key components of ecological resilience, such as diversity, variability and redundancy. On the other hand, the WFD contains reference to some ecological and chemical aspects (e.g. primary productivity, diversity of some fish species, contaminants in territorial waters) that can support the identification and achievement of marine ecological resilience. Other examples include cases where the MSFD expands the scope of other legal acts. It is the case of acts like the Habitats and Birds Directives, with the MSFD considerably extending the number and type of habitats and species to protect. It is also the case of the Regulation 708/2007, requiring Member States to assess the impacts of the introduction of alien species on aquatic habitats by aquaculture farms. To this respect, the MSFD includes a requirement to integrate such assessments with an assessment of pathways and vectors of spreading of all alien species. Also, some provisions included in the CFP may have synergies with GES Descriptors related to biodiversity and fishing. It is the case of the requirement to protect vulnerable marine ecosystems from the negative impacts of bottom fish gears (Regulation 734/08), or the prohibition of bycatches of cetaceans (Regulation 812/04). Finally, legislation regulating the discharge of waste and of contaminants from agriculture, urban and industrial activities, shows synergies with GES Descriptors 5 (eutrophication), 8 and 9 (contaminants and contaminants in fish and seafood for human consumption) and 10 (marine litter). 
However, some potential conflicts must be highlighted between the objectives of sectorial legislation and the achievement of GES. The most important relates to the CFP, whose recent reformulation explicitly introduces the concept of ecosystem-based management to fisheries, and of Maximum Sustainable Yield (MSY). MSY is defined as "the highest theoretical equilibrium yield that can be continuously taken on average from a stock under existing average environmental conditions, without significantly affecting the reproduction process" (CFP Regulation 1380/2013, art. 4). The formulation of MSY appears in line with the provisions of the MSFD, whose GES Descriptor 3 (commercially exploited fish stocks) requires criteria on fish mortality and catch/biomass ratio to be in line with it. However, according to the Regulation, multiannual plans must be formulated only for some commercially exploited species, taken individually. For species without a plan, it is necessary to set limits to catch or fishing efforts, following a precautionary approach. On one hand, it is true that these measures may contribute to lower the pressure on fish populations. On the other hand, the reference made by the Regulation to the precautionary approach is general and, more importantly, not linked to the notion of ecological resilience. As a result, practices could be in place, such as an increased exploitation of species without a plan, with potential domino effects on the food web and, ultimately, to ecological resilience.

Other examples of potential conflicts of priorities between ecological resilience and sectorial legislation relate to the CCS Directive, the Floods Directive and, marginally, to the Birds Directive. The priority of the CCS Directive is the reduction of the atmospheric concentration of carbon dioxide through its geological storage, also under the seabed. Trade-offs could be accepted in this view, which may damage the seafloor and hamper the achievement of GES 6 (seafloor integrity). At the same time, the building of offshore barriers, or other engineering works to prevent or limit coastal erosion and flooding, could entail negative consequences on sea floor integrity and, more in general, on hydrographical conditions.

The MSFD acknowledges the possibility of conflicts, and contains several statements for the improvement of the coordination with other legislation already in place. Art. 1(4) states that the MSFD "shall contribute to coherence between, and aim to ensure the integration of environmental concerns into the different policies [...] which have an impact on the marine environment". In case of a human activity having potential negative impacts on the marine environment, art. 13(5) states that Member States shall "address the competent authority or international organisation concerned with a view to the consideration and possible adoption of measures that may be necessary in order to achieve the objectives of this Directive, so as to enable the integrity, structure and functioning of ecosystems to be maintained or, where appropriate, restored". While 
these statements represent the need to integrate environmental considerations into sectorial policies, their formulation in the text of the Directive is done in a general way, and it is not possible to recognise a clear statement on the need to prioritise the objectives of the MSFD over sectorial growth and development objectives, especially in case of conflicts between them.

\subsubsection{The structure of management}

Iteration, learning and knowledge-based management are fundamental components that the MSFD introduced in the EU marine management. According to the MSFD, the management of EU marine regions and sub-regions must be articulated along four phases: (1) an initial assessment (art. 8) and (2) the identification of Good Environmental Status, environmental targets and associated indicators (art. 9 and 10), to be performed for the first time in 2012; (3) monitoring programs (art. 11), to be prepared and implemented in 2014; and (4) a program of measures for the achievement of the objectives (art. 13), to be formulated in 2015 and implemented in 2016. This policy cycle, illustrated in Fig. 3.2, must be updated every 6 years, when the results of monitoring will be used to verify the achievement of GES and will be the basis of a new policy round.

However, several other legal acts are articulated along their own policy cycle and follow their own time schedule. Fig. 3.2 illustrates the main overlaps between the policy cycle of the MSFD and of the other legislation analysed. Some legal acts contain some measures of iteration, knowledge-base and learning. The most advanced is the WFD, which contains iterative, learning and knowledge-based elements in a similar way as the MSFD. Other legal acts include obligations to perform only some specific phases. It is the case of the legislation on industrial installations and the EIA Directive, which requires competent national authorities to perform a preliminary environmental assessment of installations having potential negative impacts on the environment, and the establishment of management plans including emission limit values and continuous monitoring. Moreover, timelines are specified by some legal acts only for some phases (e.g. the Bathing Waters Directive, the Pesticides Directive 2009/128/EC and the POPs Regulation 850/2004), or for the achievement of objectives, while other acts do not provide deadlines or time frames for the activities to be performed. The latter are included in the small clouds of Fig. 3.2. For example, the Habitats and Birds Directives do not set formal deadlines neither for the assessment of habitat conservation status, nor for the attainment of the Favourable Conservation Status. It is worth noting that MSFD monitoring programs must be in place before the entry into operations of the 
program of measures; this could theoretically lead to situations where monitoring is not calibrated to evaluate the effectiveness of the measures taken.

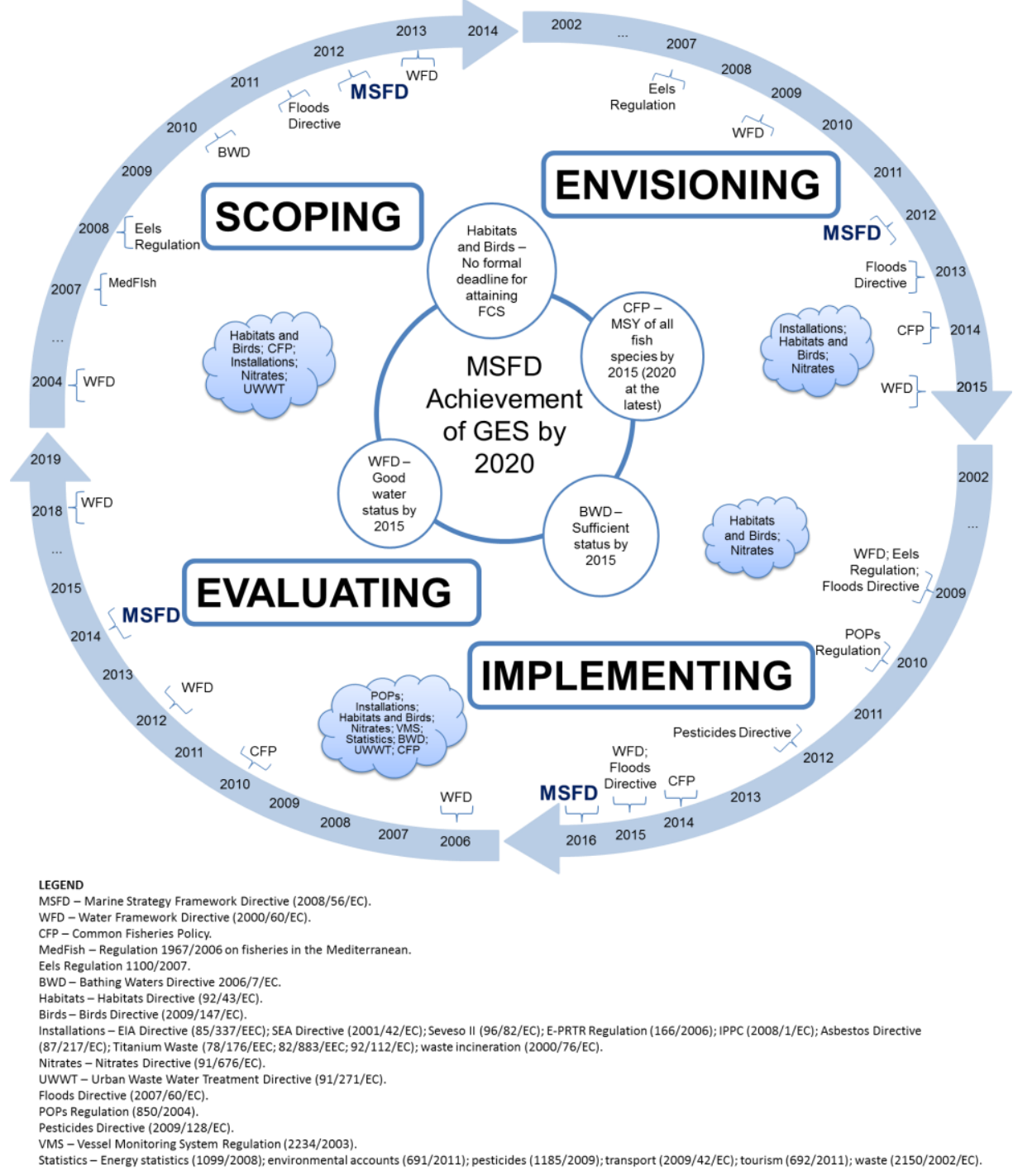

Fig. 3.2: Overlaps between the policy cycles of the MSFD and of other EU legal acts, by phase of the policy cycle. 
The MSFD acknowledges this fragmentation, and asks to build upon existing requirements from other EU legislation for all the phases of the MSFD policy cycle. The MSFD initial assessment must take into account "relevant assessments made pursuant to existing Community legislation" (art. 8(1)), the assessments carried out in the context of the WFD and of the Regional Sea Conventions. Member States must ensure that MSFD environmental targets are compatible with existing targets (art. 10(1)). Moreover, the programme of measures shall take into account existing measures required under other legislation, in particular the WFD, the UWWT Directive, the Habitats and Birds and the Bathing Waters Directives, as well as forthcoming legislation on environmental quality standards on water policy (art. 13(2)). Finally, monitoring programmes shall build upon, and be compatible with existing monitoring requirements, including the Habitats and Birds Directives (art. 11(1)).

However, temporal overlaps and misalignments are present, and there is no obligation to modify these policy cycles in order to adapt them to the new provisions of the MSFD. Even the new CFP, approved in 2014, has a policy cycle covering the period 2014-2022, where the objective of MSY of all fish species has to be achieved by 2015, that is, five years before the achievement of GES.

\subsection{Discussion}

The results of this research confirm the importance of the MSFD as the first legal act introducing a complex systems management to the EU marine systems. Section 3.4 shows that the MSFD addresses all the components of the framework presented in Section 3.2. First, marine regions and sub-regions are identified following a biogeographical approach and can be conceived as marine social-ecological systems. Second, the MSFD aims at the GES of these systems, providing in this way an operationalisation of the concept of marine ecological resilience. Third, iteration, learning and knowledge-based management elements are present, and the results of management are periodically evaluated and used to build a new initial assessment and definition of environmental targets and measures.

However, the research has identified some limitations of the MSFD, which could hamper its efforts to provide the required complexity-based approach.

The first limitation relates to the unit of management. As shown in Section 3.4.1, even if the MSFD sets the EU marine regions and sub-regions as the unit of management, it requires Member States to develop and implement strategies for the management of marine waters under national jurisdiction. Although coordination and collaboration 
among Member States sharing the same marine region or sub-region are envisaged, the formulation of this obligation in the text is weak. This confirms the findings of Van Tatenhove et al., 2014 and Van Leeuwen et al., 2014. As no instruments and mechanisms for effective cooperation are set by the MSFD, the delivery of a SocialEcological approach depends on the political will and capacity of the single Member States, as well as of the Regional Seas Conventions in place, to deliver such result.

In addition, EU legislation, with only small exceptions for the CFP, does not regulate human sectors at the scale of the marine SESs. As stated in Section 3.2, STSs should be managed at the scale of the social-ecological system, and their transitions should be considered in the light of the achievement or maintenance of ecological resilience. However, Section 3.4.1 illustrates that the regulation of maritime sectors at continental scale does not tailor the objectives of sectorial policies to the needs of the various marine regions and sub-regions.

The second limitation relates to the objectives of management. The MSFD bases the characterisation of ecological resilience mainly on ecological considerations. As shown in Section 3.4.2, GES focus on ecosystem components, anthropogenic pressures and impacts on ecosystems. Data on human systems must be included at the stage of initial assessment. However, there is only a general requirement to perform an economic and social analysis of the use of the seas and an assessment of the cost of degradation of the marine environment. Furthermore, the MSFD does not give adequate consideration to, key aspects such as ecosystem services, and the benefits humans derive from them, as well as cross-scale interactions, even though data requirements included in other legislation may help fill some gaps, as indicated in Section 3.4.2. This limitation negatively affects the capacity of the EU legal framework to adequately assess and characterise the ecological resilience of EU marine SESs.

The third limitation relates to the lack of coherence and coordination among the EU legal acts, which this research confirms. As shown in Section 3.4.1, the EU legal acts apply to various spatial scopes, and their objectives and policy cycles are independent of one another. They target specific socio-technical systems, or aspects of environmental degradation or pollution (e.g. nitrates, waste water and chemicals discharge), or specific ecological features such as priority habitats and species. Moreover, they are formulated to achieve specific objectives, which may have synergies or conflicts with the objective of ecological resilience. Whilst acknowledging that the majority of legal acts were already in place before the approval of the MSFD, the issue is that they have not been updated to incorporate ecological resilience considerations, and even when this was done, as in the case of the CFP, the alignment to the MSFD is 
questionable. Finally, all the EU legal acts analysed are articulated along a policy cycle that may, or may not, contain some elements of iteration and learning and, more importantly, include different timelines of implementation, thus creating overlaps and misalignments with the policy cycle of the MSFD.

Section 3.4.2 shows that the MSFD has a limited capacity to account for this fragmentation and coordinate with existing legislation, confirming the findings of Salomon and Dross, 2013 and Van Leeuwen et al., 2014. The obligations contained in the MSFD to coordinate with other legislation are formulated in a generic way in the consideranda (8 and 9). Moreover, the text of the act does not contain an explicit prioritisation of ecological resilience over sectorial objectives (art. 1(4) and art. 13(5)). This is especially valid for the overlaps with the WFD. As shown in Section 3.4.1, there may be overlaps among the river basins and the marine regions for the management of transitional and coastal waters. Even though the WFD includes ecological considerations, it lacks a structured conceptualisation of ecological resilience for the river basins, whilst the MSFD may not have the capacity to prioritise marine ecological resilience over these considerations.

\subsection{Conclusions}

This paper presents the first comprehensive evaluation of the EU legal framework addressing the management of marine complex social-ecological systems. This is done by combining Adaptive Management and Transition Management into a single framework centred on the notions of marine social-ecological systems, ecological resilience and iterative, learning-based policy cycle, and using these three notions as the lenses for the evaluation.

The main conclusion is that the EU legislation does not provide a fully coherent framework for the implementation of a truly adaptive, complex systems approach to the management of EU marine social-ecological systems. The MSFD is a major step forwards in the management of marine environmental and human systems as complex systems. However, the three limitations identified in this paper negatively affect the capacity of the MSFD to: (1) set the management at the required geographical scale of SES; (2) have an appropriate characterisation of ecological resilience; and (3) organise management through a coherent policy cycle, based on iteration and learning.

Further research should investigate real world practice. It should evaluate how the legal requirements translate into everyday management practices, and should evaluate whether the limitations of the legal framework highlighted in this paper represent or 
not an effective barrier to the delivery of the desired approach for the management of the ecological resilience of EU's seas and oceans.

\section{Acknowledgements}

This work is part of a PhD project, which received the financial support of the European Commission Joint Research Centre, Institute for Environment and Sustainability (Grant no. H10114). I would like to thank Arnold K. Bregt, Wageningen University, and Max Craglia, European Commission Joint Research Centre, for their supervision and support. Thanks also the anonymous reviewers that provided very useful comments, which improved the final version of the paper. 


\section{Appendix}

The following supplementary material can be accessed online from: http://www.sciencedirect.com/science/article/pii/S0308597X14003261.

Appendix A - List of acts retrieved by keyword.

Appendix B - List of legal acts analysed, by keyword.

Appendix C - Data requirements from EU legislation, by SES component and subcomponent. 


\section{Chapter}

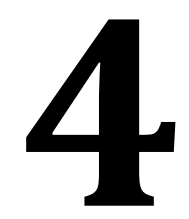

The international legal framework for the management of the global oceans social-ecological

system

Emanuele Bigagli 


\begin{abstract}
This paper evaluates the international agreements in place for the protection of the environment and the regulation of human activities taking place in world's oceans and seas. 500 multilateral agreements were reviewed against a framework of reference, grounded on the theoretical approaches of Adaptive Management and Transition Management. According to this framework, oceans complex systems management should: (1) consider the global oceans as a Social-Ecological System (SES); (2) aim to achieve or maintain their ecological resilience; and (3) implement iterative, learningbased management strategies, supported by science-based advice to policy and management. The results show that the present international legal framework for the global oceans does not require countries to adopt an adaptive, complex systems approach for global oceans ecological resilience. Instead, this study supports the perspective of a double fragmentation among international agreements. First, global agreements focus on issue-based objectives for determined human activities, ecological components or anthropogenic pressures. Second, regional agreements have a wider scope, but also a varying level of inclusion of ecological resilience considerations. There is the need to foster the inclusion of such an approach into existing and future international agreements and their implementation, including through soft-law, project-based initiatives at global and regional scales.
\end{abstract}

Keywords: International law; Social-ecological systems; Ecological resilience; Oceans; UNCLOS. 


\subsection{Introduction}

Oceans play a major role in global material and energy cycles (Costanza, 1999). Their interactions with atmospheric and terrestrial systems contribute to the regulation of global weather and climate, where water, carbon and oxygen cycles determine the transfer of heat and energy throughout the globe.

Global-scale phenomena challenge the health of global oceans, almost half of which are affected by multiple human stressors (Halpern et al., 2008). Global climate warming alters physical, chemical, and biological properties of the ocean, impacting on ocean productivity and food services globally such that fish stocks are declining, potentially at an irreversible pace (IOC/UNESCO, 2011; Moomaw and Blankenship, 2014). Ocean habitats and biodiversity continue to be lost or degraded (IOC/UNESCO, 2011). Moreover, pollution of the oceans caused by human activities, including the dumping of waste, is a serious problem affecting not only coastal areas but also open oceans.

These problems are global: as showed by Halpern et al., 2008, anthropogenic pressures affect almost any point in the ocean surface. Moreover, both climate related and anthropogenic challenges have an impact on the relations between oceans and the biosphere, and their capacity to regulate global weather and climate. For this reason, a global perspective is needed to tackle these problems. In the last decades, several scientific approaches have emerged that consider human and ecological systems as complex, adaptive systems, thereby interacting in non-linear, path dependent ways, with feedback loops and unpredictable effects also across scales (Atkins et al., 2011; Hughes et al., 2005; Levin et al., 2009; Mee, 2005; Perry et al., 2010). The most notable example is the ecosystem approach (or ecosystem-based management), which has been advocated at international level as the best strategy to cope with a changing climate, protect the global oceans and manage human activities in a sustainable way (Herr and Galland, 2009; for a review of the implementation, see Arkema et al., 2006).

Accordingly, complexity approaches started to be introduced also into the texts of international agreements aiming at the protection of the ocean environment and regulation of maritime activities. A considerable number of international agreements are today in place, regulating these issues at varying scales, from global to ocean basin, to regional and local levels. Several voices in the literature point to the fact that this legal framework is fragmented (Rothwell and Stephens, 2010; Freestone, 2011; Scott, 2011), inadequate to tackle the challenges of managing the oceans (Vidas, 2011), and in need of a paradigm shift (Freestone, 2011; O'Leary et al., 2012; Ban et al., 2014) to promote the safeguard of global ocean ecological structure and processes, and human 
communities depending on the ecosystem services generated by them. This view is shared also by the UN Secretary General, who raised the need for a better horizontal and vertical integration among levels of ocean governance to foster the implementation of an ecosystem approach to global oceans (UN Secretary General Report, 2006).

There are several analyses in the literature, investigating this fragmentation from different perspectives (Kimball, 2001; Gjerde et al., 2008; Freestone, 2011; Gjerde et al., 2013; Ban et al., 2014; Rochette et al., 2014; Warner et al., 2014; Mahon et al., 2016). However, an analysis is missing of the international legal framework for the management of the global oceans system, from the perspective of complex human and ecological systems.

The purpose of this paper is to present the results of such an evaluation, and assess whether a comprehensive legal framework is in place requiring a complex systems approach to the assessment and management of the global oceans. For this purpose, a framework for ocean assessment and management was developed, which is presented in Section 4.2. Section 4.3 presents the methodology used to select and analyse the international environmental agreements, while Section 4.4 presents the results of the analysis.

\subsection{A framework for the assessment and management of ocean complex systems}

For the purposes of this evaluation, reference is made to a framework for the management of marine complex systems, which was developed and previously used to analyse the European Union ocean legislation (Bigagli, 2015). The framework combines useful insights from two promising conceptual and methodological frameworks for sustainability of complex, adaptive systems (Foxon et al., 2009): Adaptive Management (AM) and Transition Management (TM). More specifically, if taken individually, both AM and TM have limitations, which may be overcome by their combination, as illustrated in Table 4.1.

The framework is articulated into three components. The first component is the SocialEcological System (SES) and Socio-Technical Systems (STS) as the units of management. A SES is defined as a bio-geophysical unit and its associated social actors and institutions (Glaser et al., 2008). Examples of marine SESs in the scientific literature include marine reserves (Pollnac et al., 2010) and the notion of Large Marine Ecosystems (LMEs). Developed in the USA in the 1990s (Sherman, 1991), the notion of LMEs is adopted today by international bodies, such as the United Nations Environment 
Programme (UNEP) and the Intergovernmental Oceanographic Commission (IOC) of UNESCO, as a theoretical foundation for global marine assessment and management. A limitation of theoretical and practical approaches for ocean assessment and management, based on the tenets of AM, lies in their limited capacity to characterise the complexity of human systems. Although humans are conceived as integral parts of SESs, fundamental components of human systems, such as socio-economic patterns of production, distribution and consumption of goods and services, actors' behaviour and the role of institutions and rules, are often neglected (for example, see Atkins et al., 2011, and the work of TEEB, 2010). The framework overcomes this limitation, by adopting the conceptualisation of human systems of TM, as composed of SocioTechnical Systems (STSs), actors and institutions. STSs are defined by TM as socioeconomic systems of production and consumption of goods or services, necessary to fulfil societal functions (Geels, 2004). Actors have a primary role as producers or consumers inside a STS, which in turn shapes their preferences. Moreover, institutions and rules are embedded in artefacts, while giving a context for actors' behaviour (Geels, 2004).

Table 4.1 - a framework for marine complex systems management

\begin{tabular}{ll}
\hline $\begin{array}{l}\text { Unit of } \\
\text { management }\end{array}$ & $\begin{array}{l}\text { Social-Ecological System [AM], including connected Socio- } \\
\text { Technical Systems [TM] }\end{array}$ \\
\hline $\begin{array}{l}\text { Objectives of } \\
\text { management }\end{array}$ & $\begin{array}{l}\text { Achieve or maintain the ecological resilience [AM], in } \\
\text { coordination with transitions of unsustainable Socio-Technical } \\
\text { Systems [TM] }\end{array}$ \\
\hline $\begin{array}{l}\text { Structure of } \\
\text { management }\end{array}$ & $\begin{array}{l}\text { Iterative, learning- based policy cycle, based on thorough } \\
\text { knowledge and understanding of the system [AM and TM] }\end{array}$ \\
\hline
\end{tabular}

The second component is the ecological resilience as the objective of management. Ecological resilience is defined by AM as the ability of a system to withstand shocks, maintain stability during disturbances and rebuild itself when required (Carpenter and Gunderson, 2001). It is determined by specific groups of species, whose functions, such as their role in the trophic web, support essential processes and sustain ecosystem services (Hughes et al., 2005). To characterise ecological resilience, it is necessary to identify key system components and interactions, such as diversity, variability and redundancy of biological communities (Berkes et al., 2003). Thresholds shall be assigned to these components, which act as stability limits, and mark the points beyond which regime shifts occur (Folke et al., 2010). As it is impossible to have a complete understanding of the system, such thresholds must be considered as hypotheses on the status of the system (Garmestani and Harm Benson, 2013), to be challenged and 
updated through monitoring. A weakness of TM is that it considers nature as a provider of resources and recycler of pollutants, and tends to overlook ecological boundaries and limits to growth (Dryzek, 2013; Pereira et al., 2015). Consequently, transitions triggered by TM may not be in line with ecological resilience considerations. For example, a transition of the fisheries sector of a country towards a new set of total allowable catches of certain species may have the desired positive effects on ecological diversity and resilience of a marine SES, while at the same time trigger unbalances in the trophic webs of another marine SES, with negative impacts on ecological resilience. The framework overcomes this limitation, by suggesting that ecological resilience should be placed at the core of the vision for transitions of a particular sector. In this way, it is possible to have an increased coordination of management among sectors, and the desired transition of unsustainable sectors will benefit SES ecological resilience.

The third component of the framework relates to the management process. Both AM and TM acknowledge from the outset the impossibility to have a full knowledge of the system, and require managers to base decisions on the best available scientific knowledge, and to experiment with policies, introducing iteration and learning. Hence, complex systems management should be articulated into four phases:

1. Scoping - definition of the system to manage, and its initial assessment;

2. Envisioning - setting of targets and objectives of management; development of indicators and evaluation and selection of management strategies;

3. Implementing - implementation of the management strategy; and

4. Evaluating - monitoring of the effects of the management strategy on the system and in relation to the achievement of the objectives. The results of monitoring will be the basis for a new initial assessment for the next cycle of policy.

\subsection{Methodology}

The research presented in this paper analyses the text of the international agreements in place for the global oceans. The reason for this choice lays in the fact that international agreements are the main instrument for the creation of a binding regime of rights and obligations among sovereign states, which assures continuity and avoids ad hoc or arbitrary behaviour (Kimball, 2001). Consequently, other components of global oceans governance, such as informal rules and customary principles, and the rules and working practice of international institutions, are left out of the analysis. To this purpose, the International Environmental Agreements Database Project, a database of international environmental agreements available online (Mitchell, 2002- 
2015), was used as the primary source for the texts of such international agreements. This online database is divided into three sub-sections: multilateral; bilateral, and other agreements, each divided into a specific topic (e.g. energy; freshwater resources; habitats; nature; ocean; pollution). All the topics were screened to verify if they included agreements applicable to global ocean areas. The two topics of multilateral 'ocean' and 'pollution (marine)' agreements were selected because they are the only topics containing agreements applicable to ocean areas of the world. This resulted in 500 records. The two lists of agreements were unified, and 151 records were discarded because duplicated. In addition, 179 agreements only amending other international treaties were discarded, together with the 27 records considered irrelevant for the research topic (e.g. covering only freshwater or inland systems, like the Rhine and Sava rivers, and saltwater systems beyond scope, such as the Aral and Caspian Seas).

Some agreements were not included in the list, and they were added. They are:

- The Action Plans of the UNEP Regional Sea Conventions and the North-Eastern Atlantic (OSPAR) Environmental Strategy - 14 records;

- Some Protocols to the UNEP Regional Sea Conventions - 6 records;

- Some fisheries and nature conservations agreements, whose list was taken from the analysis of Mahon et al., 2016 -19 records;

- Other international agreements included by Mahon et al., 2016 - 8 records.

Table 4.2: Summary of the methodology used for filtering international agreements.

\begin{tabular}{lr}
\hline \multicolumn{1}{c}{ Category } & $\begin{array}{r}\text { Number of } \\
\text { agreements }\end{array}$ \\
\hline Number of agreements retrieved & 500 \\
\hline Records discarded because duplicated & 151 \\
\hline $\begin{array}{l}\text { Agreements discarded because only amending or repealing other } \\
\text { agreements }\end{array}$ & 179 \\
\hline Agreements discarded because irrelevant with the research topic & 27 \\
\hline Agreements added & 47 \\
\hline Total number of agreements investigated & 190 \\
\hline
\end{tabular}

The methodology for filtering the agreements is displayed in Table 4.2. The final list of the international agreements analysed is in Appendix A. 
A specific research question was formulated for each component of the framework presented in Section 4.2 (see Table 4.3). The texts of the agreements were read a first time, in order to understand the context and purpose of the legal act. Then, a second reading was performed, in order to highlight the parts of the text connected to the three specific research questions. These sentences were pasted into a template, and subsequently the content was evaluated following the criteria illustrated in Table 4.3, related to each component of the framework.

Table 4.3: Specific research questions and evaluation criteria for each component of the framework.

\begin{tabular}{|c|c|c|}
\hline $\begin{array}{l}\text { Component } \\
\text { of the } \\
\text { framework }\end{array}$ & $\begin{array}{c}\text { Specific research } \\
\text { question }\end{array}$ & Evaluation criteria \\
\hline $\begin{array}{l}\text { Unit of } \\
\text { management }\end{array}$ & $\begin{array}{l}\text { Does the agreement } \\
\text { apply to the global } \\
\text { oceans, or to other ocean } \\
\text { areas, considered as a } \\
\text { SES? }\end{array}$ & $\begin{array}{l}\text { Identification in the text of the global } \\
\text { oceans (or other ocean areas) as a } \\
\text { single SES, following bio-geographical } \\
\text { criteria. }\end{array}$ \\
\hline $\begin{array}{l}\text { Objectives of } \\
\text { management }\end{array}$ & $\begin{array}{l}\text { Does the agreement aim } \\
\text { at the ecological } \\
\text { resilience of global } \\
\text { oceans, or other systems } \\
\text { addressed? }\end{array}$ & $\begin{array}{l}\text { Presence in the text of elements of } \\
\text { complexity and ecological resilience } \\
\text { management: ecological diversity, } \\
\text { variability and redundancy; } \\
\text { preservation of essential ecological } \\
\text { processes; ecosystem carrying } \\
\text { capacity; mentioning of ecosystem } \\
\text { approach, ecosystem-based } \\
\text { management or integrated } \\
\text { management; multi-stock or multi- } \\
\text { species approach. }\end{array}$ \\
\hline $\begin{array}{l}\text { Structure of } \\
\text { management }\end{array}$ & $\begin{array}{l}\text { Does the agreement ask } \\
\text { to implement an iterative, } \\
\text { science- and learning- } \\
\text { based policy cycle for the } \\
\text { management of the global } \\
\text { oceans, or other systems } \\
\text { addressed? }\end{array}$ & $\begin{array}{l}\text { Presence in the text of requirements } \\
\text { for: iteration of policy cycle; support } \\
\text { of science to all phases of the policy } \\
\text { cycle; learning. }\end{array}$ \\
\hline
\end{tabular}


Section 4.4 presents the results of the analysis. It is divided into three sub-sections, following the three components of the framework.

\subsection{Results}

\subsubsection{The unit of management}

The United Nations Convention for the Law of the Sea (UNCLOS), and the related Agreement on the implementation of Part XI of the UNCLOS, are the only agreements that consider the global oceans as a single system. The preamble of the UNCLOS states that "ocean problems must be considered as a whole", and aims at building a framework for the regulation of the ocean space all over the world, including specific provisions for the protection of the environment. As such, it seems that the UNCLOS adopts a complexity approach and considers the global oceans as a Social-Ecological System. However, this is not the case, as the UNCLOS view has a major limitation. It divides the ocean areas of the world into several zones, subject to jurisdiction by the coastal states: the territorial sea and contiguous area; the Exclusive Economic Zone (EEZ); the continental platform; the high seas; and the Area of seabed and ocean floor and subsoil beyond the limits of national jurisdiction. It is true that these areas are identified following geographical criteria, such as the distance from the coast and the geomorphological configuration of the seabed. But some limits are set, such as the 12 nautical miles' limit of the width of territorial seas, and the 200 nautical miles' limit of the EEZ, that do not follow geographical considerations. The result is that different regimes of rights and duties apply for each ocean area, creating fragmentation of the system of rights and duties in place for the global oceans.

45 other agreements have a global spatial scope, but do not identify and address the global oceans as a single SES. On the contrary, they focus on one specific issue, be it a Socio-Technical System, an anthropogenic pressure, or an ecological feature, which may be located in any place of the globe. Fisheries agreements, like the United Nations Fish Stocks Agreement (UNFSA); the International Convention for the Regulation of Whaling; the Convention for the Conservation of the Southern Bluefin Tuna; and the FAO Code of Conduct for Responsible Fisheries, apply to specific stocks of living marine resources located all over the globe. Similarly, nature conservation agreements, such as the Convention on Migratory Species of Wild Fauna and Flora (CMS); the Convention on Albatrosses and Petrels; and the Memorandum of Understanding on the Conservation and Management of Dugongs and their Habitats throughout their range, apply to the conservation of specified species. Finally, there are global agreements aiming at the prevention, reduction and fight against pollution, either from land-based 
(e.g. the Global Programme of Action for the Protection of the marine environment from land-based activities, GPA) or marine-based sources (e.g. the Convention on AntiFouling systems on ships; and the Convention for the Control and Management of Ships' Ballast Water).

Table 4.4.: Number of international agreements on the oceans by ocean region. Agreements applying to multiple ocean regions are counted twice.

\begin{tabular}{|c|c|c|c|c|c|c|c|}
\hline \multirow[t]{3}{*}{ Spatial Scope } & \multicolumn{6}{|c|}{ Number of agreements } & \multirow[t]{2}{*}{ Total } \\
\hline & \multirow{2}{*}{$\begin{array}{c}\text { General } \\
\text { agreements }\end{array}$} & \multicolumn{5}{|c|}{ Issue-based agreements } & \\
\hline & & Fisheries & $\begin{array}{c}\text { Nature } \\
\text { Protection }\end{array}$ & Transport & $\begin{array}{c}\text { Pollution } \\
\text { from } \\
\text { Land- } \\
\text { Based } \\
\text { Sources }\end{array}$ & $\begin{array}{l}\text { Pollution } \\
\text { from } \\
\text { Marine- } \\
\text { Based } \\
\text { Sources }\end{array}$ & \\
\hline Global & 2 & 6 & 4 & 3 & 6 & 26 & 47 \\
\hline Regional & & & & & & & \\
\hline $\begin{array}{l}\text { Western Indian } \\
\text { Ocean }\end{array}$ & 3 & 3 & 1 & & 2 & 1 & 10 \\
\hline $\begin{array}{l}\text { Eastern Indian } \\
\text { Ocean (South } \\
\text { Asian Seas) }\end{array}$ & 3 & 2 & & & & & 5 \\
\hline $\begin{array}{l}\text { Eastern Asian } \\
\text { Seas }\end{array}$ & 1 & & & & & & 1 \\
\hline $\begin{array}{l}\text { Persian Gulf / } \\
\text { Arab Gulf }\end{array}$ & 2 & & & & 2 & 2 & 6 \\
\hline $\begin{array}{l}\text { Red Sea and } \\
\text { Gulf of Aden }\end{array}$ & 2 & & 1 & & & 2 & 5 \\
\hline $\begin{array}{l}\text { Mediterranean } \\
\text { Sea }\end{array}$ & 4 & 1 & 4 & & 2 & 3 & 14 \\
\hline Black Sea & 2 & & 2 & & 3 & 1 & 8 \\
\hline Baltic Sea & 2 & 9 & 1 & & & 2 & 14 \\
\hline $\begin{array}{l}\text { North Eastern } \\
\text { Atlantic }\end{array}$ & 2 & 7 & 2 & & & 3 & 14 \\
\hline $\begin{array}{l}\text { North West } \\
\text { Atlantic }\end{array}$ & & 5 & 2 & & & & 7 \\
\hline Caribbean & 2 & 2 & 3 & & 1 & 1 & 9 \\
\hline $\begin{array}{l}\text { South Eastern } \\
\text { Atlantic }\end{array}$ & 2 & 5 & 1 & & 1 & & 9 \\
\hline $\begin{array}{l}\text { North West } \\
\text { Pacific }\end{array}$ & 1 & 4 & 3 & & & & 8 \\
\hline $\begin{array}{l}\text { North Eastern } \\
\text { Pacific }\end{array}$ & 2 & 8 & 5 & & & & 15 \\
\hline
\end{tabular}




\begin{tabular}{|c|c|c|c|c|c|c|c|}
\hline $\begin{array}{l}\text { South Eastern } \\
\text { Pacific }\end{array}$ & 3 & 5 & 3 & & 2 & 2 & 15 \\
\hline South Pacific & 2 & 8 & 1 & & 2 & & 13 \\
\hline Arctic & 3 & 5 & & & 1 & & 9 \\
\hline $\begin{array}{l}\text { Southern } \\
\text { Ocean }\end{array}$ & 1 & 1 & 2 & & & & 4 \\
\hline Total & 39 & 71 & 35 & 3 & 22 & 43 & \\
\hline
\end{tabular}

All the other agreements analysed apply to a specific ocean region of the world. Our analysis identified 18 ocean regions; they are listed in Table 4.4, while the full titles of the agreements are listed in Appendix B. They largely coincide with the ocean regions identified by the UNEP Regional Seas Programme, and related agreements. The only difference is for the North-West Atlantic region, absent in the UNEP Programme. The North-Eastern and South-Eastern Pacific, the Mediterranean, Black Sea and NorthEastern Atlantic are the regions with the highest number of agreements. The Eastern Asian Seas, Southern Ocean, Eastern Indian Ocean, and Red Sea and Gulf of Aden are the regions with the lowest number of agreements. These regional agreements identify their spatial scope following geographical criteria and, as such, seem to have a biogeographical approach. However, there appears to be a major limitation: the majority of them follow the UNCLOS criteria for the delimitation of the different ocean areas, and as such, they apply only to areas where coastal states exert their jurisdiction, excluding the high seas. Only 4 agreements out of 14 apply to the high seas. They are: the Convention for the Protection of the Marine Environment of the North-Eastern Atlantic (OSPAR Convention); the Convention for the Conservation of the Red Sea and Gulf of Aden Environment (Jeddah Convention); the Action Plan for the Protection and Management of the Marine and Coastal Environment of the South Asian Seas Region; and the Convention for the Protection of the Natural Resources and Environment of the South Pacific Region (Noumea Convention). The Noumea Convention includes only the high seas areas enclosed by all sides from areas under the jurisdiction of contracting parties. Finally, it is worth noting that the South-West Atlantic is not covered by any regional agreement.

Similarly, there are several regional issue-based agreements that regulate specific human sectors. They address especially fisheries and local marine living resources (e.g. the General Fisheries Commission for the Mediterranean, GFCM) and straddling stocks, or aim at pollution reduction, or at the protection of endangered habitats and species (e.g. the Inter-American Commission for the Protection of Sea Turtles). Some of these regional issue-based agreements span across multiple regions, like in the case of the Agreement on the Conservation of Cetaceans in the Black Sea Mediterranean Sea and Contiguous Atlantic Area (ACCOBAMS); the Agreement on the International 
Commission for the Conservation of the Atlantic Tuna (ICCAT); and the Agreement for the establishment of the Indian Ocean Tuna Commission (IOTC).

\subsubsection{The objectives of management}

There is no international agreement aiming at the ecological resilience of the global oceans. The main focus of the UNCLOS is to establish a legal regime for oceans and seas, which would "facilitate the equitable and efficient utilisation of resources, the conservation of their living resources, and the study, protection and preservation of the marine environment" (UNCLOS consideranda). Section XII contains a requirement to protect and preserve the marine environment, which is translated in: the obligation to prevent, reduce and control pollution; the duty not to transfer damage or hazards, or transform one type of pollution into another; and the prevention of introduction of alien species. The UNCLOS does not aim at global oceans ecological diversity, variability or redundancy; nor does it mention the application of the ecosystem approach, or ecosystem-based management. As such, it does not include any provision for achieving or maintaining the ecological resilience of the global oceans.

The other global agreements set specific objectives, related to the geographical areas, or SES components, they target. The majority of these global agreements consider important elements characterizing the ecological resilience of global oceans, even if with major limitations. They may be grouped into three categories, according to their main objective, as illustrated in Table 4.5. First, the most recent fisheries agreements aim at the Maximum Sustainable Yield (MSY) of the species or group of species they tackle. MSY, as a concept and tool for the conservation and optimum utilisation of fish and other marine living resources, is adopted by agreements such as the UNCLOS (Sections VI and VII), the UNFSA, and the FAO agreements and activities, among others. These agreements acknowledge the need to cope with inherent uncertainty in stock assessment, and to assess the effects of fishing on species associated with, or dependent upon harvested species. However, no fishing agreement provides multi-stock management. Even the UNFSA, which adopts an ecosystem approach to high seas fisheries, sets limits to the harvesting of each stock, individually taken. The only exception is the South Pacific Regional Fisheries Management Organisation (SPRFMO), which explicitly requires contracting parties to consider the functioning of the wider marine ecosystems and safeguard target species in the process of setting of allowable catches and limitations of fishing effort, while at the same time ensuring conservation and sustainable use of fisheries. 
Table 4.5: Global and regional issue-based agreements containing elements of complexity and ecological resilience, divided by their main objective.

\begin{tabular}{|c|c|c|}
\hline $\begin{array}{l}\text { Objective of } \\
\text { the } \\
\text { agreement }\end{array}$ & Acronym & Full title of the international agreement \\
\hline \multirow{14}{*}{$\begin{array}{l}\text { Maximum } \\
\text { Sustainable } \\
\text { Yield (MSY) }\end{array}$} & CCSBT & Convention for the Conservation of Southern Bluefin \\
\hline & & Tuna \\
\hline & & FAO Code of Conduct for Responsible Fisheries \\
\hline & GFCM & $\begin{array}{l}\text { Agreement for the Establishment of a General } \\
\text { Fisheries Commission for the Mediterranean }\end{array}$ \\
\hline & IATTC & $\begin{array}{l}\text { Convention for the Establishment of an Inter- } \\
\text { American Tropical Tuna Commission }\end{array}$ \\
\hline & ICCAT & $\begin{array}{l}\text { International Convention for the Conservation of } \\
\text { Atlantic Tunas }\end{array}$ \\
\hline & IPHC & $\begin{array}{l}\text { Convention for the Preservation of the Halibut } \\
\text { Fishery (International Pacific Halibut Commission, } \\
\text { IPHC) }\end{array}$ \\
\hline & SEAFO & $\begin{array}{l}\text { Convention On The Conservation And Management } \\
\text { Of Fishery Resources In The South East Atlantic } \\
\text { Ocean }\end{array}$ \\
\hline & SIOFA & South Indian Ocean Fisheries Agreement \\
\hline & SPRFMO & $\begin{array}{l}\text { The Convention on the Conservation and } \\
\text { Management of High Seas Fishery Resources in the } \\
\text { South Pacific Ocean }\end{array}$ \\
\hline & UNCLOS & United Nations Convention on the Law of the Sea \\
\hline & UNFSA & United Nations Fish Stocks Agreement \\
\hline & WCPFC & $\begin{array}{l}\text { Convention on the Conservation and Management of } \\
\text { High Migratory Fish Stocks in the Western and } \\
\text { Central Pacific Ocean }\end{array}$ \\
\hline & WECAFC & Western Central Atlantic Fisheries Commission \\
\hline \multirow[t]{2}{*}{$\begin{array}{l}\text { Favourable } \\
\text { Conservation } \\
\text { Status (FCS) }\end{array}$} & ACCOBAMS & $\begin{array}{l}\text { Agreement On The Conservation Of Cetaceans Of } \\
\text { The Black Sea, Mediterranean Sea And Contiguous } \\
\text { Atlantic Area }\end{array}$ \\
\hline & & $\begin{array}{l}\text { Agreement on the Conservation of Albatrosses and } \\
\text { Petrels }\end{array}$ \\
\hline
\end{tabular}




\begin{tabular}{|c|c|c|}
\hline & ASCOBANS & $\begin{array}{l}\text { Agreement on the Conservation of Small Cetaceans } \\
\text { in the Baltic, North East Atlantic, Irish and North } \\
\text { Seas }\end{array}$ \\
\hline & CBD & Convention on Biological Diversity \\
\hline & CCAMLR & $\begin{array}{l}\text { Convention for the Conservation of Antarctic Marine } \\
\text { Living Resources }\end{array}$ \\
\hline & CMS & Convention on Migratory Species of Wild Animals \\
\hline & & $\begin{array}{l}\text { Inter-American Convention For The Protection And } \\
\text { Conservation Of Sea Turtles }\end{array}$ \\
\hline & & $\begin{array}{l}\text { Memorandum of Understanding on the } \\
\text { Conservation and Management of Dugongs and their } \\
\text { Habitats throughout their Range }\end{array}$ \\
\hline & NAMMCO & $\begin{array}{l}\text { Agreement On Cooperation In Research, } \\
\text { Conservation And Management Of Marine Mammals } \\
\text { In The North Atlantic }\end{array}$ \\
\hline $\begin{array}{l}\text { Pollution } \\
\text { reduction }\end{array}$ & GPA & $\begin{array}{l}\text { Global Programme of Action for the Protection of the } \\
\text { marine environment from land-based activities }\end{array}$ \\
\hline
\end{tabular}

Second, nature conservation agreements aim at the Favourable Conservation Status (FCS) of the marine species they target. The most notable examples are: the InterAmerican Convention for the Protection and Conservation of Sea Turtles; the Conservation of Antarctic Marine Resources (CCAMLR); the Agreement on Cooperation in Research, Conservation and Management of Marine Mammals in the North Atlantic (NAMMCO); and the ACCOBAMS. In a similar way as for fisheries, these agreements focus on the conservation status of single species or groups of species (e.g. cetaceans), without considering ecological interrelations with other species, habitats and SES components. The only exception is provided by the CCAMLR, whose target is the sustained conservation of Antarctic marine living resources. This includes not only the prevention of the decrease in size of harvested populations to levels below stable recruitment, but also the maintenance of the ecological relationships with dependent and related populations, as well as the prevention of potentially not reversible changes in the marine ecosystem.

Third, there are global agreements aiming at the reduction, prevention and control (or abatement) of pollution generated either by land-based or marine-based sources. The most notable examples are: the GPA; the International Convention for the Control and Management of Ships' Ballast Waters and Sediments; and the International Convention on Oil Pollution Preparedness, Response and Cooperation. The GPA is the only 
agreement including elements of complexity and ecological resilience. Although the stated objective is very specific (protection of the marine environment from land-based activities), some elements of the GPA must be highlighted. First, the assessment of landbased sources of pollution should consider the economic and social benefits and uses of the ocean, including the cultural values human communities derive from it. Second, priorities for action should be based on the consideration of impacts on food security, public health, coastal and marine resources, ecosystem health, and socio-economic benefits, including cultural values. Finally, there is a general reference to the implementation of integrated coastal area management, where linkages between freshwater and marine systems should be acknowledged, as well as linkages between sustainable management of coastal and marine resources, poverty alleviation and protection of the marine environment.

At regional level, elements of complexity and ecological resilience have been found in some Conventions, Protocols and Action Plans. They are summarised in Table 4.6. At least one agreement, Protocol or Action Plan is in place for all the 18 ocean regions identified, excluding the North-West Atlantic, where only agreements regulating the fisheries sector are in place. The majority of the agreements have no elements, or only general formulations, of concepts like integrated management, preservation of essential ecological processes, and the need to include socio-economic considerations in the protection of the environment. These agreements do not include definitions of these concepts, and the basic underlying idea is that the environment must be taken into account in order to have a continuous socio-economic development (like the SouthEastern Asia Action Plan; the Jeddah Action Plan; and the Abidjan Action Plan), or that environmental management should be 'sound' (Cartagena Convention) or 'appropriate' (Lima Convention).

Table 4.6: Elements of ecological resilience in the Regional Sea Conventions, Protocols and Action Plans (in parenthesis, the ocean region they apply to).

\begin{tabular}{|c|c|c|c|}
\hline $\begin{array}{l}\text { Elements of complexity } \\
\text { and ecological resilience }\end{array}$ & Agreements & Protocols & Action Plans \\
\hline $\begin{array}{l}\text { No elements of complexity } \\
\text { and ecological resilience }\end{array}$ & $\begin{array}{l}\text { Lima Convention } \\
\text { (South-Eastern } \\
\text { Pacific); Noumea } \\
\text { Convention (South } \\
\text { Pacific); Abidjan } \\
\text { Convention (South } \\
\text { Eastern Atlantic); }\end{array}$ & $\begin{array}{l}\text { Lima; Noumea; Cartagena; } \\
\text { Abidjan; Bucharest (Black } \\
\text { Sea); Kuwait (Persian } \\
\text { Gulf/Arab Gulf); } \\
\text { Barcelona } \\
\text { (Mediterranean); Antigua } \\
\text { (North-Eastern Pacific); }\end{array}$ & $\begin{array}{l}\text { Lima; Abidjan; } \\
\text { Jeddah; } \\
\text { Kuwait; } \\
\text { South-Eastern } \\
\text { Asia }\end{array}$ \\
\hline
\end{tabular}




\begin{tabular}{|c|c|c|c|}
\hline & $\begin{array}{l}\text { Cartagena } \\
\text { Convention } \\
\text { (Caribbean) }\end{array}$ & $\begin{array}{l}\text { other Jeddah Protocols } \\
\text { (Red Sea and Gulf of } \\
\text { Aden) }\end{array}$ & \\
\hline $\begin{array}{l}\text { Only mentioning some } \\
\text { elements of complexity } \\
\text { and ecological resilience, } \\
\text { without definition or } \\
\text { explanation }\end{array}$ & $\begin{array}{l}\text { HELCOM (Baltic } \\
\text { Sea); Barcelona } \\
\text { Convention; } \\
\text { Bucharest } \\
\text { Convention; Kuwait } \\
\text { Convention; Nairobi } \\
\text { Convention } \\
\text { (Western Indian } \\
\text { Ocean) }\end{array}$ & $\begin{array}{l}\text { Nairobi Protected Areas } \\
\text { Protocol }\end{array}$ & $\begin{array}{l}\text { Cartagena; } \\
\text { North- } \\
\text { Western } \\
\text { Pacific; } \\
\text { Nairobi }\end{array}$ \\
\hline $\begin{array}{l}\text { Key concepts are } \\
\text { mentioned and defined, } \\
\text { but there is no clear } \\
\text { requirement to achieve } \\
\text { them }\end{array}$ & Jeddah Convention & & $\begin{array}{l}\text { Barcelona; } \\
\text { Bucharest }\end{array}$ \\
\hline $\begin{array}{l}\text { Ecosystem approach, } \\
\text { ecosystem-based } \\
\text { management or integrated } \\
\text { management are } \\
\text { mentioned as the } \\
\text { objectives of the } \\
\text { agreement. Several } \\
\text { elements of complexity are } \\
\text { mentioned and required, } \\
\text { but they are not clearly } \\
\text { prioritised over socio- } \\
\text { economic considerations }\end{array}$ & $\begin{array}{l}\text { OSPAR (North- } \\
\text { Eastern Atlantic } \\
\text { Ocean); Antigua } \\
\text { Convention }\end{array}$ & $\begin{array}{l}\text { Jeddah Protected Areas } \\
\text { Protocol }\end{array}$ & $\begin{array}{l}\text { Antigua; } \\
\text { HELCOM; } \\
\text { OSPAR; South } \\
\text { Pacific (Pacific } \\
\text { Islands } \\
\text { Regional } \\
\text { Ocean Policy } \\
\text { (PIROP)) }\end{array}$ \\
\hline $\begin{array}{l}\text { Key concepts are } \\
\text { mentioned; management } \\
\text { must prioritise ecological } \\
\text { over socio-economic } \\
\text { considerations }\end{array}$ & & Barcelona ICZM Protocol & \\
\hline
\end{tabular}

Other agreements include a definition of these complexity elements, but this is not translated into clear management measures addressed at realizing them. For example, the Barcelona Action Plan states that environmental considerations should be integrated into social and economic development, and that the complexity of relations between environmental components and socio-economic sectors require the integration of environmental policies into development. However, management measures required by the Barcelona Action Plan are limited to pollution prevention, 
reduction and control, and the promotion of planning and the Integrated Coastal Zone Management (ICZM) without further details. This is also the case of the Bucharest Action Plan, where the integration of environment into sector-based management is required, and framed into a vision to preserve ecosystems and protect resources as a condition for sustainable development. However, this is translated into a limited view, where only four ecological quality indicators are formulated, for four priority areas (eutrophication, biodiversity, living marine resources and water pollution), thus excluding other SES components and interactions.

Other agreements clearly focus on the ecosystem approach, or ecosystem-based management, as the objective of management, and include multiple elements of complexity of environmental-human systems and clear management strategies for achieving this approach. This is the case of OSPAR Convention, where the protection of the North Eastern Atlantic against the adverse effects of human activities should not only conserve marine ecosystems, but also safeguard human health. The OSPAR Action Plan adopts the Ecosystem Approach in order to achieve sustainable development, clearly linking with the European Union Marine Strategy Framework Directive (MSFD, 2008/56/EC). The vision is to achieve a sustainable use of ecosystems good and services while maintaining ecological integrity. Several priority objectives are detailed, covering ecological aspects (e.g. diversity, variability, food webs), and anthropogenic pressures (e.g. chemical and physical pressures) and impacts on ecosystems (e.g. contaminants in fish and habitat destruction). However, the OSPAR Action Plan shares its limitations with the MSFD, where economic and social data and analyses are only required at the stage of initial assessment, and ecosystem services and human benefits considerations, as well as cross-scale interactions, are not given adequate consideration (see Chapter 3). Another example is the Antigua Convention, which requires contracting parties to build integrated management plans including economic and social objectives while aiming at their "ecological balance". The ecosystem services must be assessed from an economic perspective, and the ecosystem approach to fisheries is included. This view is reflected also in the Protocol on Protected Areas of the Jeddah Convention, where the concepts of ecological diversity and variability, and carrying capacity characterise the maintenance of integrity of coastal ecosystems, which is deemed as essential for achieving a sustainable development. ICZM Plans should be considered for adoption by contracting parties, where the carrying capacity of ecosystems must not be surpassed. While this is a strong statement on the prioritisation of ecological considerations over socio-economic ones, this view is contradicted by the statement that contracting parties are only required to consider this option. 
Finally, the Barcelona Protocol on the ICZM is the only legal act where the prioritisation of ecological resilience of complex marine or coastal SESs, is clearly required to be implemented by the contracting parties. This Protocol aims at the integrated management of Mediterranean coastal zones, considered as a complex Social-Ecological System. This requires the application of the ecosystem approach, based on the idea that the carrying capacity of coastal ecosystems must be respected, and, in particular, that the economic considerations must be adapted to the fragile ecosystems.

In synthesis, there is no agreement that aims at the ecological resilience of global oceans. Global agreements focus on specific issues or human sectors, where FCS and MSY are dominant for issue-based agreements, and provide a partial view on ocean complexity and ecological resilience. Moreover, management objectives are set for regional seas and specific ocean areas, with a varying level of inclusion of ecological resilience elements, with North Eastern Atlantic and Baltic being the most advanced, followed by the Mediterranean and Southern Ocean, while Arctic, South Eastern Atlantic and South Eastern Pacific lag behind.

\subsubsection{The structure of management}

As there is no global framework for the achievement or maintenance of the resilience of the world's oceans, in a similar way there is no policy cycle in place for their adaptive management. The only global act, the UNCLOS, has a policy cycle where the required elements of iteration, learning and science-based support to management are not explicitly structured. It is true that the UNCLOS entrusts three bodies for the provision of science based advice to policy and management (namely, the United Nations Division for Ocean Affairs and the Law of the Sea (UNDOALOS); the United Nations Open-ended Informal Consultative Process on Oceans and the Law of the Sea; and the ad hoc open ended Working Group on Conservation and Sustainable Use of marine biodiversity in areas beyond national jurisdiction). However, iteration and review mechanisms are not formally articulated into specific deadlines, and are not connected with the results of periodic evaluation activities. The review of the UNCLOS does not depend on an evaluation of the measures implemented according to its provisions, but is left to the initiative of contracting parties, which may request the convening of a conference to consider the proposed amendments.

Elements of iterative, learning- and knowledge-based management structure are present in the majority of the other global agreements analysed, especially the most recent ones. First, the majority of the agreements have in place structures and mechanisms for the provision of scientific advice, and its utilisation to support 
management actions. Examples in this sense are the scientific advisory committees supporting fisheries management, like the Standing Committee on Research and Fisheries of the ICCAT; the Scientific Advisory Committee of IATTC; and the three GFCM Committees on Aquaculture, on Compliance and the Scientific Advisory Committee. Second, the majority of the agreements have compliance committees, whose main aim is to review and evaluate the activities implemented following the provisions of the related agreement. Third, the majority of agreements hold mechanisms for selfrevision, even if, in a similar way as the UNCLOS, they are not structured and formalized, but generally based on the initiative of the contracting parties. In addition to this, there are no formal mechanisms for revision of the agreements in the light of the results of the evaluation of the management measures adopted and implemented.

At regional level, the conventions, Protocols and Action Plans in place contain several elements of complexity management in their policy cycles. The most advanced agreements are the OSPAR Environmental Strategy and the HELCOM Baltic Sea Action Plan. A four-phases policy cycle is designed by the OSPAR Environmental Strategy, with clear deadlines: (1) an initial assessment and (2) the determination of characteristics for good environmental status, and associated targets and indicators (2012); (3) the establishment of monitoring programmes (2014); and (4) the design and implementation of programmes of measures (2015) for the achievement of the Good Environmental Status (GES). These requirements, and related deadlines for their realisation, are fully aligned with provisions of the EU MSFD. Similarly, the HELCOM Action Plan identifies indicators of good environmental status, which are used to review the implementation of the required measures. The results of this review process will be used to adjust the Action Plan and update the set of indicators and associated targets

In a similar way as for the global agreements, the other Action Plans contain detailed provisions for science advice to policy and management. Monitoring programmes are often required to be implemented, even if they are not linked to the evaluation of the implementation of the measures adopted, but only to the assessment of the status of the ecological systems and of the anthropogenic pressures, and impacts on ecosystems. Periodical assessments are required, and ecological objectives are set; but deadlines are not stated in the text. For example, the Bucharest Action Plan sets timing ranges for the achievement of ecological quality objectives, divided into short term (1-5 years); medium term (5-10 years) and long term (more than 10 years). Nevertheless, the policy cycle does not contain clear iteration and learning elements. Finally, Action Plans contain mechanisms for the review of the policy, usually through periodic meetings of the Contracting Parties. However, this is not automatically followed by an update of the scoping phase and of the initial assessment. 


\subsection{Discussion}

The research presented in this paper confirms that there is no international agreement applying an iterative, learning- and science-based approach to address the ecological resilience of the global oceans system. The only agreement considering the global oceans as a single system, the UNCLOS, does not aim at their ecological resilience, and does not build a policy cycle at global scale for their adaptive management. This is supported by three considerations. First, it is true that UNCLOS stresses the need to consider ocean problems as a whole, and introduces the concept of shared responsibility to protect the marine environment. However, as argued also by Rothwell and Stephens, 2010, this view does not translate neither into a bio-geographical determination of the global oceans as a SES, nor into its subdivision into jurisdiction areas determined following bio-geographical criteria. Second, it is true that the objectives of the UNCLOS include the protection and preservation of the marine environment and marine living resources. However, this is not translated into the consideration of the complexity of the oceans system, and the need to address ecological diversity and variability as fundamental components of oceans ecological resilience. Third, the UNCLOS does not contain requirements to build a global policy cycle, articulated in the four phases of scoping, envisioning, implementing and evaluating There is a requirement for science-based support to decisions; but iteration is not structured into explicit deadlines for implementation. Moreover, learning and review mechanisms are not formally linked to the results of the evaluation of the measures implemented. As such, the UNCLOS does not provide a global, coherent platform for the management of complex global oceans, which is currently missing, as found also by Ban et al., 2014.

In relation to the other agreements analysed, the present research supports the perspective generated by Mahon et al., 2016, on the twofold fragmentation of the international legal framework for the management of global oceans, at both a 'horizontal', or objective-related, and a 'vertical', or spatial level. Agreements with a global spatial scope focus on specific objectives for determined human activities (such as transport and fisheries), ecological components (habitats and species conservation), or anthropogenic pressures (either land-based or marine-based). Fisheries, MSY-based agreements often acknowledge at the outset the inherent uncertainty in stock assessment, and the need to assess the effects of fishing on other species, associated or dependent from the targeted species. The CCAMLR acknowledges the need to prevent possible regime shifts due to the trespassing of thresholds of minimum stable recruitment of Antarctic marine living resources. The GPA considers socio-economic aspects, as well as cross-scale effects of pollution patterns, due to the interaction with 
freshwater systems. However, none of these agreements frames their objective into the perspective of ocean ecological resilience. Fisheries and nature conservation agreements focus on single species, or group of species, individually taken, while the objective of the GPA is the reduction of pollution, and not oceans ecological resilience.

Regional Conventions and Action Plans have a more general focus, aiming at the environmental protection of marine and coastal areas of 18 ocean regions of the world, excluding the South-West Atlantic where no agreement is in place. First, like the UNCLOS, their spatial scope is not determined following bio-geographical criteria. Moreover, there is no coherent approach in the determination of the spatial scope, with the result that only 4 ocean regions out of the 18 identified, extend their scope to cover the high seas, as found also by Gjerde et al., 2008. Second, the level of inclusion of complexity and ecological resilience is varying, and not equally distributed along the ocean regions. In fact, the majority of the agreements contain only a general formulation of concepts like 'sound' environmental management, integrated management, preservation of essential ecological processes, or inclusion of environmental considerations for continuous socio-economic development, without further definition or, more importantly, any management measure required to reach these objectives. Instead, agreements in place for the North-Eastern Atlantic, Baltic Sea and Mediterranean regions contain a more detailed description and articulation of concepts like ecosystem approach, ecological diversity and carrying capacity, clearly linking with the cited EU MSFD. Finally, elements of iteration, learning, and science-based support to decision making are present in most of the agreements analysed. The majority of the agreements have mechanisms in place for scientific advice and for periodical review. However, no agreement includes formal mechanisms for evaluation and review of the agreement, which is left to the initiative of the Contracting Parties.

In the light of these limitations, what could be done in order to streamline complexity into global oceans governance? International agreements are the main instrument in place for the creation of a stable, predictable and accountable regime of rights and obligations among sovereign states. For this reason, it is important that a complex systems approach is introduced at the global stage, possibly through a multilateral agreement. This agreement would set general principles and objectives for global oceans ecological resilience, and periodical science-based assessments would support the establishment of a vision and options for coordinated action at regional scale. Complex systems approach elements should also be introduced into the text of both global, issue-based and regional, general agreements. The revised agreements should: apply bio-geographical criteria in the identification of their scope; include the preservation of essential ecological processes, like diversity, variability and 
redundancy into their objectives; and build iteration, experimentation and learning as fundamental strategies to cope with irreducible uncertainty and help periodically redefine policy objectives and strategies. For example, a possible strategy in this sense would be to adopt a Protocol on ecological resilience to existing Regional Sea Conventions. Similarly, it would be advisable to consider the inclusion of these aspects into the negotiations for future agreements, in particular for a future agreement on the conservation and sustainable use of marine biodiversity in areas beyond national jurisdiction.

However, adopting an international agreement on global oceans, even if conceived and developed as an UNCLOS implementing agreement, or reforming the international agreements analysed would probably prove to be too difficult and challenging. Several obstacles exist, which may hamper the achievement of such an objective. First, a wide consensus on the need for an additional international agreement should be in place, which cannot be taken for granted, especially given the multitude of environmental agreements currently in place. Similarly, a widely accepted consensus on the need for revision of an international agreement should be in place among contracting parties, where strict procedures are normally in place for notification and negotiation of the terms. Second, following the general principles of international law, contracting parties would not be obliged to become parties of revised agreements, with the risk of creating complex, parallel regimes of rights and obligations in place for the same issue or regional sea.

In these cases, a more targeted action on other components of global oceans governance could probably be more effective. Examples exist of informal rules and customary principles, as well as of international institutions and their working practices, which introduce, or advocate for, complexity into oceans assessment and management. Four examples are worth mentioning. First, Chapter 17 of the Agenda 21, devoted to the protection of the oceans, their rational use and development of their living resources, identifies the marine environment as an "integrated whole that is an essential component of the global life-support system" and advocates an integrated governance of the oceans (Rothwell and Stephens, 2010). Second, the 66 LMEs of the world are an example of systems, which are identified based on bio-geographical criteria, even if with the limitation that they extend only to coastal waters and do not cover large portions of open ocean. Third, the Strategic Directions 2013-2016 for the UNEP Regional Seas Programme (RSP) state the necessity to apply an ecosystem approach for healthy, productive and resilience oceans, and points to the need to strengthen coordination with other approaches such as the LMEs, and for the regional implementation of relevant environmental agreements. Fourth, there are examples of 
project-based activities that aim at introducing elements of ecological resilience, iteration and learning into ocean assessment and management. The most notable are: the Ecosystem Approach (EcAp) project, implemented by UNEP/MAP for the Mediterranean Sea; and the Ecologically or Biologically Significant Marine Areas (EBSA) initiative, developed in the framework of the Convention on Biological Diversity (CBD). The EcAp project aims to foster the implementation of the EU MSFD and Water Framework Directive (WFD, 2000/60/EC) in the whole Mediterranean, and shares the same strength and weaknesses as the OSPAR Environmental Strategy and HELCOM Action Plan. The EBSA initiative is a continuous process of identification of special ocean areas around the globe, supporting ocean health and ecosystem services. Although no detailed provisions for management and monitoring is required, the identification of these areas follows fundamental components of marine ecological resilience, like uniqueness or rarity, importance for threatened or endangered species, or high biological productivity or diversity.

A complex systems approach could then be introduced into global oceans governance, building on existing legal obligations and institutional mandates of bodies deputed to the implementation of the agreements analysed, and on the positive inputs and experience of the soft-law agreements and initiatives cited above. For example, projects like the cited EcAp could be developed in the context of other regional seas or other agreements, while the EBSA initiative could be strengthened by including requirements for iteration, monitoring and learning into management of identified ecologicallysignificant areas. Action Plans of Regional Sea Conventions could be updated to include the required elements of complexity into oceans governance, taking advantage of their capacity to unify obligations coming from several agreements, provide more detail and even add complementary goals (Kimball, 2001). In a similar way, an Oceans Action Plan could be adopted at global level, possibly in the context of the UNCLOS, or of the UNOCEANS (the coordinating mechanism of all UN entities for ocean and coastal issues). This Plan would consider the global oceans as a single system, and periodically identify and assess global oceans ecological resilience, by applying an iterative, learning- and science-based management strategy. It would stand as a coordination framework of UN-OCEANS, integrating with the UNEP RSP Strategic Directions, and possibly connecting with the activities of the United Nations Framework Convention on Climate Change (UNFCCC).

\subsection{Conclusions}

The need is pressing to address the present challenges to the global ocean ecological structure and functions, and its capacity to regulate global weather and climate. This 
paper presents the results of the analysis of 500 international agreements for the assessment and management of the world's oceans and seas. It shows that there is no global agreement requiring countries to develop and implement a coherent and comprehensive complex systems approach to oceans assessment and management. There is the need to overcome the identified twofold fragmentation of the international legal framework, at both horizontal, or objective-related, and vertical or spatial level, fostering the inclusion of such an approach into existing and future international agreements and their implementation. Possible strategies include the adoption of a Global Oceans Action Plan, or similar soft-law, project-based initiatives at global and regional scales, in order to overcome potential difficulties in the introduction of new agreements, or unavoidable difficulties in the revision of the current ones.

This research is limited to the analysis of the texts of international agreements, thus excluding other important components of global oceans governance, like informal and customary rules, soft law agreements, and the practice of institutions in place for the implementation of the agreements analysed. This should be the focus of further research and investigation, aiming at verifying to what extent and how the limitations of the international legal framework, which emerged from this analysis, are translated into the real practice of assessment and management of the global oceans.

\section{Acknowledgements}

This work is part of a PhD project, which received the financial support of the European Commission Joint Research Centre, Institute for Environment and Sustainability (Grant no. H10114). I would like to thank Arnold K. Bregt, Wageningen University, and Max Craglia, European Commission Joint Research Centre, for their supervision and support. I would like to thank also Robin Mahon and Lucia Fanning for their precious advices. Thanks also the anonymous reviewers, whose comments contributed to raise the quality of the paper. 


\section{Appendix}

The following supplementary material can be accessed online at:

http://www.sciencedirect.com/science/article/pii/S0308597X16300860.

Appendix A - List of international agreements investigated.

Appendix B - International agreements by spatial scope (global vs. regional) and objective (general vs. issue-based). 



\section{Chapter}

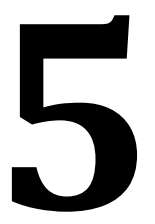

The role of the Marine Strategy Framework Directive for marine integrated management in Europe. Lessons from the Adriatic Sea

Emanuele Bigagli 


\begin{abstract}
The aim of this paper is to contribute to the evaluation of the capacity of the European Union to deliver an integrated, complex systems approach to the assessment and management of European oceans and seas. This is done through the investigation of the implementation of the Marine Strategy Framework Directive (MSFD) and other EU legislation in the case study area of the Adriatic Sea. A total of 19 semi-structured interviews were conducted in the period June 2013-January 2014 with 23 representatives of Italian public administrations and other stakeholders, engaged in the protection of the marine environment or management of maritime activities of the Adriatic Sea. The results show the importance of the MSFD as the first policy trying to deliver a complex systems approach to marine assessment and management. However, the case-study investigation confirms three limitations of the MSFD, laying in: 1) an insufficient geographical approach, where implementation is driven at national level and the requirement of cross-border cooperation is weak; 2) the vagueness of legal requirements, particularly affecting the capacity to include socio-economic aspects into the assessment; and 3) an insufficient capacity to coordinate with other laws, policies and programmes at various levels of governance. Based on the identified limitations, suggestions are advanced on how to strengthen the implementation of the MSFD, both at Adriatic and EU level.
\end{abstract}

Keywords: Marine Strategy Framework Directive; Adriatic Sea; integrated management. 


\subsection{Introduction}

All around the globe, the assessment and management of marine environmental and social systems is gradually moving from a sector-based approach, towards the introduction of an ecosystem-based management to marine social-ecological systems (Arkema et al., 2006; Bigagli, 2016). In Europe, this process started in 2008, with the issue of the Marine Strategy Framework Directive (MSFD; 2008/56/EC). The MSFD stands as a turning point of European marine governance, as it introduces for the first time in Europe a geographical, learning-based approach to the assessment and management of marine systems (Bigagli, 2015). This complexity approach is based on three main features: the use of a geographical approach to the definition of marine regions and sub-regions; the setting of Good Environmental Status (GES) as the objective of policy; and the application of policy iteration and learning strategies (Bigagli, 2015).

The MSFD was introduced into an already complex European governance landscape for the marine environment, characterised by a variety of maritime activities, often in conflict, and regulated by fragmented, sectorial public policies operating at multiple levels (van Tatenhove, 2013; Boyes and Elliott, 2014). The MSFD tries to address this fragmentation, by requiring Member States to build coordination and cooperation mechanisms on two levels: among different policies, the most notable ones being the Water Framework Directive (WFD; 2000/60/EC) and the Common Fisheries Policy; and with other MS sharing the same marine region or sub-region. However, previous research found three major obstacles to this process in the text of the Directive (Bigagli, 2015), related to: 1) the insufficient capacity of the MSFD to have a geographical, socialecological approach to marine areas, including the limited capacity to coordinate among Member States (MS) sharing the same marine region or sub-region; 2) the limited capacity of the MSFD to include socio-economic aspects, and their interactions and outcomes with ecological systems; and 3) the limited strength of the requirements to coordinate with other laws and policies. The results of this investigation are summarised in the first column of Table 5.1.

The analysis of existing policies configurations, conflicts and coordination problems among sectors and levels of governance, together with issues that enable or constrain further integration, has been advocated in literature as a means to promote good governance of marine systems (van Tatenhove, 2013). In fact, the implementation of a public policy is not a straightforward process, especially in the EU, with multiple decision points and opportunities for national governments to 'erode' the original objectives of a policy (Dimitrakopoulos and Richardson, 2001). Hence, the objective of 
this paper is to assess whether the strengths and weaknesses identified in the texts of EU legal acts are reflected in reality, and to what extent they are confirmed or coped with, by real practices. This is done through the investigation of the process of implementation of the MSFD and other EU legislation in the case study area of the Adriatic Sea.

Table 5.1: The limitations of the MSFD identified (Bigagli, 2015) and the specific research questions for the case study.

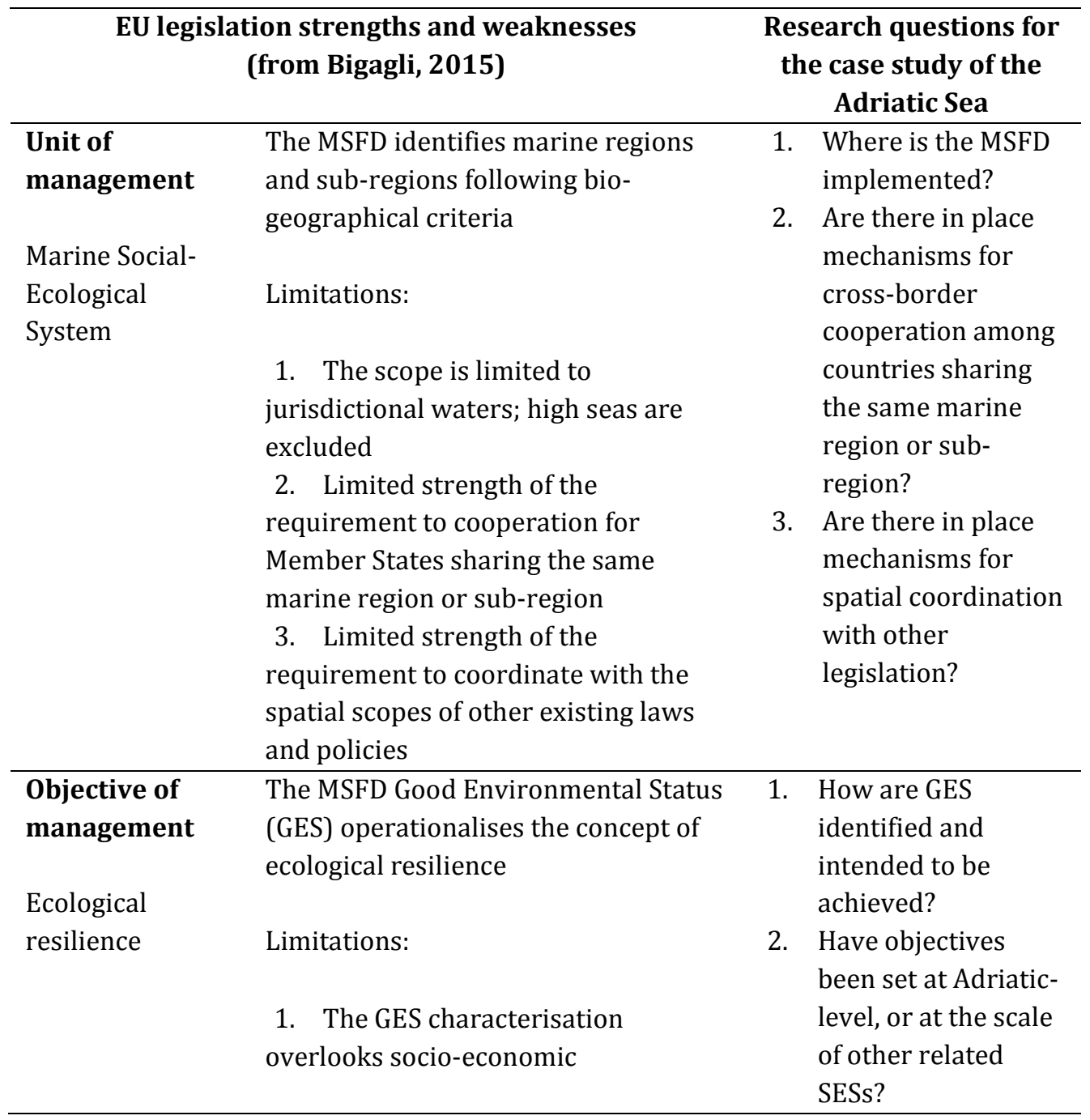




\begin{tabular}{|c|c|c|c|}
\hline & $\begin{array}{l}\text { components, their internal dynamics } \\
\text { and influences on ecological resilience } \\
\text { 2. Limited strength of the } \\
\text { requirement to coordinate GES } \\
\text { objectives with other Member States } \\
\text { sharing the same marine region or } \\
\text { sub-region } \\
\text { 3. Limited strength of the } \\
\text { requirement to coordinate with the } \\
\text { objectives of other legal acts, which } \\
\text { may overlap and conflict with GES }\end{array}$ & 3. & $\begin{array}{l}\text { Have the objectives } \\
\text { of other legislation } \\
\text { been integrated } \\
\text { with MSFD into a } \\
\text { common } \\
\text { framework? }\end{array}$ \\
\hline $\begin{array}{l}\text { Structure of } \\
\text { management }\end{array}$ & $\begin{array}{l}\text { The MSFD requires an iterative, } \\
\text { learning- and science-based policy } \\
\text { cycle }\end{array}$ & 1. & $\begin{array}{l}\text { How is the MSFD } \\
\text { policy cycle } \\
\text { implemented? }\end{array}$ \\
\hline $\begin{array}{l}\text { Iterative, } \\
\text { learning- and } \\
\text { science-based }\end{array}$ & Limitations: & 2. & $\begin{array}{l}\text { Is the MSFD policy } \\
\text { cycle coordinated at } \\
\text { Adriatic scale? }\end{array}$ \\
\hline policy cycle & $\begin{array}{l}\text { 1. Lack of coordination with other } \\
\text { laws and policies: different policy } \\
\text { cycles with overlapping and } \\
\text { misaligned phases and timelines of } \\
\text { implementation }\end{array}$ & 3. & $\begin{array}{l}\text { Are there initiatives } \\
\text { and mechanisms in } \\
\text { place to foster the } \\
\text { coordination of } \\
\text { MSFD with other } \\
\text { legal acts? }\end{array}$ \\
\hline
\end{tabular}

The Adriatic Sea is a shallow, semi-enclosed basin located in the northern, central part of the Mediterranean Sea (see Figure 5.1). For its bio-geographical characteristics, the MSFD identified it as a marine sub-region of the Mediterranean Sea. Moreover, the European Commission identified the Adriatic-Ionian area as one of the European macro-regions, and launched in 2014 a Strategy for the Adriatic and Ionian Region (EUSAIR, European Commission, 2014), aiming at creating synergies and fostering coordination among all territories in the area. In parallel, an increasing number of scientific, political and economic initiatives have been launched, aiming at protecting the marine environment and fostering sustainability and socio-economic integration among the EU (Croatia, Greece, Italy and Slovenia) and non-EU coastal countries (Albania, Bosnia-Herzegovina and Montenegro). An integrated, ecosystem-based approach is fundamental to preserve essential ecological processes and achieve or maintain the ecological resilience of the Adriatic Sea social-ecological system, while at the same time fostering the sustainability of maritime activities. For these reasons, it is 
important to verify the extent to which an integrated approach for the assessment and management of the Adriatic Sea social-ecological system is already in place, and identify major strengths and weaknesses in current practices.

The paper is structured as follows. Section 5.2 presents the methodology followed to develop the case study and derive the required information. Section 5.3 provides a short description of the case study area of the Adriatic Sea. Finally, section 5.4 presents the results of the investigation.

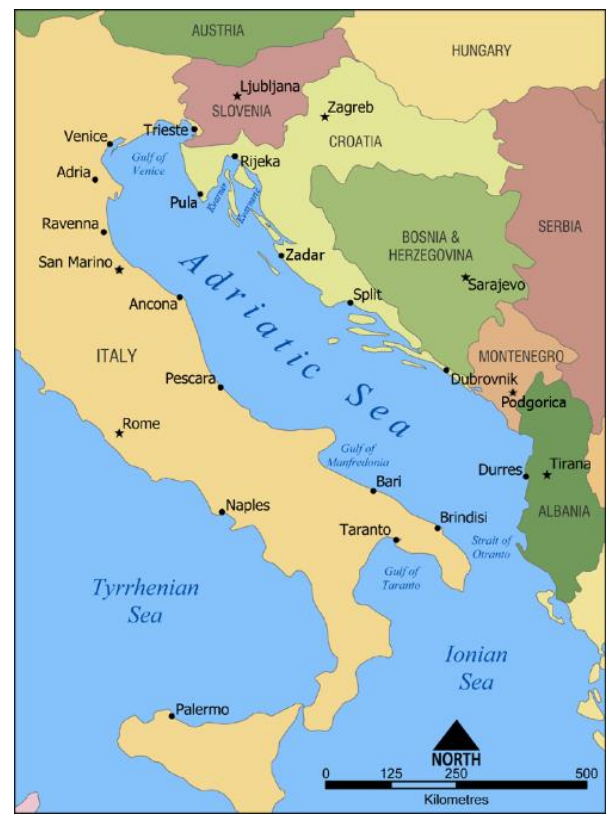

Figure 5.1: Map of the Adriatic Sea. Licensed under Creative Commons AttributionShare Alike 3.0 via Wikimedia Commons.

\subsection{Methodology}

The case study investigation presented in this paper is based on the findings of previous research, aimed at assessing the current international and European legal frameworks for the management of marine social-ecological systems (Bigagli, 2015; Bigagli, 2016). They are summarised in Table 5.1. Specific research questions for investigation were formulated, related to each of the findings of previous research (Bigagli, 2015). In order to answer to these questions, semi-structured interviews were conducted in the period June 2013-January 2014 with representatives of Italian public administrations and 
other subjects at various levels, engaged in the management of the marine environment or maritime activities of the Adriatic Sea. A total of 19 interviews were conducted, with 23 people: representatives of public administration, both at national and regional government level (16 people); representatives of scientific research bodies (4); relevant stakeholders in nature protection and fisheries (2); and international organisations involved in Adriatic cooperation (1). The full list of all subjects interviewed, together with a brief description and reasons for choice, is attached in Appendix. Because of their role or involvement, these people were expected to give the most complete picture about the current legal and policy practices and challenges for the management of the Adriatic Sea. The topics of discussion in the interviews were: their role within the institution; the competences and activities of their institution for the management of the marine environment and maritime activities; existing problems, challenges or good practices related to the governance of the marine environment and human activities, also in a coordinated way with other competent bodies; and existing problems, opportunities and challenges to the coordination of activities at Adriatic level. Transcripts were sent back to the interviewees shortly after the interview, in order to double-check the information included and reduce the risk of misunderstandings or lack of information. Information coming from the interviews was integrated with other documentary evidence, such as legal acts at national, regional and local level, other types of policy documents, like local plans and programmes of measures, and scientific research on the topic. The results of the case study investigation are presented in Section 5.4 and related sub-sections.

\subsection{Results}

\subsubsection{The unit of management}

1) Where is the MSFD implemented?

The MSFD identifies the Adriatic Sea as one of the marine sub-regions of the Mediterranean Sea marine region (art. 4). Accordingly, the Italian Ministry of Environment, responsible for the implementation of the MSFD, coordinated the elaboration of the initial assessment and the monitoring programmes, which considered the Adriatic Sea as one of the three assessment areas (the other two being the Italian sections of the Ionian Sea and of the Western Mediterranean Sea subregions). Italy's initial assessment and monitoring programmes cover Italian jurisdictional waters of the Adriatic Sea, which include the territorial sea up to $12 \mathrm{~nm}$ from the coast and the continental platform, whose borders were agreed in several bilateral treaties with the then Yugoslavia (now valid for Slovenia and Croatia), Albania 
and Greece (Italy did not declare any Exclusive Economic Zone (EEZ) in the Adriatic Sea).

2) Are there in place mechanisms for cross-border cooperation among countries sharing the same marine region or sub-region?

Interviewees reported that coordination with other Member States (MS) for the implementation of the MSFD is low or absent. Italy organized one meeting with Malta, Greece and Slovenia in 2012. Interviewees pointed to the lack of a stable forum at basinscale as a major obstacle for the coordinated implementation of the MSFD with other EU countries (Croatia, Greece and Slovenia). One interviewee highlighted that the EU institutions should assume a leading role in pushing Member States to cross-border cooperation for the implementation of MSFD.

3) Are there in place mechanisms for spatial coordination with other legislation?

All interviewees reported the existence of several plans, programmes and policies in place for the Adriatic coastal and marine waters, each of them managed by a specific public body at various levels of governance. Their spatial scope is illustrated in Figure 5.2, built on information coming from interviewees and from literature review; for an explanation of the acronyms used, see Table 5.2.

Some of these plans, programmes and policies apply to coastal zones, as it is the case for e.g.: the regional Integrated Coastal Zone Management (ICZM) Plans; the ATO plans for wastewater management; the Port Regulatory Plans (for ports of national importance); and the coastal parks management plans. Others cover coastal waters, like the WFD River Basin Management Plans (RBMPs) and the Hydro-Geological Risk Plans (PAI), which extend to $1 \mathrm{~nm}$ offshore. Regional Water Protection Plans (PTA) extend the application of the WFD and other related Directives up to $3 \mathrm{~nm}$ offshore. Other plans, programmes and policies extend further into territorial waters; they are usually developed at national level and are under the responsibility of the competent Ministry. For example, the Ministry of Economic Development is responsible for the issuance of permits for prospection, exploration and production of oil and natural gas, in an area that extends up to the continental platform. The Ministry of Agriculture and Forestry is responsible for the implementation of the Common Fisheries Policy (CFP), applicable to territorial seas and to fishing vessels flying the flag of a Member State. Maritime traffic control and Search and Rescue (SAR) operations are under the responsibility of the Coast Guard, and apply to the Italian SAR Area, which extends in the Adriatic high seas, up to the outer limit of the continental platform. Finally, it is worth noting that 
Italy established a contiguous zone, up to $24 \mathrm{~nm}$ from the coastline, for the protection of the marine environment from pollution and for protection and valorisation of cultural heritage.

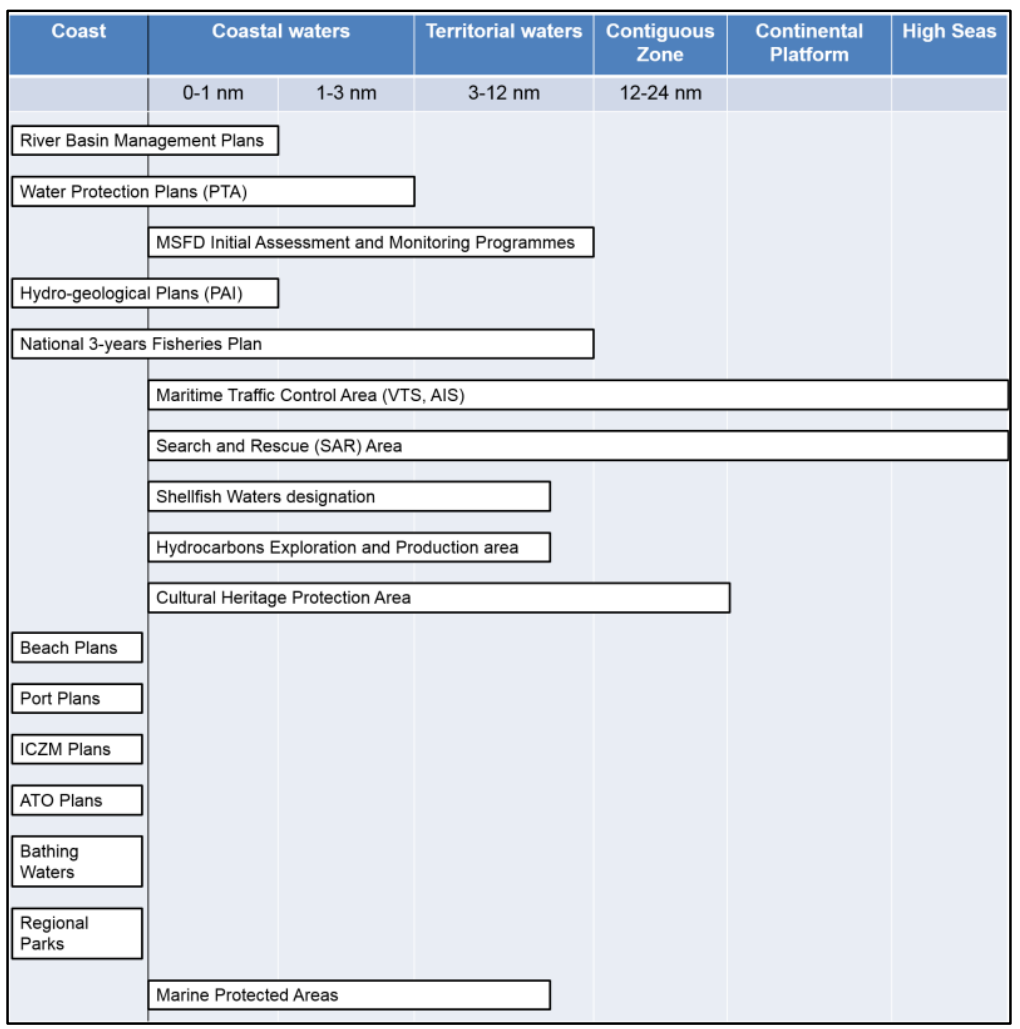

Figure 5.2: The spatial extension of the main plans and programmes in place in the Italian waters of the Adriatic Sea.

Interviewees reported that all these policies are implemented in an autonomous way, where public bodies have generally no mandate to coordinate with others in relation to spatial measures. As such, each maritime activity is regulated independently, with provisions spanning across several European marine regions (as it is the case for the fisheries and maritime transportation sectors regulated by the Common Fisheries Policy, CFP), or at different governance scales. Several interviewees reported the absence of mechanisms for spatial coordination between these policies, with no coordination activities performed in the context of the implementation of the MSFD. 
Table 5.2: Explanation of the acronyms used in Figures 5.2 and 5.3.

\begin{tabular}{ll}
\hline Acronym & \\
\hline AIS & Automatic Identification System - automatic vessel tracking system \\
\hline ATO & $\begin{array}{l}\text { Optimal Territorial Area (Ambito Territoriale Ottimale) - Area of } \\
\text { organisation of integrated waste and wastewater public services; it is } \\
\text { defined at regional level. }\end{array}$ \\
\hline ICZM & Integrated Coastal Zone Management \\
\hline PAI & Regional Hydro-geological Risk Plan (Piano di Assetto Idrogeologico) \\
\hline PTA & Regional Water Protection Plan (Piano di Tutela delle Acque) \\
\hline SAR & Search and Rescue \\
\hline VMS & EU Vessel Monitoring System Regulation (2244/2003) \\
\hline VTS & Vessel Traffic Service - marine traffic monitoring \\
\hline
\end{tabular}

\subsubsection{The objectives of management}

1) How are GES identified and intended to be achieved?

GES and environmental targets have been defined by the Italian Ministry of Environment in the initial assessment (ISPRA, 2012), with the scientific, technical and coordination support of the Italian National Institute for Environmental Protection and Research (ISPRA), and refined through the publication of monitoring programmes. The programme of measures has been elaborated and will be published in 2016 . The lack of the right quantity and type of data and information was indicated by one interviewee as one of the main reason for the adoption by Italy of qualitative criteria to identify GES and environmental targets. The same interviewee pointed to the ambiguity and vagueness of MSFD legal requirements on this aspect as a further obstacle.

The socio-economic analysis of the use of marine waters, required by the MSFD, was performed by Italy using the Marine Water Accounts approach, which included three types of macro-economic data for each maritime sector: production value, added value and employment. Moreover, the analysis of the cost of degradation of the marine environment was performed using the Cost-based approach, where the expenses of various public bodies for remedying environmental damage and impacts are included. While, as acknowledged in the Italian initial assessment, this provides a good snapshot of actual costs sustained to remedy environmental damage to the marine environment in Italy, however Italy acknowledges that it misses the loss of social wealth derived by the degradation (ISPRA, 2012). 
2) Have objectives been set at Adriatic level, or at the scale of other related SESs?

The only experience of coordination of management at institutional level reported by interviewees is the Fisheries District of Northern Adriatic. Launched in 2010 and operative from 2012, it aims at coordinating the management of fish resources of the Northern Adriatic Sea, by promoting partnerships between producers and enterprises of the fisheries sector. The spatial scope of the District includes the marine waters of the three northernmost Italian Adriatic regions: Friuli-Venezia Giulia, Veneto and Emilia-Romagna, as well as Croatian and Slovenian marine waters. Another experience of coordination at the scale of marine region is the UNEP/MAP-led EcAp project, for an Ecosystem Approach to the Mediterranean Sea, based on the provisions of the MSFD and, marginally, of the WFD. Some interviewees acknowledge the importance of this initiative in the establishment of a framework for discussion on these issues, especially in combating episodes of pollution discharge, reported to take place in high seas and in other countries, where legislation and control of competent authorities is less stringent. However, the same interviewees also underline that major threats to EcAp implementation lay in the varying level of commitment to the project by the single countries, especially outside the EU, and in the lack of effective mechanisms for enforcing compliance. One interviewee argued that the presence of different legal systems among Mediterranean countries for ship-generated waste management, often results in 'dumping' practices, where ships discharge their waste in a faster, easier and cheaper way in countries with lower environmental standards, with increased risks of damaging the marine environment. Common rules are envisaged for the fisheries sector by another interviewee, especially in relation to the protection of nursery sites and to a clearer delimitation of fishing grounds.

3) Have the objectives of other legislation been integrated with MSFD into a common framework?

All interviewees reported the existence of several plans, programmes and policies, implemented by several bodies in an autonomous way and with no mechanisms in place for the coordination of objectives. Some plans try to coordinate the implementation of multiple EU legal acts, the most notable example being the regional PTAs for WFDrelated legislation. Coordination is in place also for the regulation of port activities, where the Port Regulation Plan has to be developed in synergy with local town plans. Moreover, the National Biodiversity Strategy, elaborated and implemented by the Ministry of Environment in 2010, aims at creating a national platform for the protection of biodiversity across socio-economic sectors, including marine biodiversity. The Strategy identifies objectives and actions to be implemented, linked to WFD, MSFD, CFP, 
energy and tourism legislation, in order to integrate the protection of biodiversity into sector policies. It is worth noting that the Strategy does not create new obligations; it only asks to consider the protection of biodiversity while implementing other policies. Finally, some regions have adopted Integrated Coastal Zone Management (ICZM) Plans, aiming at coordinating the management of multiple activities and interests in the coastal zone. However, as some interviewees highlighted, some of them, like the Marche region ICZM Plan, focus on specific issues like erosion and coastal defence, while others, even if with a larger scope, are just a set of non-compulsory guidelines, for which one interviewee pointed to the need for more cogent legislation (like in the case of the Emilia-Romagna region ICZM Plan). Existing plans, programmes and policies for the marine environment and maritime sectors, including their relations, are illustrated in Figure 5.3; acronyms are explained in Table 5.2.

A major effort in trying to build a platform for cross-sector management of the marine environment is the Technical Committee for the coordinated implementation of the MSFD. The Technical Committee is composed of representatives of Ministries (Ministry of the Environment; Ministry of Agriculture, Food and Forestry; Ministry of Infrastructures and Transport; Ministry of Health; Ministry of Defence; Ministry of Foreign Affairs; Ministry of Education, University and Research; Ministry of Cultural Heritage; Ministry of Economic Development; and the Department for Regional Affairs), Regions, Provinces and Municipalities. Its aim is to participate to the definition of the activities for the implementation of the MSFD. A further platform for cooperation was piloted in 2012 with a Protocol of Understanding between the Ministry of Environment and the Italian coastal regions, grouped by marine sub-region, and aiming at integrating the initial assessment with investigation on three priority themes (marine litter, habitats and species and socio-economic aspects). A Coordination Body (Cabina di regia) was created, and reportedly represented the first attempt to establish a platform for cooperation and coordination of activities among public bodies for the marine environment. However, interviewees reported a low level of interest and involvement on the activities of the Technical Committee from non-coastal regions. One interviewee pointed out that the process of implementation of the MSFD needs time and resources, and that all public administrations involved at all levels need to learn to collaborate, with the objective of building a stable structure and a common methodology of work. 


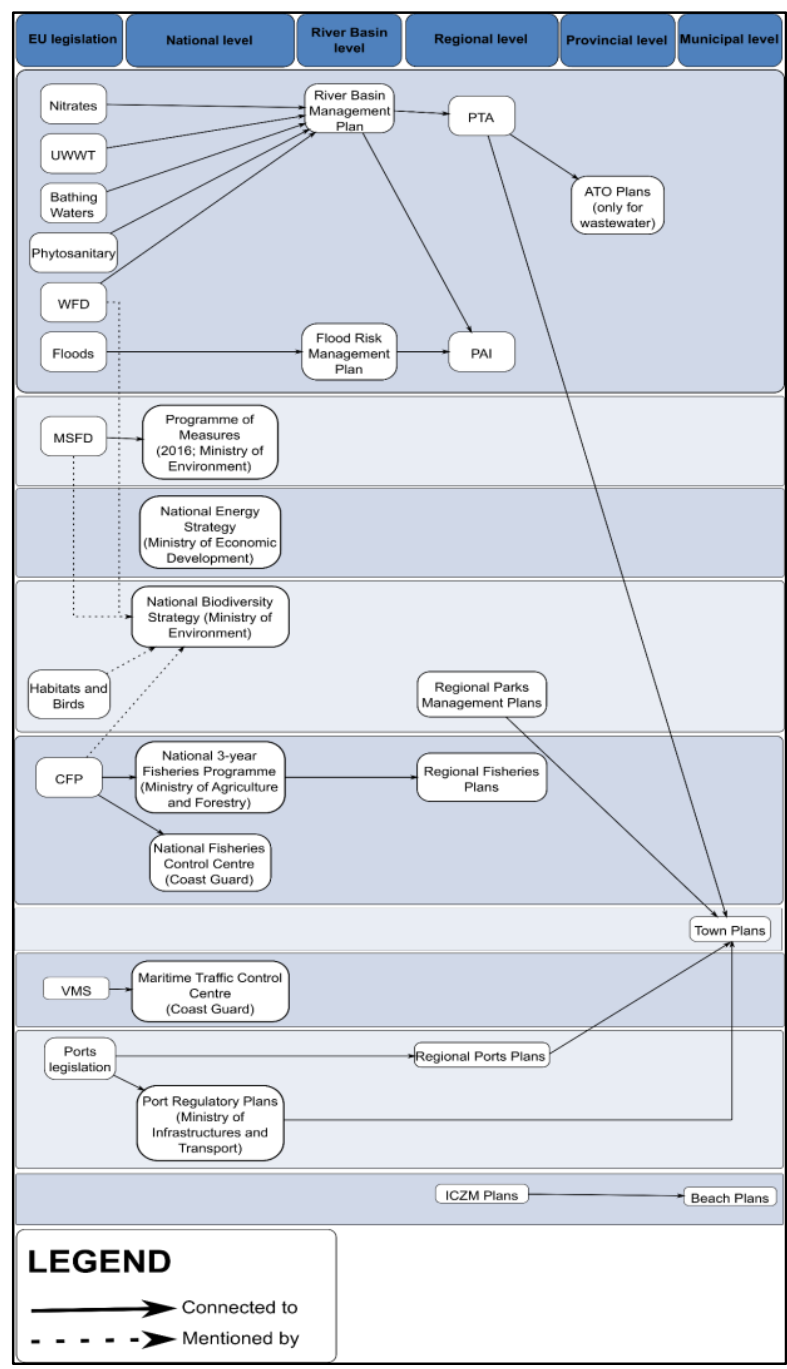

Figure 5.3: Connections between EU legislation and existing policies, plans or programmes for the Adriatic Sea.

Low or absent coordination was reported by the interviewees, not only between different levels of authority (state; regions; provinces and municipalities), but also inside the same public body. For example, departments of the Regions that are responsible for erosion, coastal defence and ICZM, are usually not involved in the activities of the MSFD, and vice versa. One interviewee reported that current legislation does not include provisions for the coordination of dredging activities among the responsible bodies, i.e. Regions and National Port Authorities, especially in relation to 
Sites of National Importance (particularly polluted areas identified at national level). Moreover, regional River Basin Authorities, which are responsible for the implementation of flood risk management activities, have no coordination with tourism or coastal public area managers, let alone the two departments mentioned above. Cooperation among regions is reported by interviewees as left to personal relations between the single actors. It is the opinion of one interviewee that coordination among public bodies is hampered by the quantity of laws and regulations, which often generates confusion instead of clarifying competencies. The institutional setting of the RBDs adds to this complexity and fragmentation, as the River Basin Authorities of three RBDs (Northern Apennines; Central Apennines; and Southern Apennines) have still not been created. RBMPs for these are still pending at the moment of writing, where national law required the River Basin Authorities of rivers Arno and Tevere (two rivers flowing into the Tyrrhenian Sea) to perform the duties to be assigned to the Northern and Central Apennines RBDs, thus including rivers flowing to the Adriatic Sea.

\subsubsection{The structure of management}

1) How is the MSFD policy cycle implemented?

Italy reported the initial assessment and definition of GES and environmental targets to the European Commission in 2012 (ISPRA, 2012), with an integration of missing data and information dated April 2013. Next, monitoring programmes were elaborated and reported in 2014, while the programme of measures was reported in 2015 (still not published at the time of writing). Both the initial assessment and the elaboration of monitoring programmes have been elaborated starting from the knowledge available and accessible by the Ministry, building on existing data held by, and existing monitoring programmes conducted by, other Ministries or other public bodies, such as regions and national research bodies. In the case of monitoring programmes, the intention of the Ministry of Environment was to integrate existing data collection activities with new monitoring, aiming at filling the data gaps identified in the initial assessment. To this respect, two interviewees highlighted the need for further coordination on data collection and monitoring activities among deputed bodies, especially in relation to the evaluation of the status of habitats and species for the requirements of Habitats and Bird Directives. Another interviewee reported a structural lack of data in the hands of Regions, which hampers the development of adequate knowledge in support to MSFD implementation. 
The major obstacles being faced in the implementation of the MSFD, as reported by interviewees, are: the lack of funds and staff; the lack of precise addresses and strategies at national level; the differences in legal frameworks among the Italian Adriatic regions, which may slow down the activities or require their adaptation to different sets of rules; the overlaps and misalignments of various legal acts, especially at EU level; and the fragmentation of duties and responsibilities, not only among different bodies, but also among different departments or services of the same body (e.g. Ministry, Region).

2) Are there initiatives and mechanisms in place to foster the coordination of MSFD with other legal acts?

Overlaps in competences and relative isolation of policies have been highlighted by interviewees, with no connection with, and sometimes reported knowledge of, the implementation of the MSFD (one interviewee). Interviewees reported the existence of different calendars and deadlines for the implementation of each policy, plan or programme, creating sometimes difficulties in the organisation of the workload and the capacity of the public body to fulfil the requirements. This is especially true for these regions, whose territory lays within the area of multiple RBDs, and where RBMPs are formulated and implemented in an autonomous way, without coordination or cooperation with other marine plans and programmes. The governance is particularly complex in the case of some sectors, like the wastewater management. As reported by one interviewee, several bodies are involved in wastewater management, and the capacity of the regions to coordinate them was reported as low.

\subsection{Discussion}

The analysis of the legal and policy landscape for the governance of the Adriatic Sea, presented in this paper, showed the importance of the MSFD as the first policy trying to deliver an integrated, complex systems approach to the assessment and management of European oceans and seas. For the first time in Italy an assessment of the status of the marine environment was performed, together with the setting of institutional mechanisms and structures for the coordinated implementation of the MSFD. However, the present case study investigation confirms the three limitations of the MSFD, presented in Section 5.1 (Bigagli, 2015).

First, the MSFD seems to provide an insufficient geographical approach to EU marine regions and sub-regions. Italy implemented the MSFD in an autonomous way, without much coordination at Adriatic level. This stands as another case of 'nationalisation' of the implementation of the MSFD, as stated by Freire-Gibb et al. (2013). Moreover, it 
seems to lack the creative thinking on future options for cross-border cooperation, which emerges from the analysis of other marine sub-regions of the Mediterranean (Jouanneau and Raakjaer, 2014). This seems to be mainly due by the fact that crossborder, marine region-based cooperation is formulated in a general way in the text of the MSFD, without much detail on governing structures and mechanisms (as found also by Salomon and Dross, 2013; van Tatenhove et al., 2014; and van Tatenhove, 2016). As a result, MS are left to the capacity of the Regional Sea Conventions (RSCs) to act. It is true that the EcAp project of the UNEP/MAP is one of the most advanced examples of complex systems approach to marine assessment and management at global stage (Bigagli, 2016). However, the present research points to two limitations of the EcAp approach, mainly lying in the low interest of non-EU Mediterranean countries to support its implementation, and the lack of mechanisms to enforce compliance. This confirms the findings of van Leeuwen et al. (2012), who stated that the institutional ambiguity of the Mediterranean governance framework is the highest in Europe, as support from the RSC is lacking.

Second, the vagueness of the MSFD is confirmed as an obstacle to the process of performing the required socio-economic assessment. The MSFD legal requirements for the socio-economic analysis were evaluated by the interviewees as general and vague; this led Italy to adopt the methodology that best suited data availability. The result is that important aspects, such as the complex dynamics between socio-economic activities and their impacts on marine ecological resilience, or the assessment of marine ecosystem services and benefits, or cross-scale interactions and effects, were not adequately taken into consideration. This confirms findings from other research, on the lack of clarity of the meaning of GES (Brennan et al., 2014), and on its low level of accuracy at technical level (Bellas, 2014). This adds to the lack of the right quantity and quality of data, an aspect pointed out by various interviewees, and acknowledged also in literature (Tunesi et al., 2013). What emerges from the present analysis is that this structural lack of data appears to be mainly due to two factors: the lack of data, where several ecological aspects are insufficiently monitored, or not monitored at all; and the insufficient level of sharing of data among public administrations.

Third, the MSFD seems to suffer from an insufficient capacity to coordinate with other laws, policies and programmes in place at various levels. The case study of the Adriatic Sea showed a high level of fragmentation of marine governance. It also showed that thanks to the process of implementation of the MSFD, some initiatives are slowly starting to take place, like the MSFD Technical Committee, while the Regional Water Protection Plans (PTA) already coordinate the implementation of the WFD and related legislation. However, the case of Italy shows that integration and coordination are being 
realised in the opposite direction, with sector-based policies being included into the implementation of the MSFD and not vice versa, as suggested also by Salomon and Dross (2013). More in general, as reported also by one interviewee, the current organisation of public administrations still reflects a Weberian, silo-based model, where competences are split along departments and single administration, a view which is now clearly inadequate to address current complex, unpredictable environmental problems.

In the light of these findings, what can be done in order to strengthen the implementation of the MSFD?

First, there is the need to foster mechanisms and structures for cross-border coordination at the level of marine regions and sub-regions. Adriatic cooperation could be improved by setting up a permanent table of coordination at marine sub-region level, involving other Adriatic EU and, possibly, non-EU countries in the implementation of the EcAp project. In this context, the EUSAIR can play a primary role, by directing funding on marine environmental cooperation in support of Adriatic countries. Second, existing efforts on improving marine data access, sharing and re-use should be fostered, integrating also socio-economic data. The implementation of existing policies, like INSPIRE (Infrastructure for Spatial Information in Europe; Directive 2007/2/EC), Marine Knowledge 2020 and EMODNet, as well as the building of a Mediterranean marine SDI (Cinnirella et al. 2012) would contribute to an improved quality of data and information, underlying all phases of the implementation of the MSFD. This should be accompanied by efforts to foster scientific research in order to fill data and knowledge gaps. Third, solutions to improve coordination among sectors and organisational levels should be promoted, for example through the integration of the objectives of the MSFD into sector policies. Moreover, inter-sector coordination units could be set among departments and units of the same public administration (e.g. a same Ministry or Region), possibly involving other bodies at lower levels (e.g. provinces and coastal municipalities), in a way similar to the Technical Committee already in place in Italy, in order to foster collaboration and cooperation.

\subsection{Conclusions}

The complexity of current environmental problems requires an integrated, coherent governance of marine social-ecological systems. This paper presents the results of a case study analysis, aiming at investigating the degree of implementation of the MSFD and other relevant legislation for European oceans and seas, using the case study area of the Adriatic Sea. It shows that the MSFD triggered important efforts at all levels of 
governance, introducing a geographical, learning-based approach for the achievement of the GES of EU marine social-ecological systems. However, this research pointed to three major challenges that must be faced in the implementation of the MSFD, which are related to: (i) the capacity to establish effective cross-border cooperation with other countries sharing the same marine region; (ii) the ability to include socio-economic aspects and assess their complex relations with GES; and (iii) the capacity to coordinate the implementation of the MSFD with other existing marine and maritime policies. Possible strategies to tackle these challenges include the setting of mechanisms and structure for cross-border cooperation, possibly in the context of existing efforts at Regional Sea level; the improvement of data availability, access, sharing and re-use, especially on socio-economic aspects; and the integration of the ecological objectives of the MSFD into sectorial policies, accompanied by the introduction of mechanisms for inter-sector coordination at national, regional and local levels. 


\section{Appendix}

\section{List of organisations interviewed}

\section{Adriatic-Ionian Initiative (AII)}

No. of people interviewed: 1

The Adriatic-Ionian Initiative (AII) is an initiative of foreign policy promoted by the Italian government, and targeted at building a permanent table of cooperation and peace with other countries of the area, promoting the Adriatic-Ionian Macro-Region. The Secretariat of the AII has the function of giving continuity to the political activities of AII countries, by providing administrative and documental support to the Ministries of Foreign Affairs. AII funds micro-projects at 50\% in various themes, including on the environment (Regional Cooperation Programme).

The AII was chosen because of its activities in support to cross-border coordination on the marine environment and maritime sectors at Adriatic level.

\section{Ancona Port Authority}

No. of people interviewed: 1

The port of Ancona is one of the biggest Adriatic ports in terms of transit of maritime passengers on ship lines, excluding cruise ships passengers. The Ancona Port Authority (PA) is responsible for the following activities: planning, programming, coordination and control of port operations, and of the other commercial and industrial activities performed in port; supervision, management and regulation of land-based port facilities and services; maintenance of the common spaces in the port areas, including the depth of the port basins; appointment and control of the activities of port operators. The PA was chosen because it is responsible for the implementation of existing legislation on maritime transport and environmental protection in the port.

\section{Harbourmaster Corps - Coast Guard}

No. of people interviewed: 1

The main duties of the Corpse are the safeguard of life at sea, the security and safety of maritime transport, the protection of the marine environment and marine ecosystems, and the surveillance over the fisheries sector.

The Corpse depends functionally from three Ministries: the Ministry of Infrastructures and Transport; the Ministry of Agriculture, Food and Forestry; and the Ministry of Environment, Territorial and Sea Protection.

The Coast Guard was chosen because of its responsibilities in the implementation of existing legislation regulating maritime transport, fisheries and marine environment protection. 


\section{Marche River Basin Authority}

No. of people interviewed: 1

The Marche Region River Basin Authority is responsible for the implementation of regional policies in the fields of hydro-geological and floods risk management.

The River Basin Authority was chosen because it is involved in the assessment and management of coastal floods and river basin management, which includes coastal waters.

\section{Ministry of the Environment, Territory and Sea Protection}

No. of people interviewed: 1

The Ministry of the Environment is responsible for the implementation of environmental policy at national level.

The Division of Coastal and Marine Environment Protection was chosen because it is responsible for the implementation of the MSFD at national level.

\section{Mount Conero Regional Natural Park}

No. of people interviewed: 2

The Regional Park of Mount Conero is a coastal protected area in the territory of the Marche region, whose management is regulated at regional level. It covers a sea strip delimited by the foreshore line, at the depth of 6 meters. The Park includes three coastal Sites of Community Importance (SCI), designated in the framework of the Natura 2000 network.

The Conero Park was chosen because it is a protected area on the coasts of the Adriatic Sea, contributing to the implementation of existing nature legislation, especially the Habitats and Birds Directives.

\section{Province of Macerata}

No. of people interviewed: 1

The Province of Macerata is one of the five provinces of the Marche region.

The Environment and Water Protection Unit was chosen because of its responsibilities in the implementation of waste water discharge legislation at provincial level.

\section{Region Emilia-Romagna}

No. of people interviewed: 2

Emilia-Romagna is one of the Italian coastal regions of the Adriatic Sea (about $130 \mathrm{~km}$ of coasts). Interviews were held with representatives of two Units. 
The Unit "Water resources protection and recovery" (1 interviewee) was chosen because it is responsible for the implementation at regional level of the MSFD, the WFD and related legislation.

The Unit "Soil and coastal defence, and remediation" (1 interviewee) was chosen because it is responsible for the management of coastal hazards and for the implementation of the regional Integrated Coastal Zone Management Plan (ICZM).

\section{Region Marche}

No. of people interviewed: 7

Marche is one of the Italian coastal regions of the Adriatic Sea (about $180 \mathrm{Km}$ of coasts). Interviews were held with representatives of the following Units: Fisheries and Hunting; Coastal Defence; Marine Strategy Framework Directive Implementation; Maritime State Property Administration; and Biodiversity, Ecological Networks and Animal Protection.

The Units were chosen because involved in the implementation of marine/maritime legislation at regional level. More into detail:

- Fisheries and Hunting Unit ( 1 interviewee) - responsible for the implementation of regional fisheries policies;

- Coastal Defence (1 interviewee) - responsible for coastal erosion and hazards, and for the ICZM Plan;

- MSFD (1 interviewee) - responsible for the implementation of the MSFD;

- State Property (1 interviewee) - responsible for the coordination of municipalities in the management of tourism and other coastal activities;

Biodiversity ( 3 interviewees) - responsible for the management of coastal Natura 2000 sites and other protected areas in the region.

\section{ARPAM - Marche Region Environmental Protection Agency}

No. of people interviewed: 2

The main duties of the ARPAM are, among others: environmental analysis, measures, monitoring and sampling; investigations of environmental risks prevention and control; technical support to Region and Provinces on waste control and management; educational activities and professional training; support to regional Environmental Impact Assessments (EIA).

The ARPAM was chosen because it is responsible for coastal and marine monitoring in the stretch of the Adriatic Sea under jurisdiction of the Marche region.

\section{CNR ISMAR - Marine Science Institute of the Italian National Research Council} No. of people interviewed: 1 
CNR-ISMAR is the section of CNR devoted to marine studies. It conducts research in Mediterranean, oceanic and polar regions, in the fields of oceanography, geology and geophysics, coastal systems and human impacts, climate and paleoclimate, ecosystems and biogeochemistry, and fisheries and aquaculture.

ISMAR was chosen because it is involved in marine data collection and monitoring activities in the Adriatic Sea.

\section{ISPRA - Italian National Institute for Environmental Protection and Research} No. of people interviewed: 1

ISPRA is the national centre for scientific research in the field of environmental protection. The person interviewed was working at the Water Department, Marine Waters Unit.

The Water Department, Marine Waters Unit was chosen because it provides scientific and technical support to the Ministry of Environment, for the implementation of the MSFD.

\section{Lega Pesca - Association of Cooperatives operating in the Fisheries Sector} No. of people interviewed: 1

Association of cooperatives of the fisheries sector; it is part of LEGACOOP (National Association of Cooperatives and Mutual Aid Societies), the oldest and biggest Italian cooperative organisation, with more than 13,000 members.

Lega Pesca was chosen because it represents the interests of fishermen, and was expected to provide their point of view on the implementation of existing fisheries and environmental legislation.

\section{WWF - World Wildlife Fund Italy, Marche Region}

No. of people interviewed: 1

The World Wide Fund for Nature is a global organisation for nature conservation. The Italian branch was born in 1966 and is divided into 19 regional sections, with about 200 territorial structures.

The WWF was chosen because of its interests in nature protection and the work done at national level for the protection of the marine environment. 


\section{Chapter}

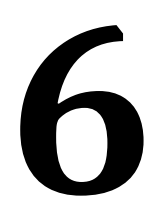

\section{Marine monitoring in the European Union: how to fulfil the requirements for the Marine Strategy Framework Directive in an efficient and integrated way?}

Nikolaos Zampoukas, Henna Piha, Emanuele Bigagli, Nicolas Hoepffner, Georg Hanke, Ana Cristina Cardoso 


\section{Abstract}

The Marine Strategy Framework Directive requires from European Union Member States to establish by 2014 ecological monitoring programmes covering all their marine waters and therefore extend existing monitoring and include additional elements. Principles of integrated monitoring and large scale approaches discussed in this communication could contribute to effective and cost efficient programmes.

Keywords: Monitoring; Marine Strategy Framework Directive; Integration. 
The Marine Strategy Framework Directive (MSFD) requires all European marine waters to be in Good Environmental Status (GES) by 2020. GES is reached when 11 Descriptors (biodiversity, alien species, fish stocks, food-webs, eutrophication, sea-bed integrity, hydromorphology, contaminants in the sea, contaminants in seafood, litter and energy) do not deviate significantly from the undisturbed state.

In order to ensure that GES is reached and/or maintained EU Member States should set, among other things, and according to Article 11 of the MSFD, monitoring programmes by 2014. These programmes should take into account the indicative characteristics, pressures and impacts set in Annex III of the MSFD that includes several abiotic and biotic elements (Table 6.1). Some are characteristics of species, populations and communities while others are physicochemical characteristics and pressures. A related Commission Decision (2010/477/EU) lists 29 criteria and 56 indicators based on which GES should be defined. Ideally, monitoring programmes should be able to provide data for the calculation of the indicators set by the Commission Decision.

Monitoring can be defined as the systematic measurement of biotic and abiotic parameters of the marine environment, with predefined spatial and temporal schedule, having the purpose to produce datasets that can be used for application of assessment methods and derive credible conclusions on whether the desired state is achieved or not and on the trend of changes for the marine area concerned. In this frame, monitoring includes the choice of the elements to measure, the location of sampling sites, the periodicity of sampling, the collection of field samples and data, processing of the samples in the laboratory and the compilation and management of the data. Development of assessment methods and classification of status as good or less than good is not included in although very much related to monitoring. In a nutshell, monitoring should provide the data to allow assessment methods to classify a marine area as reaching or failing to reach GES (Zampoukas et al., 2012).

Despite existing relevant European legislation, such as the Water Framework Directive (WFD; 2000/60/EC), the Environmental Quality Standards Directive (EQS; 2008/105/EC), the Habitats Directive (HD; 92/43/EC), the Birds Directive (BD; 2009/47/EC), the Data Collection Framework Regulation for the Common Fisheries Policy (CFP; 199/2008/EC) and other international agreements the coordination of monitoring programmes in the marine environment "is still in its infancy" (Heslenfeld and Enserink, 2008). According to OSPAR (2008), many institutions are involved in monitoring efforts which would benefit in efficiency and cost-effectiveness from better coordination. 
Table 6.1: Monitoring elements required by marine related EU legislation

\begin{tabular}{|c|c|c|c|c|c|c|}
\hline MSFD monitoring element & $\begin{array}{c}\text { Characteristics } \\
\text { (if defined) }\end{array}$ & WFD & EQS & BD & HD & CFP \\
\hline Phytoplankton, zooplankton & $\begin{array}{l}\text { Species } \\
\text { composition }\end{array}$ & + & & & & \\
\hline $\begin{array}{l}\text { Angiosperms, macroalgae, } \\
\text { zoobenthos }\end{array}$ & $\begin{array}{l}\text { Biomass and } \\
\text { species composition }\end{array}$ & + & & & & \\
\hline Fish & $\begin{array}{l}\text { Abundance, } \\
\text { distribution } \\
\text { age/size structure }\end{array}$ & & & & + & + \\
\hline $\begin{array}{l}\text { Reptiles, marine mammals } \\
\text { and other protected species }\end{array}$ & $\begin{array}{l}\text { Range, population } \\
\text { dynamics, status }\end{array}$ & & & & + & \\
\hline Seabirds & $\begin{array}{l}\text { Range, population } \\
\text { dynamics, status }\end{array}$ & & & + & & \\
\hline $\begin{array}{l}\text { Habitats (predominant, } \\
\text { special, protected, } \\
\text { endangered) }\end{array}$ & & & & & + & \\
\hline $\begin{array}{l}\text { Currents, depth, salinity ice } \\
\text { cover }\end{array}$ & & + & & & & \\
\hline Waves & Exposure & + & & & & \\
\hline \multicolumn{7}{|l|}{ Mixing, residence time } \\
\hline Seabed & $\begin{array}{l}\text { Topography, } \\
\text { bathymetry, } \\
\text { structure, substrata } \\
\text { composition }\end{array}$ & + & & & & \\
\hline Temperature, turbidity & & + & & & & \\
\hline \multicolumn{7}{|l|}{$\begin{array}{l}\text { Upwelling, abrasion, } \\
\text { extraction, sealing }\end{array}$} \\
\hline \multicolumn{7}{|l|}{ siltation } \\
\hline Contaminants & $\begin{array}{l}\text { Changes in } \\
\text { concentrations and } \\
\text { biological effects }\end{array}$ & + & + & & & \\
\hline Oxygen & & + & & & & \\
\hline \multicolumn{7}{|l|}{$\mathrm{pH}$} \\
\hline \multicolumn{7}{|l|}{ Marine litter } \\
\hline \multicolumn{7}{|l|}{ Underwater noise } \\
\hline \multicolumn{7}{|l|}{ Microbial pathogens } \\
\hline Non-indigenous species & $\begin{array}{l}\text { Occurrence, } \\
\text { distribution, } \\
\text { abundance, } \\
\text { translocations }\end{array}$ & & & & & \\
\hline Selective extraction of species & & & & & & + \\
\hline
\end{tabular}


Considering that the marine territory of the EU is larger than its land territory, a considerable effort is needed to fulfil this legislative requirement in a meaningful and pragmatic manner. In this communication the concept of integrated monitoring is discussed and some large scale approaches are shortly reviewed.

A monitoring programme can be considered integrated when it provides data relevant to different MSFD descriptors, criteria and indicators, to different pieces of legislation, for more than one Member State and collected in comparable way.

Some elements of integration are obvious and simple to achieve. The same monitoring data could be, in some cases, useful for the assessment of different descriptors, e.g., data on zoobenthos abundance and taxonomic composition are useful for both the assessment of biodiversity (descriptor 1) and sea-bed integrity (descriptor 6).

At first sight, it might seem that many of the MSFD monitoring requirements are already covered by other EU legislation (Table 6.1) and that only the additional monitoring of some physicochemical elements (ice cover, mixing, residence time, siltation, $\mathrm{pH}$ ) and pressures (abrasion, extraction, sealing, litter, energy, alien species) is needed. In reality, there are many more gaps. The WFD applies to coastal waters (up to 1 nautical mile from the baseline from which territorial waters are defined) and the EQS, for priority substances, to territorial waters (up to 12 nautical miles). The HD and BD apply where listed species and habitats occur while the CFP where fish stocks and fishing activities take place. The MSFD has a much wider geographical scope as it covers all marine waters under the sovereignty and jurisdiction of Member States of the EU (including territorial waters and Exclusive Economic Zones). It thus requires additional monitoring in areas where it was not previously required by EU law. Therefore, the extension of existing marine monitoring out of the coastal areas is a major challenge for EU Member States.

Comparability of assessment approaches within and between marine regions and/or subregions is another important requirement of the MSFD and could be facilitated by the collection of data in a harmonized, or at least, comparable way. One way to achieve this is to follow the existing standards of the International Organisation for Standardisation (ISO) and the European Committee for Standardisation (CEN). Although at present these cover only a few descriptors (mainly for chlorophyll-a, phytoplankton and hard-substrate benthic communities) they should be considered and used if appropriate while the effort to develop more standards should be continued and intensified. Other related EU legislation provided very few and only rough monitoring guidelines. For example, the WFD sets some minimum requirements for 
monitoring frequency in coastal waters and allow EU Member States to develop their own methods to sample and assess the required parameters. As a result, a plethora of different national ecological assessment methods was developed that had to be compared with a sophisticated exercise (intercalibration) (Birk et al., 2012). The variety of different ways of data collection could be a major difficulty in testing and demonstrating comparability of assessments and, if possible, should be avoided in the implementation of the MSFD. An important effort to develop common monitoring approaches is being pursued by some Regional Seas Conventions, particularly HELCOM and OSPAR. Examples include the OSPAR Ecological Quality Objectives (OSPAR, 2008), the COMBINE manuals (HELCOM, 2003) and the Joint Assessment and Monitoring Programming (OSPAR, 2004) but for many MSFD descriptors (e.g., energy, alien species) well developed and agreed monitoring guidelines do not exist. Moreover, the level of development and agreement of monitoring methods in the Mediterranean and the Black Sea is considerably inferior.

A secure way to ensure comparability of approaches and interoperability of monitoring data between two or more countries is to have joint monitoring cruises and making use of the same sampling instrumentation. Although pilot joint cruises sometimes take place in the frame of research projects (e.g., SESAME) such cruises are not known to take place in a regular way or, if they exist, are uncommon. Different national or regional monitoring traditions and confidentiality issues could be factors prohibiting such collaborations. As the cost savings resulting from joint monitoring efforts could be important, the intensive monitoring requirements of the MSFD can be a trigger to reconsider such potentialities. A good example of the use of same or shared instrumentation exists in the North Sea where United Kingdom and The Netherlands have a collaborative monitoring programme and are jointly operating a buoy measuring the rapidly changing environmental conditions in Dutch coastal waters (UKNetherlands Collaborative Monitoring Programme). The main aim of this collaboration is to allow comparison of the measurements obtained from the standard methods employed in a ship-based monitoring programme with the automated in situ buoy data.

In addition to the principles of integration and taking into account the wide spatial application of the MSFD, marine monitoring could potentially gain in effectiveness by approaches that are able to collect data from wide geographic areas [1]. A short overview of some indicative approaches follows below.

The Continuous Plankton Recorder (Warner and Hays, 1994) is a sampling instrument designed to be towed from ships at approximately $10 \mathrm{~m}$. Water passes through the CPR and plankton is filtered onto a slow-moving band of silk. CPR can sample larger areas 
than other phytoplankton and zooplankton devices such as bottles and nets. Data on biomass can be easily taken while taxonomic identification requires the same skills and human power as with any other sampling method. CPR has also been used to monitor microlitter in the water column (Thompson et al., 2004) but not floating debris.

The very efficient transmission of sound in water allows for hydroacoustic monitoring surveys. Sonars can be used for the detection and assessment of underwater physical (depth, bottom roughness and hardness) and biological (abundance, size, behaviour and distribution of biota) characteristics. They are already widely used both by fishermen and scientists for the investigation of fish populations. Furthermore, detectors of passive acoustic signal could be considered for monitoring marine mammals (abundance, movements and location of their habitats) (André et al., 2011).

Underwater video cameras can take images of both the sea-bed and water column and collect information on the structure of the sea-bed, composition and abundance of macroscopic biota and non-living items, such as litter. They are being used for counting Nephrops burrows (Tuck et al., 1997) and to obtain macrobenthos quantitative data (Sheehan et al., 2010).

Video cameras as well as other instrumentation can be tethered to oceanographic vessels but also to volunteer ferries, cruise ships and merchant vessels (ships of opportunity). A particularly interesting application is the FerryBox (Petersen et al., 2003), an automatic flow-through system pumping sea water on the side of the ship and propelling it in an internal loop at constant velocity to conduct various measurements.

Earth Observation from satellites carrying optical sensors provides information at unprecedented time scales over large and distant areas of the world ocean in a real costeffective way, where only few observations can be conducted by traditional methods using oceanographic vessels. Information includes chlorophyll, total suspended matter, pigmented fraction of dissolved organic matter and phytoplankton functional groups. Data are accessible freely through space agencies or via specific web sites such as the Environmental Marine Information System from the Joint Research Centre (EMIS). Additional information on the physical and biogeochemical state of EU marine areas can also be retrieved from the marine component of the European Commissioncoordinated initiative on Global Monitoring for the Environment and Security (GMES) that integrates data collected by satellites and model outputs as well as in situ observations. 
Autonomous underwater vehicles are free-swimming torpedo-shaped devices remotely operated from the surface, most often powered by rechargeable batteries and/or buoyancy-based techniques (gliders). They can cover large distance at various depths to provide a 3D view of the water column. They can carry physical and biooptical instruments and measure nutrients, contaminants, phytoplankton biomass, temperature and oxygen. Video cameras and detectors of passive acoustic signals can also be installed.

The above-listed large-scale approaches have several limitations in terms of application in certain depths and habitats, taxonomic resolution, costs and technical expertise required but are worth considering, particularly in relation with the principles of integrated monitoring.

In conclusion, marine monitoring is needed for several pieces of EU legislation and MSFD requires some additional ones. It should be integrated in order to also be cost effective and could be facilitated by large scale approaches.

\section{Acknowledgements}

This work was partially funded by the European Commission Directorate General for Environment. We thank the anonymous reviewer for the constructive comments. 


\section{Chapter}

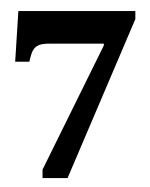

Synthesis 


\subsection{Introduction}

Oceans are affected by anthropogenic and climatic stressors worldwide. Flexible, science-based legal and policy frameworks are required to achieve or maintain marine ecological resilience or, if not possible, to adapt to change and regime shifts. The overall objective of this thesis is to evaluate if a complex systems approach is in place for the assessment and management of marine systems. More into detail, the main objective is divided into four sub-objectives:

1. Sub-objective 1: Develop a framework for marine complex adaptive systems assessment and management;

2. Sub-objective 2: Evaluate the entire European Union (EU) legal framework against the framework developed;

3. Sub-objective 3: Evaluate the legal framework for the assessment and management of the global oceans against the framework developed; and

4. Sub-objective 4: Evaluate the implementation of the EU and global legal frameworks into practice.

This chapter is structured as follows. Section 7.2 briefly summarises the findings of this thesis for each of the four sub-objectives. Section 7.3 contains a general reflection on the capacity of the framework developed to be used to assess legal frameworks and management practices. Section 7.4 advances suggestions to improve the current legal frameworks and management practices, both at EU and global level. Finally, Section 7.5 suggests directions for further scientific research.

\subsection{Research findings}

\section{Research objective 1: Develop a framework for marine complex systems assessment and management.}

Adaptive Management (AM) and Transition Management (TM) are two promising theoretical approaches for the assessment and management of marine complex adaptive systems. They are at the foundations of a framework, which was developed to evaluate the EU and global legal frameworks for marine complex systems and their implementation. The framework combines AM and TM in order to overcome their limitations. On the one hand, AM theory and practices do not pay enough attention to micro-level socio-economic components and their complex interactions with ecological resilience. On the other hand, TM has been criticised for its relative isolation, and for giving ecological aspects only a general value, without incorporating them into the assessment of socio-technical systems and the triggering of transitions. The framework 
proposed suggests to foster synergies among the two approaches, along three components: the unit of management; the objectives of management; and the structure of management. First, at the level of unit of management, the two sets of marine socialecological systems and connected socio-technical systems (e.g. fisheries, maritime transportation, coastal tourism and energy) must be clearly identified, and the complex interactions and influences between socio-economic patterns of production and consumption, and ecological components must be assessed. Second, at the level of objectives of management, the achievement of ecological resilience of a marine socialecological system should be performed in coordination with transitions of connected socio-technical systems that have been assessed as unsustainable. Such sustainability assessment should be performed by reference to the effects of the system on the ecological resilience of connected social-ecological systems. Third, at the level of structure of management, the implementation of the two approaches should be articulated into iterative, learning- and science-based policy cycles, with mechanisms in place to foster coordination between the policy cycles of social-ecological and sociotechnical systems. The benefits of this framework are threefold. First, the adoption of TM's characterisation of socio-technical systems, actors and institutions, as well as the identification of their interactions and influences with social-ecological systems, allows AM managers to include micro-level socio-economic components into the assessment of ecological resilience. Second, by systematically including AM managers into established transition arenas, it is possible to improve the consideration of ecological aspects into the TM process. In this way, there is potential for ecological resilience to play a role in the transition, as stakeholders will debate whether to take them into account, and to what extent. Third, by linking the policy cycles of AM and TM, it is possible to reduce the current fragmentation of management along several legal frameworks and management practices.

\section{Research objective 2: Evaluate the European Union (EU) legal framework}

The application of the framework to the first comprehensive evaluation ever done of the more than 12,000 EU legal acts shows that they do not provide a fully coherent framework for the assessment and management of EU marine complex adaptive systems. The Marine Strategy Framework Directive (MSFD; 2008/56/EC) is a major step forwards in this direction for three reasons. First, it identifies marine regions and sub-regions as units of management, following bio-geographical criteria. Second, the objective of MSFD is to achieve or maintain the Good Environmental Status (GES) of these social-ecological systems, providing in this way an operationalisation of the concept of ecological resilience. Third, iteration, learning and knowledge-based management elements are present, and the results of management are periodically evaluated in order to build following policy cycles. However, three limitations of the 
MSFD have been identified, which negatively affect its capacity to deliver the required approach. The first limitation lays in the spatial scope of the MSFD, where significant portions of marine social-ecological systems like the high seas are excluded, and in the fact that strategies must be formulated and implemented at national level, with only a weak formulation of the obligation for cross-border cooperation through existing Regional Sea Conventions (RSC). The second limitation lays in the objectives of management, where the GES exclude important components, like ecosystem services and benefits to human communities, and cross-scale interactions, while at the same time the socio-economic assessment focuses on the use of marine waters and the cost of their degradation, with unclear prescriptions on how to link this to the GES assessment. Finally, the third limitation is connected to the existing fragmentation of the EU legal framework into several legal acts, applying to various spatial scopes, with objectives and policy cycles that are independent one another. To this respect, MSFD obligations to coordinate with other legislation are formulated in a generic way, pointing to the need to take into account existing assessment and management measures required under other legislation, but without suggesting ways to reduce this fragmentation.

\section{Research objective 3: Evaluate the legal framework for the global oceans}

The results of the analysis of 500 international agreements for the assessment and management of the world's oceans and seas show that there is no global agreement requiring countries to develop and implement a complex systems approach to oceans assessment and management. Instead, elements of complexity into marine assessment and management can be found, scattered along two dimensions: horizontally, or across issues and sectors (e.g. fisheries, biodiversity conservation and pollution prevention and control); and vertically, or across ocean regions and regional seas. The United Nations Convention on the Law of the Sea (UNCLOS) is the only agreement that considers the global oceans as a single system. However, it divides oceans into jurisdiction zones (the territorial sea and contiguous area; the Exclusive Economic Zone (EEZ); the continental platform; the high seas; and the Area of seabed and ocean floor and subsoil beyond jurisdiction limits) that are not identified following biogeographical considerations. Moreover, although it aims to "facilitate the equitable and efficient utilisation of resources, the conservation of their living resources and the study, protection and preservation of the marine environment" (UNCLOS consideranda), it does not mention the application of an ecosystem approach, or ecosystem-based management and does not consider ecological resilience. The objectives of Maximum Sustainable Yield (MSY) and Favourable Conservation Status (FCS) are dominant for global issue-based agreements, but provide only a partial view on ocean complexity and ecological resilience, as they apply only to specific species or 
groups of species taken singularly, without considering ecological interrelations with other species, habitats and social-ecological components. Regional Seas Conventions (RSCs) and Action Plans apply only to specific ocean regions, with a varying level of inclusion of ecological resilience elements, where North-Eastern Atlantic and Baltic regions are the most advanced, followed by the Mediterranean and Southern Ocean, while the South-Eastern Atlantic and South-Eastern Pacific lag behind. There is the need to overcome the identified twofold fragmentation of the international legal framework, and support the introduction of a complex systems approach into existing and future international agreements and their implementation. Possible strategies include the adoption of a Global Oceans Action Plan, or soft-law, project-based initiatives at global and regional scales, in order to overcome potential difficulties in the introduction of new agreements, or unavoidable difficulties in the revision of the current ones.

\section{Research objective 4: Evaluate the implementation of the EU and global legal frameworks into practice}

The case study analysis of the Adriatic Sea shows the importance of the MSFD in triggering important efforts at all levels of governance in the introduction of a geographical, learning-based approach for the achievement of the ecological resilience of marine complex adaptive systems. For the first time in Italy an assessment of the status of the marine environment was performed, together with the setting of institutional mechanisms and structures for the coordinated implementation of the MSFD at national level. However, this research pointed to three major challenges that must be faced in the implementation of the desired approach. The first challenge is the capacity to establish effective cross-border cooperation with other countries sharing the same marine region. To this respect, notwithstanding successful experiences like the Fisheries District of Northern Adriatic, and the EcAp project led by UNEP/MAP for an Ecosystem Approach to the Mediterranean Sea, Adriatic cross-border cooperation was found as low or inexistent. This is mainly due to the weaknesses in the formulation of the obligation of cooperation in the text of the MSFD, and the low interest of non-EU Mediterranean countries to support the work of the UNEP/MAP, together with the lack of mechanisms to enforce compliance. The second challenge is the capacity to include socio-economic aspects and assess their complex relations with ecological resilience (i.e. GES). In this respect, two obstacles emerged from the case-study analysis. On the one side, the vagueness of the MSFD, together with the lack of the right quantity and type of data (due to the need to develop scientific knowledge of marine complex systems and the need to improve data sharing among public administrations), which pushed Italy to adopt a qualitative approach to the determination of GES and environmental targets. On the other hand, the Marine Water Accounts and the Costbased approach adopted for the MSFD socio-economic assessment include only some 
macro-economic variables for each maritime sector (production value; added value; and employment). The third challenge is the capacity to coordinate the implementation of the MSFD with other existing laws and policies. The Italian side of the Adriatic Sea suffers a high level of fragmentation of governance, where several policies, plans and programmes exist, each of them managed by a specific public body at different levels of governance (EU; national; regional; provincial; municipal), in an autonomous way and with no mechanisms in place for the coordination of objectives. Thanks to the MSFD, some initiatives are slowly starting to take place, the most notable being the Technical Committee for the coordinated implementation of the MSFD. However, the case of Italy and the Adriatic Sea shows the need to consider the importance of integrating ecological objectives into existing sector-based policies, rather than simply including public bodies implementing sector-based policies into the MSFD. Possible strategies to tackle these challenges include: the setting of mechanisms and structures for cross-border cooperation, possibly in the context of existing efforts at Regional Sea level; the fostering of data availability, access, sharing and reuse, especially for socio-economic aspects; and the integration of the ecological objectives of the MSFD into sector-based policies, accompanied by the introduction of mechanisms for inter-sector coordination at national, regional and local levels. In addition to this, as discussed in Chapter 6, joint monitoring cruises and the use of standardised instrumentation, together with approaches that are able to collect data from wide geographic areas, like the Continuous Plankton Recorder, sonars, Earth Observation and Autonomous Underwater Vehicles, may prove to be useful in order to improve the effectiveness and cost-benefit of marine monitoring required by the MSFD.

\subsection{Overall reflection}

\subsubsection{Understanding marine Complex Adaptive Systems}

The research presented in this thesis shows the potential of the proposed framework to be used as an analytical tool to improve our understanding of marine complex adaptive systems. The framework gives us useful insights on the EU and global legal frameworks regulating marine social-ecological systems, and their implementation into the practice of the case study area of the Adriatic Sea.

Using the terminology of Smith and Stirling (2010), the framework allows us to clarify what system 'really counts' for management, and what vision of sustainability is implemented into practice. The findings of this research showed that a shift is occurring in the determination of the system that 'really counts' for management. The view of environmental and human systems as coupled social-ecological systems is gradually 
being introduced in the legal frameworks and management practices analysed, with traditional, jurisdiction-based approaches being replaced by the determination of the system following bio-geographical criteria. This process is more advanced in Europe, with the MSFD and related Regional Seas Conventions for the Baltic (HELCOM), NorthEast Atlantic (OSPAR), Mediterranean and Black Seas at the forefront of this process. At the same time, the framework stands as a useful tool to understand socio-economic activities as the complex interactions between socio-technical systems, actors and institutions. The case study analysis of the Adriatic Sea showed the presence of several types of actors (managers, stakeholders) at various levels, interacting and interpreting existing rules emanated from institutions placed at various levels of governance (EU, national, regional, local), and interacting with several socio-technical systems. Moreover, the application of the framework allows us to appreciate the fact that several socio-technical systems are regulated at different levels of governance; for example, the fisheries sector is regulated at EU level with the Common Fisheries Policy (CFP), and spans across all EU marine social-ecological system. At the same time, national policies on sectors like transportation and tourism, apply to multiple marine social-ecological systems, while regional and local regulations apply only to specific ecological or jurisdictional zones inside a same marine social-ecological system.

In addition to this, the framework allows us to clearly determine the objectives of management of each legal act. Results show that different visions of sustainability are embedded into a plethora of legal acts, with potential or real conflicts and synergies among them. MSFD GES may have positive or negative synergies with other existing objectives, like the Maximum Sustainable Yield (MSY) for the fisheries sector, or the Favourable Conservation Status (FCS) for specific flora and fauna species, either set through international agreements or through EU Directives and Regulations. Using the framework, it is possible to determine their limitations, as well as their potential synergies and conflicts. The framework allows us to understand if and to what extent the notions of ecological resilience, environmental boundaries and transitions are embedded into the legal frameworks and policy practices.

Finally, the framework gives us useful insights on the structure of management. It helps us to understand what activities of policy formulation and implementation, required by law and implemented into practice, include the elements of a complex systems approach. It helps us understand their temporal distribution and setting, and the strategies and tools that may be used in order to achieve this objective, i.e. through repeated experimentation and learning, and through the setting of policy measures by managers and stakeholders participating in the policy arena. 


\subsubsection{Limitations of AM and TM}

The application of the framework to the analysis of legal frameworks and management practices allowed us to evaluate if, and to what extent, AM really holds the limitations that have been attributed to by existing literature, and which are at the basis of the combination proposed in the framework. The findings of this thesis confirm that AM strategies have a strong focus on the interactions and connections between environmental and human systems, and that this is translated into both legal frameworks and management practices. The MSFD and related European Regional Sea Conventions contain the requirement to perform a socio-economic assessment of the use of marine waters and of the cost of degradation. The Antigua Convention for the protection of the environment of South-East Pacific requires contracting parties to achieve "ecological balance" of marine areas, integrating economic and social objectives. The Protocol on Integrated Coastal Zone Management of the Barcelona Convention (for the protection of the marine environment of the Mediterranean Sea) refers to the application of an ecosystem approach, based on the idea that the carrying capacity of coastal ecosystems must be respected, and that economic considerations must be adapted to the fragile coastal ecosystems.

At the same time, this thesis confirms that AM tends to focus on ecological aspects, while at the same time lacking attention not only to micro-level, but also to macro-level socioeconomic components. The methodologies applied to perform the socio-economic assessment of the use of marine waters and the cost of their degradation, required by the MSFD (Marine Water Accounts approach and Cost-based approach, respectively) focus on specific macro-level socio-economic components and overlook the complexity of the interactions between actors, institutions and socio-technical systems. In addition to this, the socio-economic assessment is not clearly linked to the assessment of the GES and hence of marine ecological resilience.

In a parallel way, the framework developed in this thesis allowed us to evaluate the limitations attributed to TM by scientific literature, which relate to two aspects: the relative isolation of TM experiences, with little or no connections with other initiatives of systems; and the consideration of ecological aspects only as background variables, with no inclusion into the sustainability assessment. Although there are no current examples of application of TM strategies to the management of maritime sociotechnical systems, however it is possible to derive useful insights on the capacity to use $\mathrm{TM}$ as a lens to understand reality. A transitions approach is not embedded neither into EU and global legal acts, nor into management practices of marine socio-technical systems. Informal arenas exist, which are composed of informal procedures and 
processes for the implementation of specific policies, but no explicit process of debate and bottom-up participatory building of a vision for sustainability of maritime sectors is in place. The application of the framework allowed us to verify that sector-based policies are formulated and implemented in an autonomous and independent way, with few or no links among sectors and with environmental protection. By way of example, some mechanisms are being set in Italy to implement the MSFD in closer cooperation with other public administrations having a stake in the marine environment and maritime activities. However, the framework allows us to identify a weakness of this arena, laying in the fact that it includes stakeholders coming from other sectors into the implementation of the MSFD, and not vice versa. The result is that the MSFD remains as another 'sector-based' policy, with poor results in terms of building bridges among sectors. Policies are being implemented with a top-down approach, with policy formulation and arenas set at various levels of governance, and managers having little room for variation, experimenting and learning. In addition to this, MSY, FCS and pollution reduction objectives are the objective of several legal acts aiming at setting environmental boundaries into sector-based legislation. However, their effectiveness is questionable, both in terms of their focus on some species taken singularly, and because of the possibility to conflict with the objectives of ecological resilience.

\subsubsection{Synergies between AM and TM: are they really possible?}

The framework proposed by this thesis suggests to foster synergies between AM and TM in order to overcome their limitations. This synergy should be realised by linking the two sets of management along three levels: unit of management; objectives of management; and structure of management. Three main challenges emerge from the findings of the present thesis, related to the capacity of the framework proposed to be applied into legal frameworks and management practices of marine complex adaptive systems. They are summarised in the first column of Table 7.1, and briefly discussed below.

A first challenge in implementing this approach lays at the level of unit of management. As socio-technical systems are not place-bound but span across multiple socialecological systems, the framework suggests to identify the connections between the two sets of systems. The point of this suggestion is that, by identifying the systems "that count", it is possible to assess in a deeper and more complete way both ecological resilience on the one side, and the unsustainability of the socio-technical system on the other side. 
Table 7.1: Challenges in implementing the proposed framework and suggestions to improve legislation and management practices, for each component of the framework proposed.

\begin{tabular}{|c|c|c|c|}
\hline & Theory & Legislation & Management Practices \\
\hline & $\begin{array}{l}\text { Evaluation of the } \\
\text { applicability of the } \\
\text { framework into } \\
\text { legislation and } \\
\text { management } \\
\text { practices }\end{array}$ & $\begin{array}{l}\text { Actions foster the } \\
\text { implementation } \\
\text { of the framework } \\
\text { proposed into } \\
\text { legislation }\end{array}$ & $\begin{array}{l}\text { Actions to foster the } \\
\text { implementation of the } \\
\text { framework proposed into } \\
\text { management practices }\end{array}$ \\
\hline $\begin{array}{l}\text { Unit of } \\
\text { management }\end{array}$ & $\begin{array}{l}\text { It is difficult to set } \\
\text { up clear boundaries } \\
\text { to the systems to } \\
\text { assess and manage, } \\
\text { as socio-technical } \\
\text { systems are not } \\
\text { place bound }\end{array}$ & $\begin{array}{l}\text { Introduction of } \\
\text { bio-geographical } \\
\text { criteria for } \\
\text { system } \\
\text { identification } \\
\text { and assessment }\end{array}$ & $\begin{array}{l}\text { Soft-law or project-based } \\
\text { initiatives to extend } \\
\text { assessment and } \\
\text { management beyond } \\
\text { jurisdictional waters; } \\
\text { Foster international } \\
\text { cooperation through } \\
\text { formal or informal } \\
\text { institutional mechanisms } \\
\text { at marine-region level }\end{array}$ \\
\hline \multirow[t]{2}{*}{$\begin{array}{l}\text { Objectives of } \\
\text { management }\end{array}$} & $\begin{array}{l}\text { The assessment of } \\
\text { ecological } \\
\text { resilience may be } \\
\text { highly challenging } \\
\text { and impossible to } \\
\text { achieve }\end{array}$ & $\begin{array}{l}\text { Introduce (or } \\
\text { strengthen) the } \\
\text { objective of } \\
\text { ecological } \\
\text { resilience into } \\
\text { marine } \\
\text { international } \\
\text { agreements }\end{array}$ & $\begin{array}{l}\text { Support the ecological } \\
\text { resilience assessment } \\
\text { through improved } \\
\text { guidance at EU level and } \\
\text { through the use of } \\
\text { existing integrative tools } \\
\text { (e.g. } \mathrm{CHI}, \mathrm{OHI} \text { ); }\end{array}$ \\
\hline & & & $\begin{array}{l}\text { Improve marine and } \\
\text { maritime data collection } \\
\text { and monitoring, access } \\
\text { and sharing }\end{array}$ \\
\hline $\begin{array}{l}\text { Structure of } \\
\text { management }\end{array}$ & $\begin{array}{l}\text { Relative isolation of } \\
\text { AM and TM } \\
\text { approaches, with } \\
\text { different visions on }\end{array}$ & $\begin{array}{l}\text { Consolidate } \\
\text { iteration, } \\
\text { learning and } \\
\text { science-based }\end{array}$ & $\begin{array}{l}\text { Introduce a "marine } \\
\text { ecological resilience } \\
\text { impact assessment"; }\end{array}$ \\
\hline
\end{tabular}




$\begin{array}{ll}\begin{array}{l}\text { the management of } \\ \text { conflicts among } \\ \text { principles and }\end{array} & \begin{array}{l}\text { into marine and } \\ \text { maritime policy }\end{array} \\ \text { objectives } & \text { cycles }\end{array}$

\author{
Support the \\ establishment of \\ institutional mechanisms \\ and formal or informal \\ for a for cross-sector \\ management (including \\ provisions to align \\ conflicting deadlines);
}

Foster ocean literacy and citizen participation

However, given the complexity of the patterns of production and consumption of goods and services at global level, and the cross-scale interactions and effects across socialecological systems, without setting clear boundaries to the system, too many processes and interactions could be performed, including far-fetched assessments holding questionable added value. For example, following the proposed framework, the assessment of Adriatic Sea could be enlarged enough to include any system that is suspected to have an effect on its ecological resilience. This could mean not only to include the EU fisheries or agricultural sectors, currently regulated at EU and national levels, but also other systems, pressures and impacts, like the nutrients discharge of African countries through the Nile river, which may influence the eutrophication level of the Mediterranean and, marginally, of the Adriatic.

In addition, the framework would imply the desirability of investigating e.g. how actors of the energy sector lobby and resist the introduction of incentives to offshore renewable energy production, and how this affects marine ecological resilience; or e.g. the impact of the preferences and values of Italian consumers on seafood production and sustainability. As another example, the assessment of Adriatic ecological resilience could include the complex interactions between e.g. the Chinese plastic industry sociotechnical system and Chinese actors and institutions, and their effects on Adriatic marine litter through pressures generated by plastic consumption of coastal countries. In a parallel way, if sector-based (TM) managers have to include the complex interactions between, say, the EU maritime transportation sector and all socialecological systems connected, the risk is to have to embark into complex assessments of ecological effects on all marine regions of the world where ships flying the flag of EU Member States cross. In synthesis, TM's conceptualisation of socio-technical systems, actors and institutions may be a useful heuristic tool to support managers into the development of policy options and management measures, but may not be easily used, 
as practical computational applications built on this have not been developed yet, as acknowledged by van der Brugge and van Raak (2007). A possible solution to this issue would be to establish clear links and mechanisms and procedures for a continuous exchange of knowledge between the two sets of managers. In this way, AM managers would perform an initial assessment of the most important pressures and impacts on the social-ecological systems in the first place, which would be then used as the basis by sector-based (TM) managers to assess the sustainability of their socio-technical systems.

A second challenge relates to the objectives of management, namely to the notion of ecological resilience and the capacity to assess it. The framework is based on the idea that it is possible and feasible to assess the ecological resilience of a system. However, several voices in scientific literature highlighted that this process may be hard to implement and even impossible to achieve. Eason et al. (2016) point to the difficulty to identify critical variables driving system transitions and shift towards different status, such that there may never be the capacity to fully quantify the resilience of a socialecological system. Borja et al. (2016a) highlight the fact that there are currently no methods to assess marine health in a holistic way, integrating information from multiple ecosystem components, nor methods to evaluate cumulative effects of multiple pressures. The analysis of legal frameworks and management practices presented in this thesis seems to confirm this difficulty. In fact, at the global stage the notion of ecological resilience is only loosely incorporated into a few international agreements or Action Plans, like the HELCOM and OSPAR Action Plans, and the Barcelona ICZM Protocol. At EU level, the notion of GES of the MSFD does not include important components of social-ecological systems, like ecosystem services and human benefits. The analysis of the case study of the Adriatic Sea showed that the vagueness in the text of the MSFD, as well as the lack of guidance from the EU institutions led Italy to adopt a qualitative approach in the identification of GES and environmental targets, while other MS have used different methodologies (Palialexis et al., 2014). As reported by Borja et al. (2016b), there is an ongoing debate at European level on the opportunity to have a 'pass/fail' approach, or to assess each GES Descriptor independently.

A third challenge to the implementation into practice of the framework proposed lays at the level of structure of management. The findings of this thesis show that both AM and TM have been conceived and implemented as isolated processes, without paying much effort on the issue of integrating management across sectors, themes and issues. To this respect, AM tends to have a sort of 'authoritarian' view of sustainability (Dryzek, 2005), where, although not explicitly expressed, in case of conflicts ecological resilience should have a 'principled prioritisation' (Lafferty, 2003) over socio-economic 
considerations, mainly because of its role in maintaining the capacity of the system to provide ecosystem services and benefits to dependent human communities.

This thesis shows that AM's approach may not be easily embedded into the legal texts and management practices. Neither the international agreements and the EU legislation, nor the management practices analysed in this thesis hold a clear stand in favour of this prioritisation. Only two international agreements take a strong position in this respect, requiring contracting parties to prioritise the ecological status over socio-economic considerations: the Jeddah Convention for the Red Sea and Gulf of Aden, and the ICZM Protocol of the Barcelona Convention for the Mediterranean. In the EU, the MSFD holds a more balanced view, where Member States are required to ensure that the "collective pressure of maritime activities is kept within levels compatible with the achievement of good environmental status and that the capacity of marine ecosystems to respond to human-induced changes is not compromised, while enabling the sustainable use of marine goods and services by present and future generations" (art. 1(3)). This is the case also of the EIA and SEA Directives, which require Member States to perform a preliminary environmental impact assessment of public and private projects, and of planned policies, respectively. The guidelines and procedures in place for these assessments may not guarantee that environmental considerations are always given such prioritisation, especially in relation to the MSFD GES, which are not specified as criteria for evaluation. Accordingly, the analysis of the case-study of the Adriatic Sea showed how fragmentation is deeply embedded into the organisation of public administrations. In fact, they are organised following a "Weberian" model where complex problems are split into smaller, more digestible bits, each of them being assigned to a different administration or working group inside a same public body. Some initiatives try to fill this gap and reduce this fragmentation, like the MSFD Technical Committee in Italy. However, AM would expect MSFD managers to participate to sector-based policy formulation and implementation, and not the other way round, as found in practice.

Another implication relates to the potential conflicts between the objectives of ecological resilience of different social-ecological systems, especially across scales. For example, the ban of fishing certain species may contribute to the re-building of the food web of a marine social-ecological systems, but have negative consequences on the food web of a connected river basin, where for example the high number of fish predates a protected species present in a nearby river delta. In such cases, the sustainability of which system should be prioritised? Neither AM nor the proposed framework seem to offer hints to answering this question. 
TM contains at the outset a more democratic approach, where the visions and values of the stakeholders participating in the arena contribute, through dialogue and debate, to the framing of a concerted vision of sustainability of the sector. Seen from the perspective of $\mathrm{AM}$, the requirement to systematically include $\mathrm{AM}$ managers into the arena in order to foster the respect of ecological resilience and environmental boundaries, benefits the TM process, because transitions acquire a clear context and a clear direction, i.e. towards the respect of ecological boundaries. However, seen from the perspective of TM, this could be seen as a tentative to "capture" the arena by powerful incumbents of the status quo, a vulnerability already acknowledged in literature especially for the Dutch energy sector (Kern and Smith 2008; Smith and Kern 2009; Voss et al., 2009). Moreover, TM has a clear focus on transitions of specific sectors, like energy and waste (Loorbach et al., 2003; Kern and Smith, 2008), or areas, like local or corporate governance (Loorbach and Rotmans, 2010), in an isolated way. What would happen in case of conflicting views of sustainability across sectors? What if, for example, the transition of the EU energy sector to a low- or no-carbon model would include the promotion of offshore wind farms, with negative impacts on marine habitats and species (and consequently on tourism activities) or forcing the modification of ship routes to burn more fossil fuel for their detour? TM does not seem to shed light on this respect.

\subsection{Improving legal frameworks and management practices}

This Section discusses the current barriers in legislation and management practices for the implementation of the proposed framework, which emerge from the findings of the thesis, and advances suggestions on how to foster the implementation of the proposed framework into legal texts and management practices. They are presented in the second and third column of Table 7.1, and briefly discussed below.

First, there are gaps in the geographical coverage of legal frameworks at both global and regional seas level. The South-West Atlantic Ocean is not covered by any Regional Sea Convention. Moreover, although the United Nations Convention on the Law of the Sea (UNCLOS) considers the global oceans as a whole, however it establishes a regime for the identification of waters under the sovereignty or jurisdiction of coastal waters that does not apply bio-geographical criteria, and thus does not extend to the high seas, with the exception of four international agreements (the OSPAR Convention for the North Sea; the Jeddah Convention for the Red Sea and Gulf of Aden; the Action Plan for South-East Asia; and the Noumea Convention for the South Pacific). This is mirrored in the EU, where the MSFD and other EU legislation do not apply to the high seas. The risk 
of this approach is to miss the characterisation of important ecological structures and processes, taking place outside jurisdictional waters, which will have an impact on the ecological resilience of marine systems.

As mentioned in Chapter 4, the best strategy to tackle this issue would be to introduce a multilateral agreement for the global oceans, together with the revision of all issuebased and regional sea agreements. However, this option would prove too difficult or challenging, because of the need for a wide global consensus among countries, and the low 'appetite' for further global binding agreements. Hence, a more targeted action through soft-law or project-based initiatives could prove to be more effective. A "Global Oceans Action Plan" could be adopted in the frame of UN-OCEANS, the UN inter-agency coordination mechanism for the coordination of activities on global oceans and coasts. Similarly, the extension of the experience of the UNEP/MAP Ecosystem Approach (EcAp) project into other marine social-ecological systems could be fostered, also in the case of the South-West Atlantic where no agreement is in place. In addition to this, although the UNCLOS regime of jurisdictional waters may not be easily challenged, possible solutions may derive from innovative approaches. The most notable example in this direction is represented by the negotiations for an international agreement on the conservation and sustainable use of biodiversity in ocean areas beyond national jurisdiction. Negotiations of this agreement formally started in 2016 on a "Package Deal" of four priority themes: marine genetic resources; area-based management tools; environmental impacts assessments; capacity building and the transfer of marine technology.

Second, the capacity to establish and enforce international cooperation among countries sharing the same marine system is currently limited, mainly because of the varying capacity and willingness of states to collaborate, and the lack of mechanisms to enforce compliance. The MSFD tackles this issue by referring to existing Regional Sea Conventions (RSC). On the one side, this may have the positive outcome of avoiding the establishment of new institutions or mechanisms, which would inevitably overlap with the existing ones. At the same time, it may provide a stimulus for improved participation and collaboration. However, on the other side, all is left to the capacity of RSCs to act and involve coastal states. This thesis showed that in the Adriatic and Mediterranean Sea the capacity and willingness of non-EU coastal states was low and varying, also because of the lack of compliance mechanisms to enforce a coordinated implementation of the MSFD.

To this respect, compliance in international cooperation could be strengthened through improved action at international level. The EU may consider to foster formal and 
informal ad-hoc mechanisms for cross-border coordinated implementation of the MSFD, especially in marine sub-regions that are currently 'lagging behind', as in the case of the Adriatic. Action to strengthen Mediterranean-scale cooperation could be considered in the frame of the EcAp project, which for the period 2015-2018 focuses only non-EU Mediterranean countries.

Third, the concept of ecological resilience should be introduced, or strengthened where already present, into the texts of the international agreements (and related Protocols and Action Plans) for the global ocean and for the regional oceans and seas. The cited "Global Oceans Action Plan" could be instrumental in introducing the required elements of complexity into global oceans assessment and management, with a view to coordinate with the objectives of Maximum Sustainable Yield (MSY), Favourable Conservation Status (FCS) and pollution reduction laid down in the text of the other global, issue-based agreements. In relation to Regional Sea Conventions, Figure 7.1 ranks them according to the level of inclusion of ecological resilience into the text of their international agreements, Protocols and Action Plans. Scores from 0 to 4 have been assigned to each international agreement, protocol and Action Plan, as illustrated in Table 7.2, built from the results in Table 4.6 (see Chapter 4). Figure 7.1 It shows that SE Pacific, SE Atlantic and SE Asia are the three ocean regions where efforts should concentrate in the first place, followed by the NW Pacific, Persian Gulf/Arab Gulf and the Caribbean.

Table 7.2: Scores assigned to the categories of inclusion of ecological resilience in the Regional Sea Conventions, Protocols and Action Plans (see Table 4.6).

\begin{tabular}{ll}
\hline Score & \multicolumn{1}{c}{ Description } \\
\hline 0 & No elements of complexity and ecological resilience \\
\hline 1 & $\begin{array}{l}\text { Only mentioning some elements of complexity and ecological resilience, } \\
\text { without definition or explanation }\end{array}$ \\
\hline 2 & $\begin{array}{l}\text { Key concepts are mentioned and defined, but there is no clear requirement to } \\
\text { achieve them }\end{array}$ \\
\hline 3 & $\begin{array}{l}\text { Ecosystem approach, ecosystem-based management or integrated } \\
\text { management are mentioned as the objectives of the agreement. Several } \\
\text { elements of complexity are mentioned and required, but they are not clearly } \\
\text { prioritised over socio-economic considerations }\end{array}$ \\
\hline 4 & $\begin{array}{l}\text { Key concepts are mentioned; management must prioritise ecological over } \\
\text { socio-economic considerations }\end{array}$ \\
\hline
\end{tabular}




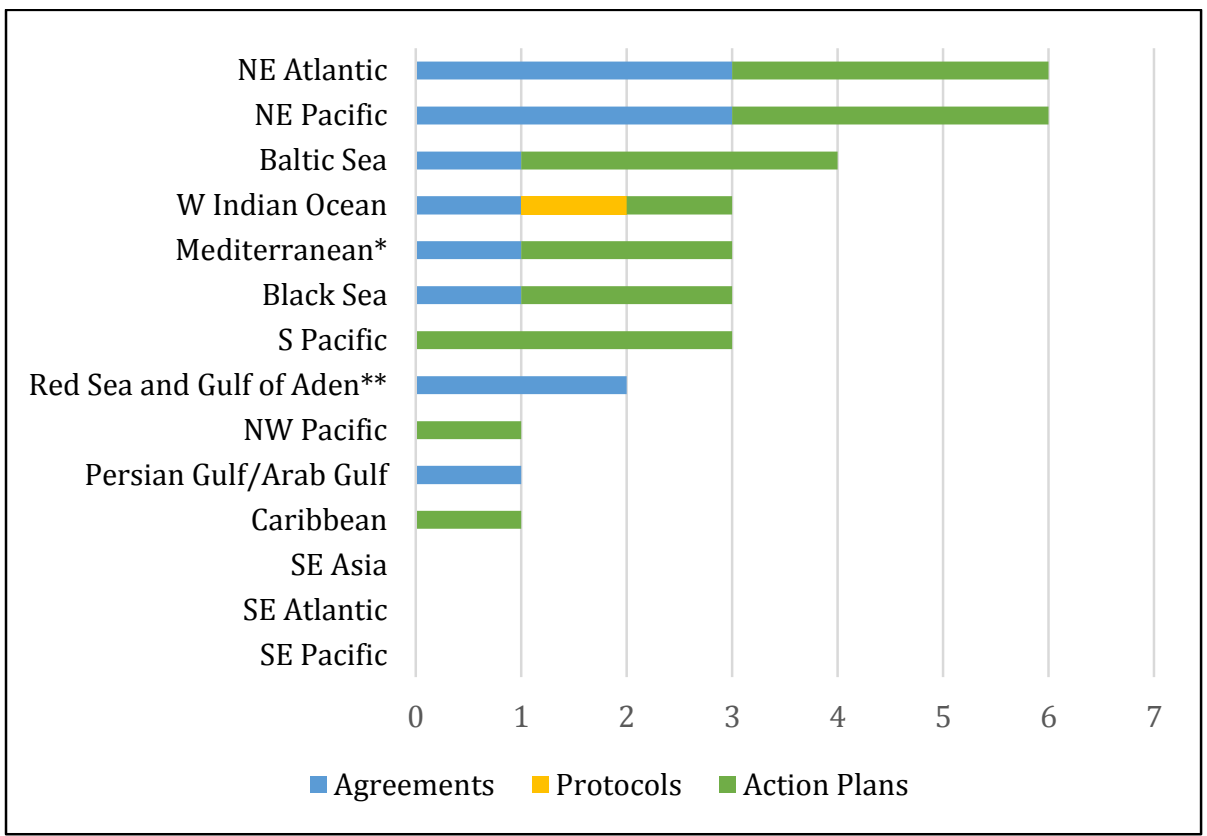

* Protocols in place for the Mediterranean have a score of 0, excluding the Protocol on Integrated Coastal Zone Management of the Mediterranean that has a score of 4 .

** Protocols in place for the Red Sea and Gulf of Aden have a score of 0, excluding the Protected Areas Protocol that has a score of 3 .

Figure 7.1: Ranking of ocean regions by inclusion of ecological resilience elements into the texts of international agreements, Protocols and Action Plans. Based on Table 4.6.

At EU level, the vagueness and lack of clear guidance from the MSFD calls for an improved effectiveness of EU-wide coordination in the implementation of the MSFD, which is already taking place through the established Common Implementation Strategy (CIS). Work in the CIS should focus on exploring ways to link the socioeconomic assessment with the GES and environmental targets assessments, in order to provide a more complete picture of the complex interactions between socio-economic activities and ecological resilience. In addition to this, attention should be given to the inclusion of the outcomes of current scientific research on integrative tools for the ecological assessment of marine systems. Several integrative tools already exist, aiming to provide a concise and informative indication of the ecological status of marine ecosystems and of the human pressures. Examples include the Cumulative Human Impact (CHI; Halpern et al., 2008) index and the Ocean Health Index (OHI). The CHI is a quantitative method to measure the spatial impact of human activities on the ocean, and includes pressures like ocean pollution, commercial and artisanal fisheries, 
maritime transportation, and climate-related impacts like ocean acidification, sea level rise and UV radiation intensity (Halpern et al., 2008). The OHI is another comprehensive and quantitative method to measure and evaluate the health of coupled human-ocean systems, based on features like food provision, biodiversity and support to coastal livelihoods and economies (Halpern et al., 2012). Also the notion of Essential Ocean Variables (EOV; UNESCO, 2012), developed in the context of the GOOS (Global Ocean Observations System), aims to gather ocean data around fundamental physical, biogeochemical and biological data. Finally, the use of tools developed in the context of the DEVOTES project should be fostered, like the Nested Environmental status Assessment Tool (NEAT), a software for the integrated, consistent and comparative assessment of biodiversity status and GES across regional seas.

Fourth, data collection and monitoring should be improved, especially on aspects that are currently under-monitored, such as complex ecological structures and processes like e.g. ecological diversity and variability, marine food webs, or pressures like marine litter and underwater noise. The MSFD has a wide geographical scope and challenges EU Member States in setting up and implementing additional monitoring in areas where it was not previously required by law. In addition to this, as proposed in Chapter 6, marine data collection can benefit from the possibility to have joint monitoring cruises, which would allow coastal countries to increase time- and resource-efficiency of monitoring activities and improve comparability. Borja et al. (2016b) identify four main tools that can be combined in order to strengthen marine data collection practices. They are: (i) genomic tools, like metabarcoding and metagenomics, which can be used to calculate biotic indices based on taxonomic composition or understanding trophic interactions; (ii) remote sensing to assess phytoplankton and algal blooms; (iii) acoustic devices, especially for the assessment of abundance and composition of fish and cetaceans; and (iv) certain types of modelling, useful to increase spatial coverage of environmental variables and predict spatial distribution patterns. New technologies, like web-enabled, low cost sensors may help gather data in a more cost- and timeeffective way (ENVIROFI, 2011). Moreover, citizens-contributed information could also prove to be useful in this direction, for example by involving tourists, divers and fishermen through the use of smartphone and internet-based applications. Positive examples in this line are the PERSEUS Jellyfish Spotting campaign, where citizens are encouraged to report sightings of jellyfish through a web-based platform and the Invasive Alien Species App, developed by the Joint Research Centre of the European Commission to gather and share information about invasive alien species in Europe.

Fifth, a problem of data availability and sharing emerged from the findings of this thesis, because of the presence of organisational barriers that prevent their sharing and use by 
public administrations. The case of the Adriatic Sea shows that the issues of data access, harmonisation and sharing paired up with the short time frame needed to submit the initial assessment for the MSFD, and resulted in data gaps that were only partially filled by Italy with further data collection activities. These difficulties in data availability, access and sharing may be tackled through fostering initiatives for open access, sharing and harmonisation of data among the public administrations involved. In Europe, this process includes further implementation of INSPIRE (Directive 2007/2/EC) and EMODnet. INSPIRE is a framework Directive, aiming at building an infrastructure for better access to, and sharing of harmonised, high-quality environmental data in support to European environmental policies. It requires Member States to publish environmental data held by public administrations following common technical specifications. In a complementary way with the top-down approach followed by INSPIRE stands the bottom-up experience of the European Marine Observation and Data Network (EMODnet). EMODnet is a consortium of several organisations involved in marine data, data products and metadata; its aim is to favour the discovery, access and sharing of high quality, harmonised and interoperable data, free of restrictions on use. To this respect, the European Union recently launched a European Union Location Framework (EULF) Marine Pilot project, aiming at understanding how INSPIRE specifications can support the sharing of marine data across borders and support the process of reporting to the European institutions. It shows that both INSPIRE and EMODnet have potential to be put in synergy in order to deliver a more efficient and cost-effective approach to marine data sharing and reporting (Abramic et al. 2015). Similar initiatives are being held at the global stage, for example with the establishment of the "Blue Planet" initiative in the context of GEOSS (Global Earth Observation System of Systems), whose objective is, among others, to exploit synergies among the many observational programmes devoted to ocean and coastal waters around the globe.

Sixth, at global level iteration, learning and science-based approaches should be streamlined into all policy cycles, with a view to identify and promote mechanisms to cope with potential conflicting implementation timelines. At EU level, the inclusion of environmental considerations into sector-based policies is realised mainly through environmental impact assessments, regulated through the cited EIA and the SEA Directives. However, their capacity to effectively prevent and reduce adverse anthropogenic impacts on marine systems do not emerge clearly from the findings of this thesis. In this context, a possible way to strengthen cross-sector coordination could be to have a 'marine ecological resilience assessment' streamlined into the EIA and SEA practice, for every policy and activity that is likely to have an impact on the marine environment. In this way it would be possible to foster the inclusion of marine ecological considerations and environmental limits into sector-based (TM) practices. In 
addition to this, formal or informal institutional mechanisms to coordinate across policies could be fostered, both across administrations at various levels and inside a same administration. The Italian Technical Committee for the implementation of the MSFD is a good example of a forum bringing together major public administrations dealing with marine and maritime policies. Opportunities may be generated also by the adoption of marine spatial plans, i.e. "public processes of analysing and allocating the spatial and temporal distribution of human activities in marine areas to achieve ecological, economic, and social objectives that are usually specified through a political process" (Ehler and Douvere, 2009). In Europe, this process is taking place with the adoption of a Directive on Marine Spatial Planning (MSP Directive; 2014/89/EU), whose purpose is to establish a framework for marine spatial planning in Europe, based on the implementation of an ecosystem approach. Marine spatial plans have the potential to act as a forum for participatory discussion and building of a shared vision of sustainability of a marine area. However, the issue is left open, and not really tackled by this new tool, on the possibility to balance the respect of ecological considerations with 'Blue Growth' and job creation (Qiu and Jones, 2010; Brennan et al., 2014). A basic pre-requisite to support this process is to raise awareness on coordination of policy ycles and management at the various levels of governance. As showed in Chapter 5, the participation to the MSFD Technical Committee by representatives of non-coastal regions was low or inexistent, even though the impacts of some of these regions on marine eutrophication, mainly through agricultural and waste-water discharges to rivers like the Po river, is considered to be as one of the major environmental issues for the northern portion of the Adriatic Sea. Finally, ocean literacy initiatives and projects are being implemented, like the Sea Change Project, which aims to empower citizens "to take direct and sustainable action towards a healthy ocean and seas, healthy communities and ultimately a healthy planet". Initiatives like these have the potential to make more informed citizens, an essential pre-requisite for improved participation into decision-making and implementation of decisions at all levels of governance.

\subsection{Further research}

The conclusions of this thesis open the way for several strands of scientific research.

Further case-studies should be conducted, whose evidence would confirm or contest the conclusions of this work. The analysis of marine social-ecological systems located into other geographical and socio-political contexts, like for example the North Sea or the Caribbean Sea, would provide evidence in favour or against the findings of this thesis. Case studies could be conducted also for Large Marine Ecosystems (LMEs) like the Bay of Bengal, where coastal states participate into a project to improve 
international coordination and integrated management of this LME. Analysis of current legal frameworks and management practices in other countries of the world, like United States of America (USA), Canada, Japan, Brazil, Russia and China, could also prove to be useful to this respect. Moreover, as the TM approach is officially adopted by the Netherlands as a strategy for sustainability (NMP-4, 2000), the investigation of the Dutch marine and maritime legislation and practices would be useful to test the findings of this work, especially regarding the relations between TM practices and the implementation of the MSFD and other marine legislation.

Scientific research should also focus on improving existing integrative tools for ecological assessment, and developing new ones, which would incorporate TM's perspective on socio-technical systems, actors and institutions in the assessment of ecological resilience.

Finally, from a legal perspective, further research should explore and suggest innovative ways to 'bypass' the limitations of legal systems highlighted in this work, and foster the inclusion of geographically-based approaches into legal texts, in the direction currently being explored by the UNCLOS-related agreement on the protection of biodiversity in marine areas beyond national jurisdiction. 

References 
Abramic, A., Smits, P., Nunes de Lima, V., 2015. Analysis of requirements that link INSPIRE and MSFD. Available at: https://joinup.ec.europa.eu/sites/default/files/ckeditor_files/files/D12\%20Analysis\%20of\%20MSFD\%20and\%20INSPIRE\%20requirements\%20REV\%202.pdf

André, M., Van der Schaar, M., Zaugg, Houégnigan, S., Sánchez, A.M., Castell, J.V., 2011. Listening to the deep: live monitoring of ocean noise and cetacean acoustic signals. Marine Pollution Bulletin 63: 18-26.

Arkema, K.K., Abramson, S.C., Dewsbury, B.M., 2006. Marine ecosystem-based management: from characterisation to implementation. Frontiers in Ecology and the Environment 4(10): 525532.

Atkins, J.P., Burdon, D., Elliott, M., Gregory, A.J., 2011. Management of the marine environment: Integrating ecosystem services and societal benefits with the DPSIR framework in a systems approach. Marine Pollution Bulletin 62: 215-226.

Ban, N.C., Bax, N.J., Gjerde, K.M., Devillers, R., Dunn, D.C., Dunstan, P.K., Hobday, A.J., Maxwell, S.M., Kaplan, D.M., Pressey, R.L., Ardron, J.A., Game, E.T., Halpin, P.N., 2014. Systematic Conservation Planning: A Better Recipe for Managing the High Seas for Biodiversity Conservation and Sustainable Use. Conservation Letters 7(1): 41-54.

Barbier, E.B., 2012. Progress and challenges in valuing coastal and marine ecosystem services. Review of Environmental and Economic Policy 6(1): 1-19.

Barnes, M., Matka, E., Sullivan, H., 2003. Evidence, understanding and complexity: evaluation in non-linear systems. Evaluation 9(3): 265-284.

Beaumont, N.J., Austen, M.C., Atkins, J.P., Burdon, D., Degraer, S., Dentinho, T.P., Derous, S., Holm, P. Horton, T., van Ierland, E., Marboe, A.H., Starkey, D.J., Townsend, M., Zarzycki, T., 2007. Identification, definition and quantification of goods and services provided by marine biodiversity: Implications for the ecosystem approach. Marine Pollution Bulletin 54: 253-265.

Bellas, J., 2014. The implementation of the Marine Strategy Framework Directive: Shortcomings and limitations from the Spanish point of view. Marine Policy 50: 10-17.

Berkes, F., Colding, J., Folke, C., 2003. Navigating social-ecological systems - Building resilience for complexity and change. Cambridge University Press, Cambridge, UK.

Bigagli, E., 2015. The European Union legal framework for the management of marine complex social-ecological systems. Marine Policy 54: 44-51.

Bigagli, E., 2016. The international legal framework for the management of the global oceans social-ecological system. Marine Policy 68: 155-164. 
Binder, C.R., Hinkel, J., Bots, P.W.G., Pahl-Wostl, C., 2013. Comparison of frameworks for analyzing social-ecological systems. Ecology and Society 18(4): 26.

Birk, S., Bonne, W., Borja, A., Brucet, S., Courrat, A., Poikane, S., Solimini, A., Van de Bund, W., Zampoukas, N., Hering, D., 2012. Three hundred ways to assess Europe's surfacewaters: an almost complete overview of biological methods to implement the Water Framework Directive. Ecological Indicators 18: 31-41.

Borja, A., Bricker, S.B., Dauer, D.M., Demetriades, N.T., Ferreira, J.G., Forbes, A.T., Hutchings, P., Jia, X., Kenchington, R., Marques, J.C., Zhu, C.,2008. Overview of integrative tools and methods in assessing ecological integrity in estuarine and coastal systems worldwide. Marine Pollution Bulletin 56: 1519-1537.

Borja, A., Elliott, M., Snelgrove, P.V., Austen, M.C., Berg, T., Cochrane, S., Carstensen, J., Roberto, D., Greenstreet, S., Heiskanen, A., Lynam, C.P., Mea, M., Newton, A., Patrício, J., Uusitalo, L., Uyarra, M.C., Wilson, C., 2016a. Bridging the gap between policy and science in assessing the health status of marine ecosystems. Frontiers in Marine Science 3: 175.

Borja, A., Elliott, M., Andersen, J.H., Berg, T., Carstensen, J., Halpern, B.S., Heiskanen, A.-S., Korpinen, S., Lowndes, J.S.S., Martin, G., Rodriguez-Ezpeleta, N., 2016b. Overview of integrative assessment of marine systems: the ecosystem approach in practice. Frontiers in Marine Science 3.

Boyes, S.J., Elliott, M., 2014. Marine legislation - The ultimate "horrendogram": International law, European directives \& national implementation. Marine Pollution Bulletin, 86(1-2): 39-47.

Brennan, J., Fitzsimmons, C., Gray, T., Raggatt, L., 2014. EU marine strategy framework directive (MSFD) and marine spatial planning (MSP): Which is the more dominant and practicable contributor to maritime policy in the UK? Marine Policy 43: 359-366.

Carpenter S.R., Gunderson, L.H., 2001. Coping with collapse: Ecological and social dynamics in ecosystem management. Bioscience 51: 451-7.

Carpenter, S., Walker, B., Anderies, J.M., Abel, N., 2001. From Metaphor to Measurement: Resilience of What to What? Ecosystems 4: 765-781.

Cicin-Sain, B., Belfiore, S., 2005. Linking marine protected areas to integrated coastal and ocean management: A review of theory and practice. Ocean and Coastal Management 48(11-12): 847-868.

Cinnirella, S., March, D., O’Higgins, T., Murciano, C., Sardà, R., Albaigés, J., Pirrone, N., 2012. A multidisciplinary Spatial Data Infrastructure for the Mediterranean to support the 
implementation of the Marine Strategy Framework Directive. International Journal of Spatial Data Infrastructures Research 7: 323-351.

Costanza, R., 1999. The ecological, economic and social importance of the oceans. Ecological Economics 31(2): 199-213.

Craglia, M., de Bie, K., jackson, D., Pesaresi, M., Remetey-Fülöpp, Wang, C., Annoni, A., Bian, L., Campbell, F., Ehlers, M., van Genderen, J., Goodchild, M., Guo, H., Lewis, A., Simpson, R., Skidmore, A., Woodgate, P., 2012. Digital Earth 2020: towards the vision for the next decade. International Journal of Digital Earth 5(1): 4-21.

Crowder, L.B., Osherenko, G., Young, O.R., Airamé, S., Norse, E.A., Baron, N., Day, J.C., Douvere, F., Ehler, C.N., Halpern, B.S., Langdon, S.J., McLeod, K.L., Ogden, J.C., Peach, R.E., Rosenberg, A.A., Wilson, J.A., 2006. Resolving mismatches in US ocean governance. Science 313: 617-618.

Crowder, L., Norse, E., 2008. Essential ecological insights for marine ecosystem-based management and marine spatial planning. Marine Policy 32: 772-778.

Cumming, G.S., Barnes, G., Perz, S., Schmink, M., Sieving, K.E., Southworth, J., Binford, M., Holt, R.D., Stickler, C., Van Holt, T., 2005. An Exploratory Framework for the Empirical Measurement of Resilience. Ecosystems 8: 975-987.

Curtin, R., Prellezo, R., 2010. Understanding marine ecosystem based management: A literature review. Marine Policy 34(5): 821-830.

de Jonge, V.N., Pinto, R.R., Kerry Turner, R.K., 2012. Integrating ecological, economic and social aspects to generate useful management information under the EU Directives' 'ecosystem approach'. Ocean and Coastal Management 68: 169-188.

De Santo, E.M. 2010. 'Whose Science?' Precaution and Power-Play in European Marine Environmental Decision-Making. Marine Policy 34: 414-420.

Dimitrakopoulos, D., Richardson, J. 2001. Implementing EU public policy. In: Richardson, J. (ed.). European Union. Power and Policy-making, Routledge, London and New York.

Dryzek, J., 2013. The Politics of the Earth: Environmental Discourses. Oxford University Press, Oxford, UK.

Eason, T., Garmestani, A.S., Stow, C.A., Rojo, C., Alvarez-Cobelas, M., Cabezas, H., 2016. Managing for resilience: an information theory-based approach to assessing ecosystems. Journal of Applied Ecology 53: 656-665. 
Ehler, C., Douvere, F., 2009. Marine Spatial Planning: a step-by-step approach toward ecosystembased management. Intergovernmental Oceanographic Commission and Man and the Biosphere Programme. IOC Manual and Guides No. 53, ICAM Dossier No. 6. Paris: UNESCO.

ENVIROFI, 2011. The Environmental Observation Web and its Service Applications within the Future Internet. D3.2.1 Use Case Requirements Report I Marine Institute. Available at: http://cordis.europa.eu/fp7/ict/netinnovation/deliverables/envirofi/envirofi-d321.pdf.

European Commission, 2007. Communication from the Commission to the European Parliament, the Council, the European Economic and Social Committee and the Committee of the Regions - An Integrated Maritime Policy for the European Union. COM (2007) 575 final.

European Commission, 2008. Staff Working Document Regulatory Concerns raised during the Consultation Process on a future Maritime Policy for the European Union. SEC (2008) 2993 final.

European Commission, 2009. Report from the Commission to the Council, the European Parliament, the European Economic and Social Committee and the Committee of the Regions. Progress Report on the EU's Integrated Maritime Policy. COM (2009) 540 final.

European Commission, 2010. Communication from the Commission to the European parliament and the Council. Marine Knowledge 2020. Marine data and observation for smart and sustainable growth. COM (2010) 461 final.

European Commission, 2014. Communication from the Commission to the European Parliament, the Council, the European Economic and Social Committee and the Committee of the Regions concerning the European Union Strategy for the Adriatic and Ionian Region. COM (2014) 357 final.

FAO, 2003. The ecosystem approach to fisheries. FAO technical guidelines for responsible fisheries; 4.

Fischer-Kowalski, M., Rotmans, J., 2009. Conceptualizing, observing and influencing SocialEcological transitions. Ecology and Society 14(2): 3.

Folke, C., Carpenter, S.R., Walker, B., Scheffer, M., Chapin, T., Rockström, J., 2010. Resilience thinking: integrating resilience, adaptability and transformability. Ecology and Society 15(4): 20.

Foxon, T.J., Reed, M.S., Stringer, L.C., 2009. Governing long-term Social-Ecological change: what can the Adaptive Management and Transition Management approaches learn from each other? Environmental Policy and Governance 19: 3-20. 
Freestone, D., 2011. Problems of High Seas governance. In: Vidas, D., and Schei, P. J. (eds). The world ocean in globalisation: Climate Change, Sustainable Fisheries, Biodiversity, Shipping, Regional Issues. Martinus Nijhoff, pp. 99-124.

Freire-Gibb, L. C., Koss, R., Margonski, P., Papadopoulou, N., 2014. Governance strengths and weaknesses to implement the marine strategy framework directive in European waters. Marine Policy 44: 172-178.

Garmestani, A.S., Harm Benson, M., 2013. A Framework for Resilience-based Governance of Social-Ecological Systems. Ecology and Society 18(1): 9.

Geels, F.W., 2004. From sectoral systems of innovation to socio-technical systems - Insights about dynamics and change from sociology and institutional theory. Resource Policy 33: 897-920.

Gjerde, K.M., Dotinga, H., Hart, S., Molenaar, E.J., Rayfuse, R., Warner, R., 2008. Regulatory and Governance Gaps in the International Regime for the Conservation and Sustainable Use of Marine Biodiversity in Areas beyond National Jurisdiction. IUCN, Gland, Switzerland.

Gjerde, K.M., Currie, D., Wowk, K., Sack, K., 2013. Ocean in peril: Reforming the management of global ocean living resources in areas beyond national jurisdiction. Marine Pollution Bulletin 74: 540-551.

Glaser, M., Krause, G., Ratter, B., Welp, M., 2008. Human/nature interaction in the anthropocene Potential of social-ecological systems analysis. GAIA 17(1): 77-80.

Golden, C.D., Allison, E.H., Cheung, W.W.L., Dey, M.M., Halpern, B.S., McCauley, D.J., Smith, M., Vaitla, B., Zeller, D., Myers, S.S., 2016. Nutrition: Fall in fish catch threatens human health. Nature 534(7607): 317-320.

Grumbine, R.E., 1994. What is ecosystem management? Conservation Biology 8(1): 27-38.

Grus, L., Crompvoets, J., Bregt, A.K., 2010. Spatial data infrastructures as complex adaptive systems. International Journal of Geographical Information Science 24(3): 439-463.

Guerry, A.D., 2005. Icarus and Daedalus: conceptual and tactical lessons for marine ecosystembased management. Frontiers in Ecology and the Environment 3(4): 202-11.

Gunderson, L.H., Holling, C.S., (eds), 2002. Panarchy: understanding transformations in human and natural systems. Island Press, Washington, D.C., USA.

Hagstrom, G.I., Levin, S.A., 2016. Managing Marine Ecosystems as Complex Adaptive Systems: Emergent Patterns, Critical Transitions, and Public Goods. bioRxiv 056838. 
Halpern, B.S., Walbridge, S., Selkoe, K.A., Kappel, C.V., Micheli, F., D’Agrosa, C., Bruno, J.F., Casey, K.S., Ebert, C., Fox, H.E., Fujita, R., Heinemann, D., Lenihan, H.S., Madin, E.M.P., Perry, M.T., Selig, E.R., Spalding, M., Steneck, R., Watson, R., 2008. A global map of human impact on marine ecosystems. Science 319: 948-952.

Hattam, C., Atkins, J.P., Beaumont, N., Börger, T., Böhnke-Henrichs, A., Burdon, D., de Groot, R., Hoefnagel, E., Nunes, P.A.L.D., Piwowarczyk, J., Sastre, S., Austen, M.C., 2015. Marine ecosystem services: Linking indicators to their classification. Ecological Indicators 49: 61-75.

HELCOM, 2003. Manual for marine monitoring in the COMBINE Programme of HELCOM. Part C. Programme for monitoring of eutrophication and its effects. Helsinki: HELCOM.

Herr, D., Galland, G. R., 2009. The Ocean and Climate Change. Tools and Guidelines for Action. IUCN, Gland, Switzerland.

Heslenfeld, P., Enserink, L., 2008. OSPAR ecological quality objectives: the utility of health indicators for the North Sea. ICES Journal of Marine Sciences 65: 1392-1397.

Holling, C.S., 1973. Resilience and Stability of Ecological Systems. Annual Review of Ecology and Systematics 4: 1-23.

Holling, C. S., 2001. Understanding the Complexity of Economic, Ecological and Social Systems. Ecosystems 4: 390-405.

Holling, C.S., Gunderson, L.H., Peterson, G.D., 2002. Sustainability and panarchies. In: Gunderson, L.H., Holling, C.S. (eds). Panarchy: Understanding Transformations in Human and Natural Systems. Island Press, Washington, Covelo, London, pp. 62-102.

Hughes, T. P., Bellwood, D. R., Folke, C., Steneck, R. S., Wilson, J., 2005. New paradigms for supporting the resilience of marine ecosystems. Trends in Ecology and Evolution 20(7): 380386.

IOC/UNESCO, IMO, FAO, UNDP., 2011. A Blueprint for Ocean and Coastal Sustainability. IOC/UNESCO, Paris, France.

ISPRA, 2012. Strategia per l'ambiente marino. La valutazione iniziale dello stato dell'ambiente marino e proposte per la determinazione del buono stato ambientale e la definizione dei traguardi ambientali.

Jouanneau, C., Raakjaer, J., 2014. 'The Hare and the Tortoise': Lessons from Baltic Sea and Mediterranean Sea governance. Marine Policy 50: 331-338. 
Katsanevakis, S., Stelzenmueller, V., South, A., Sorensen, T. K., Jones, P. J. S., Kerr, S., Badalamenti, F., Anagnostou, C., Breen, P., Chust, G., D’Anna, G., Duijn, M., Filatova, T., Fiorentino, F., Hulsman, H., Johnson, K., Karageorgis, A. P., Kröncke, I., Mirto, S., Pipitone, C., Portelli, S., Qiu, W., Reiss, H., Sakellariou, D., Salomidi, M., van Hoof, L., Vassilopoulou, V., Vega Fernández, T., Vöge, S., Weber, A., Zenetos, A., ter Hofstede, R., 2011. Ecosystem-based marine spatial management: Review of concepts, policies, tools, and critical issues. Ocean and Coastal Management 54: 807-820.

Kelble, C.R., Loomis, D.K., Lovelace, S., Nuttle, W.K., Ortner, P.B., Fletcher, P., Cook, G.S., Lorenz, J.J., Boyer, J.N., 2013. The EBM-DPSER Conceptual Model: Integrating Ecosystem Services into the DPSIR Framework. PLoS ONE 8(8).

Kemp R., Loorbach D., Rotmans J., 2007. Transition management as a model for managing processes of co-evolution towards sustainable development. The International Journal of Sustainable Development and World Ecology 14(1): 78-91.

Kern, F., Smith, A., 2008. Restructuring energy systems for sustainability? Energy transition policy in the Netherlands. Energy Policy 36: 4093-4103.

Kimball, L. A., 2001. International Ocean Governance: Using International Law and Organisations to Manage Marine Resources Sustainably. IUCN, Gland, Switzerland and Cambridge, UK.

Lafferty, W., Hovden, E., 2003. Environmental policy integration: towards an analytical framework. Environmental Politics, 12(3): 1-22.

Lees, K., Pitois, S., Scott, C., Frid, C., Mackinson, S., 2006. Characterizing regime shifts in the marine environment. Fish and Fisheries 7: 104-127.

Levin, S.A., 1998. Ecosystems and the biosphere as complex adaptive systems. Ecosystems 1(5): 431-436.

Levin, S.A., Lubchenco, J., 2008. Resilience, robustness, and marine ecosystem-based management. BioScience 58: 27-32.

Levin, P.S., Fogarty, M.J., Murawski, S.A., Fluharty, D., 2009. Integrated Ecosystem Assessments: Developing the Scientific Basis for Ecosystem-Based Management of the Ocean. PLoS Biology $7(1): 23-28$.

Levin P.S., Mölmann C., 2015. Marine ecosystem regime shifts: challenges and opportunities for ecosystem-based management. Philosophical Transactions of the Royal Society B 370. 
Liu, J., Dietz, T., Carpenter, S.R., Alberti, M., Folke, C., Moran, E., Pell, A.N., Deadman, P., Kratz, T., Lubchenco, J., Ostrom, E., Ouyang, Z., Provencher, W., Redman, C.L., Schneider, S.H., Taylor, W.W., 2007. Complexity of Coupled Human and Natural Systems. Science 317: 1513-1516.

Loorbach, D., Parto, S., Kemp, R., 2003. From waste disposal to waste management: Transitions in waste management in the Netherlands. Paper presented at the Netherlands Organisation for Scientific Research (NOW), May 2003.

Loorbach, D., 2010. Transition Management for Sustainable Development: A Prescriptive, Complexity-Based Governance Framework. Governance: An International Journal of Policy, Administration, and Institutions 23(1): 161-183.

Loorbach, D., Rotmans, J., 2010. The practice of transition management: Examples and lessons from four distinct cases. Futures 42: 237-246.

Lotze, H.K., Lenihan, H.S., Bourque, B.J., Bradbury, R.H., Cooke, R.G., Kay, M.C., Kidwel, S.M., Kirby, M.X., Peterson, C.H., Jackson, J.B.C., 2006. Depletion, Degradation, and Recovery Potential of Estuaries and Coastal Seas. Science 23: 1806-1809.

Mahon, R., Fanning, L., Gjerde, K.M., Young, O., Reid, M., Douglas, S., 2015. Transboundary Waters Assessment Programme (TWAP) Assessment of Governance Arrangements for the Ocean, Volume 2: Areas Beyond National Jurisdiction. UNESCO-IOC, Paris. IOC Technical Series, 119: $91 \mathrm{pp}$.

Mee, L.D., 2005. Assessment and monitoring requirements for the adaptive management of Europe's regional seas. Managing European Coasts: Past, Present and Future. In: Vermaat, J., W. Salomons, L. Bouwer, and K. Turner (Eds.), Managing European Coasts. Springer, Berlin Heidelberg, Germany, pp. 227-237.

Meiner A., 2010. Integrated Maritime Policy for the European Union - Consolidating Coastal and Marine Information to Support Maritime Spatial Planning. Journal of Coastal Conservation: 14: 1-11.

Mitchell, R.B., 2002-2015. International Environmental Agreements Database Project (Version 2014.3). Available at: http://iea.uoregon.edu/ (Date accessed: 7 January 2015).

Moomaw, W., Blankenship, S., 2014. Charting a new course for the oceans. The Center for International Environment \& Resource Policy - Water and Oceans Program, the Fletcher school, Tufts University 11.

Mosetti R., Lipizer, M. (Eds.), 2014. ADRIPLAN Report: AIP-1.2-1.1 - Initial Assessment. doi: 10.6092/a0c08436-868b-4cc2-9cb8-532dd32f2621. 
MSFD CIS, 2014. Marine Strategy Framework Directive (MSFD) Common Implementation Strategy (CIS) Strategic document including a work programme for 2014 and beyond "Learning the lessons and launching a re-enforced phase of implementation".

Nixon, S.C., Rees Y.J., Gendebien A., Ashley S.J. ,1996. Requirements for Water monitoring. EEA, European Topic Centre on Inland Waters, 06/1996, ISBN 92-9167-003-4.

NMP-4 (2000), Een wereld en een wil. Werken aan duurzaamheid. (A World and a will. Working on Sustainability), The Hague.

O'Leary, B.C., Brown, R.L., Johnson, D.E., von Nordheim, H., Ardron J., Packeiser T., Roberts, C.M., 2012. The first network of marine protected areas (MPAs) in the high seas: the process, the challenges and where next. Marine Policy 36: 598-605.

Olsson, P., Galaz, V., Boonstra, W.J., 2014. Sustainability transformations: a resilience perspective. Ecology and Society 19.

OSPAR, 2004. Strategy for a joint assessment and monitoring programme (JAMP). OSPAR Commission.

OSPAR, 2008. Marine biodiversity monitoring and assessment: activities to improve synergies between EU directives and international conventions. OSPAR monitoring and assessment series 357.

Ostrom, E., 2007. A diagnostic approach for going beyond panaceas. Proceedings of the National Academy of Science USA 104(39): 15181-15187.

Palialexis, A., Tornero, V., Barbone, E., Gonzalez, D., hanke, G., Cardoso, A.C., Hoepffner, N., Katsanevakis, S., Somma, F., Zampoukas, N., 2014. In-Depth Assessment of the EU Member States' Submissions for the Marine Strategy Framework Directive under articles 8, 9 and 10. JRC Scientific and Policy Report EUR 26473 EN.

Pereira, L., Karpouzoglou, T., Doshi, S., Frantzeskaki, N., 2015. Organising a Safe Space for Navigating Social-Ecological Transformations to Sustainability. International Journal of Environmental Research and Public Health 12: 6027-6044.

Perry, R.I., Barange, M., Ommer, R.E., 2010. Global changes in marine systems: A social-ecological approach. Progress in Oceanography 87: 331-337.

Petersen, W., Petschatnikov, M., Schroeder, F., Colijn, F., 2003. FerryBox systems for monitoring coastal waters. In: Dahlin H, Flemming NC, Nittis K, Petersson SE, editors. Building the European capacity in operational oceanography, Proceedings of the Third International Conference on EuroGOOS. Elsevier Oceanography Series Publication Series 19: 325-333. 
Peterson, C.H., Lubchenko, J., 1997. Marine ecosystem services. In: Daily, G.C. (ed). Nature's services - societal dependence on natural ecosystems. Island Press, Washington, Covelo.

Pollnac, R., Christie, P., Cinner, J.E., Dalton, T., Daw, T.M., Forrester, G.E., Graham, N.A.J., McClanahan, T.R., 2010. Marine reserves as linked social-ecological systems. Proceedings of the National Academy of Sciences 107: 18262-18265.

Qiu, W., Jones, P.J.S., 2010. The emerging policy landscape for marine spatial planning in Europe. Marine Policy 39: 182-190.

Rip, A., Kemp, R., 1998. Technological Change. In: Human Choice and Climate Change, Vol. II, Resources and Technology. Battelle Press, Columbus, OH, USA, pp. 327-399.

Rochette, J., Unger, S., Herr, D., Johnson, D., Nakamura, T., Packeiser, T., Proelss, A., VIsbeck, M., Wright, A., Cebrian, D., 2014. The regional approach to the conservation and sustainable use of marine biodiversity in areas beyond national jurisdiction. Marine Policy 49: 114-117.

Rothwell, D.R., Stephens, T., 2010. The international law of the sea. Hart Publishing, Oxford.

Rotmans, J. 2006. Tools for Integrated Sustainability Assessment: A two-track approach. Integrated Assessment Journal 6(4): 35-57.

Rotmans, J., Loorbach, D., 2008. Transition management: reflexive governance of societal complexity through searching, learning and experimenting, in: Van den Bergh, J., Bruinsma, F. Managing the transition to the renewable energy. Edward Elgar, Cheltenham, UK, pp. 15-46.

Ruckelshaus, M., Klinger, T., Knowlton, N., DeMaster, D.P., 2008. Marine Ecosystem-based Management in Practice: Scientific and Governance Challenges. Bioscience 58(1): 53-63.

Salomon, M., 2009. Recent European initiatives in marine protection policy: towards lasting protection for Europe's seas? Environmental Science and Policy 12(3): 359-366.

Salomon, M., Dross, M., 2013. Challenges in cross-sectoral marine protection in Europe. Marine Policy 42: 142-149.

Scott, K.N., 2011. International environmental governance: managing fragmentation through institutional connection. Melbourne Journal of International Law 12(1).

Sheehan, E.V., Stevens, T.F., Attrill, M.J., 2010. Quantitative, non-destructive methodology for habitat characterisation and Benthic monitoring at offshore renewable energy developments. PLoS One: e14461. 
Sherman K., 1991. The Large Marine Ecosystem Concept: Research and Management Strategy for Living Marine Resources. Ecological Applications 1: 349-360.

Smith, A., Kern, F., 2009. The transitions storyline in Dutch environmental policy. Environmental Politics, 18(1): 78-98.

Smith, A., Stirling, A., 2010. The Politics of Social-ecological Resilience and Sustainable Sociotechnical Transitions. Ecology and Society 15(1): 11.

Tallis, H., Levin, P.S., Ruckelshaus, M., Lester, S.E., McLeod, K.L., Fluharty, L., Halpern, B.S., 2010. The many faces of ecosystem-based management: Making the process work today in real places. Marine Policy 34(2): 340-348.

Tett, P., Gowen, R.J., Painting, S.J., Elliott, M., Forster, R., Mills, D., Bresnan, E., Capuzzo, E., Fernandes, T., Foden, J., Geider, R., Gilpin, L., Huxham, M., McQuatters-Gollop, A., Malcolm, S., Saux Picart, S., Platt, T., Racault, M., Sathyendranath, S., van der Molen, J., WIlkinson, M., 2013. Framework for understanding marine ecosystem health. Marine Ecological Progress Series 494: 1-27.

The Economics of Ecosystems and Biodiversity (TEEB), 2010. Ecological and Economic Foundations. Edited by Pushpam Kumar, Earthscan, London and Washington. ISBN 978-184971-212-5.

The Economics of Ecosystems and Biodiversity (TEEB), 2012. Why value the oceans? A discussion paper. Edited by Beaudouin, Y., Pendleton, L.

Thompson, R.C., Olsen, Y., Mitchell, R.P., Davis, A., Rowland, S.J., John, A.W.G., McGonigle, D., Russell, A.E., 2004. Lost at sea: where is all the plastic? Science 304: 838.

Tuck, I.D., Chapman, C.J., Atkinson, R.J.A., 1997. Population biology of the Norway lobster, Nephrops norvegicus (L.) in the firth of Clyde, Scotland-I, growth and density. ICES Journal of Marine Science 54: 125-135.

Tunesi, L., Casazza, G., Dalù, M., Giorgi, G., Silvestri, C. 2013. The implementation of the Marine Strategy Framework Directive in Italy: knowledge to support the management. Biologia Marina Mediterranea 20(1): 35-52.

UN Report of the Secretary-General A/61/63. UN General Assembly sixty-first session, 2006.

UNEP, 2013. Strategic Directions 2013-2016 for the UNEP Regional Seas Programme (RSP). 
UNEP/MAP, 2012. Initial integrated assessment of the Mediterranean Sea: Fulfilling step 3 of the ecosystem approach process. United Nations Environment Programme, Mediterranean Action Plan, Athens, Greece.

UNEP/MAP, 2013. State of the Mediterranean marine and coastal environment. United Nations Environment Programme, Mediterranean Action Plan, Athens, Greece.

UNESCO, 2012. A Framework for Ocean Observing. By the Task Team for an Integrated Framework for Sustained Ocean Observing, UNESCO 2012, IOC/INF-1284.

Van der Brugge, R., Rotmans, J., 2007. Towards transition management of European water resources. Water Resource Management 21: 249-267.

Van der Brugge, R., Van Raak, R., 2007. Facing the adaptive management challenge: insights from transition management. Ecology and Society 12(2): 33.

Van der Lei, T.E., Bekebrede, G., Nikolic, I., 2009. Critical infrastructures: A review from a complex systems perspective. International Journal of Critical Infrastructures 6: 380-401.

Van Leeuwen, J., Raakjaer, J., van Hoof, L., van Tatenhove, J., Long, R., Ounanian, K., 2014. Implementing the Marine Strategy Framework Directive: A policy perspective on regulatory, institutional and stakeholder impediments to effective implementation. Marine Policy 50(B): 325-330.

Van Leeuwen, J., van Hoof, L., van Tatenhove, J., 2012. Institutional ambiguity in implementing the European Union Marine Strategy Framework Directive. Marine Policy 36; 636-643.

Van Tatenhove, J. P. M., 2013. How to turn the tide: Developing legitimate marine governance arrangements at the level of the regional seas. Ocean and Coastal Management 71: 296-304.

Van Tatenhove, J., Raakjaer, J., van Leeuwen, J., van Hoof, L., 2014. Regional cooperation for European seas: Governance models in support of the implementation of the MSFD. Marine Policy 50: 364-372.

Van Tatenhove, J.P.M., 2016. The environmental state at sea. Environmental Politics 25:1; 160 179.

Vidas, D., 2011. The anthropocene and the international law of the sea. Philosophical Transactions of the Royal Society A 369.

Voss, J.P., Smith, A., Grin, J., 2009. Designing long-term policy: rethinking transition management. Policy Sciences 42(4): 275-302. 
Voss, J. P., Bornemann, B., 2011. The Politics of Reflexive Governance: Challenges for Designing Adaptive Management and Transition Management. Ecology and Society 16(2): 9.

Walters, C.J., 1986. Adaptive Management of Renewable Resources. McMillan, New York, NY, USA.

Warner, A.J., Hays, G.C., 1994. Sampling by the continuous plankton recorder survey. Progress in Oceanography $34:$ : 237-256.

Warner, R., Gjerde, K., Freestone, D., 2014. Regional governance for fisheries and biodiversity. In S. M. Garcia, J. Rice and A. Charles (Eds.), Governance of Marine Fisheries and Biodiversity Conservation: Interaction and Coevolution. United Kingdom: John Wiley and Sons; pp. 211224.

Zampoukas, N., Piha, H., Bigagli, E., Hoepffner, N., Hanke, G., Cardoso, A.C., 2012. Monitoring for the Marine Strategy Framework Directive: requirements and options. JRC Scientific and Technical Reports 68179. 
Summary 
Anthropogenic and climate-related stressors challenge the health of nearly every part of the global oceans. They affect the capacity of oceans to regulate global weather and climate, as well as ocean productivity and food services, and result in the loss or degradation of marine habitats and biodiversity. Moreover, they have a negative impact on maritime economic sectors and on the social welfare of dependent coastal populations. In order to overcome the deficiencies of traditional single-sector management, in the recent decades several scientific approaches emerged, based on the view of marine systems as Complex Adaptive Systems (CAS), i.e. systems where components interact in non-linear, path dependent ways, with lock-in and feedback loop mechanisms, and unpredictable effects also across scales. These approaches have been introduced into the texts of several international agreements related to marine CAS, and related management practices, with contrasting results in relation to effectiveness and integration of governance.

This thesis evaluates for the first time the current international and European legal frameworks from the perspective of marine CAS. To accomplish this objective, four research objectives are formulated: (1) Develop a framework for marine CAS assessment and management; (2) Evaluate the entire European Union (EU) legal framework against the framework developed; (3) Evaluate the international legal framework for the assessment and management of the global oceans against the framework developed; and (4) Evaluate the implementation of the EU and global legal frameworks into practice.

Chapter 2 develops a framework for marine CAS, based on the combination of two promising theoretical approaches: Adaptive Management (AM) and Transition Management (TM). The framework is based on the idea that AM and TM have the potential to overcome each other's limitations, which are related to the insufficient attention to micro-level socio-economic components, and to the limited incorporation of environmental aspects into socio-technical assessments, respectively. More into detail, the proposed framework is articulated into three components. First, the two sets of marine social-ecological systems and connected socio-technical systems (e.g. fisheries, maritime transportation, coastal tourism and energy) must be clearly identified, and the complex interactions and influences between socio-economic patterns of production and consumption, and ecological components must be assessed. Second, the achievement of ecological resilience of a marine social-ecological system should be performed in coordination with transitions of unsustainable connected sociotechnical systems. This implies that sustainability should be evaluated in relation to the pressures socio-technical systems generate on the ecological resilience of connected social-ecological systems, and related impacts. Third, the implementation of the two 
approaches should be articulated into iterative, learning- and science-based policy cycles, with mechanisms to foster coordination between the policy cycles of socialecological and socio-technical systems. The benefits of this framework are threefold. First, the assessment of the two sets of social-ecological and socio-technical systems, taken together, allows to overcome current AM limitations and include micro-level socio-economic components into the assessment of ecological resilience. Second, by linking AM managers with established transition arenas, it is possible to overcome TM limitations and streamline the consideration of ecological aspects into the TM process. Third, by linking AM and TM policy cycles, it is possible to reduce the current legal and policy fragmentation.

Chapters 3 and 4 apply the framework proposed in Chapter 2 to evaluate the EU and global legal frameworks for the assessment and management of marine CAS. Chapter 3 presents the first comprehensive review ever realised of the entire EU legal framework, composed of more than $12,000 \mathrm{EU}$ legal acts, from the perspective of marine CAS assessment and management. It concludes that the EU legislation does not provide a fully coherent framework for the assessment and management of EU marine CAS. Although the Marine Strategy Framework Directive (MSFD; 2008/56/EC) is a major step towards this purpose, the present research highlights three major limitations: (1) the limited capacity of the MSFD to support the coordination between Member States sharing the same marine region or sub-region; (2) the insufficient characterisation of marine ecological resilience, in particular in relation to socio-economic elements, ecosystem services, human benefits and cross-scale interactions; and (3) the limited capacity of the MSFD to tackle the fragmentation of the EU legal framework and integrate ecological resilience into the objectives of sector-based laws and policies.

Chapter 4 reviews 500 multilateral agreements, evaluated for the first time from the perspective of marine CAS. It shows that there is no international agreement aiming at the ecological resilience of the global oceans social-ecological system. Instead, the international legal framework is fragmented along two dimensions. On the one side, global agreements focus on specific objectives for determined socio-economic activities, ecological features or anthropogenic pressures. On the other side, regional agreements are in place for 18 ocean regions of the world, with a varying level of inclusion of elements of marine CAS assessment and management. The need is highlighted for a reformed global ocean governance framework, which should be based on a bio-geographical approach to the ecological resilience of the global oceans, and build on iteration, learning, and science-based advice to policy and management. 
Chapter 5 evaluates the implementation of the EU and global legal frameworks into the practice of assessment and management of a case-study area, the Adriatic Sea. It shows the importance of the MSFD as the first policy trying to deliver a CAS approach to marine assessment and management. However, the case-study investigation confirms the three limitations of the MSFD, laying in: 1) an insufficient geographical approach, where implementation is driven at national level and the requirement of cross-border cooperation is weak; 2) the vagueness of legal requirements, and the limited capacity to include socio-economic aspects into the required assessment; and 3) an insufficient capacity to coordinate with other laws, policies and programmes at various levels of governance. Based on the identified limitations, suggestions are advanced on how to strengthen the implementation of the MSFD, both at Adriatic and EU level. These suggestions are further advanced in Chapter 6, which includes detailed proposals on how to foster integrated large-scale marine monitoring in the $\mathrm{EU}$, in order to contribute to the implementation of the MSFD in an efficient and effective way, also in relation to costs.

Chapter 7 synthesizes the major findings of this thesis and evaluates the capacity of the framework to deliver a CAS approach to marine systems. It concludes that AM and TM, although holding different visions on sustainability and referring to different principles, have the potential to be put in synergy at the practical level. Further scientific research and management practices should focus on the need for AM and TM to overcome the relative isolation and foster synergies across sector-based management, in order to integrate environmental considerations into economic sectors. Suggestions are advanced to improve legal frameworks and policy practices at the global and EU level. They focus on the need: (i) to fill the gaps in the geographical scope of legal texts and to foster international cooperation at the right social-ecological scale; (ii) to increase guidance in translating complex scientific requirements into clear management objectives, and improve related data collection and sharing; and (iii) to reduce current legal and policy fragmentation through targeted, ecological resilience-based marine environmental impact assessments and maritime spatial planning. Lines for further scientific research are suggested, focusing on: (i) improving the evidence-base through additional case-studies; (ii) analysing legal frameworks and governance regimes in place for other marine social-ecological systems, like e.g. the United States of America, Canada, Australia and China; (iii) improving existing tools, or creating new ones for marine ecological resilience assessment; and (iv) developing innovative instruments and mechanisms to strengthen global oceans governance. 
Riassunto 
Il buono stato ecologico degli oceani globali è messo sotto pressione dal cambiamento climatico e dalle crescenti pressioni antropiche, le quali incidono negativamente sulla capacità degli oceani di regolare il clima ed il tempo globali, sulla loro produttività e sui servizi di supporto all'alimentazione umana, contribuendo in tal modo alla perdita o alla degradazione di habitat marini e biodiversità, nonché sui settori economici marittimi e sul benessere delle popolazioni costiere che da essi dipendono. Al fine di superare le limitazioni degli approcci tradizionali alla gestione del mare, basati sui singoli settori, negli ultimi anni sono emersi vari approcci scientifici, accomunati dalla visione dei sistemi marini sociali ed ambientali come sistemi complessi adattativi (Complex Adaptive Systems, CAS). I CAS sono sistemi che interagiscono in modo non lineare e dipendente dal percorso (path dependent), con meccanismi di lock in e anelli di retroazione (feedback loops) ed effetti imprevedibili anche su scale spaziali differenti. I principi e la visione di tali approcci scientifici, sono stati gradualmente riconosciuti nell'ordinamento giuridico internazionale e trasposti nei testi di vari accordi, miranti alla protezione dell'ambiente marino ed alla regolamentazione delle attività economiche connesse, con risultati contrastanti in termini di efficacia e integrazione tra i vari livelli di governance.

La presente tesi analizza per la prima volta i quadri legislativi globale ed Europeo per la protezione dell'ambiente marino e la regolamentazione delle attività marittime, a partire dalla prospettiva dei CAS marini. A tal fine, sono formulati quattro obiettivi di ricerca: (1) lo sviluppo di un quadro teorico di riferimento per la valutazione e gestione dei CAS marini: (2) l'analisi e valutazione dell'intero Acquis comunitario in relazione al quadro teorico formulato; (3) l'analisi e valutazione del quadro legislativo internazionale per la valutazione e gestione degli oceani globali in relazione al quadro teorico formulato; e (4) la valutazione dell'attuazione dei quadri legislativi analizzati nella pratica di un caso di studio.

Il capitolo 2 sviluppa un quadro teorico di riferimento per la valutazione e gestione dei CAS marini, suggerendo una strategia per l'integrazione in un quadro coerente di due promettenti approcci teorici per la valutazione della sostenibilità di sistemi complessi: l'approccio di Gestione Adattativa (Adaptive Management, AM), e l'approccio di Gestione delle Transizioni (Transition Management, TM). Il quadro teorico proposto suggerisce la possibilità di combinare i due approcci teorici al fine di superare le loro limitazioni, relative rispettivamente ad un'insufficiente attenzione data agli aspetti socio-economici di livello micro, e dalla limitata inclusione delle considerazioni ambientali nella valutazione di sostenibilità e delle transizioni. Più nel dettaglio, il quadro teorico proposto è articolato in tre punti, o componenti. Primo, le politiche di gestione del mare dovrebbero considerare i sistemi marini come sistemi socio-ecologici 
e identificare i sistemi socio-tecnici (es. pesca, trasporti marittimi e turismo costiero) ad essi collegati, così come le complesse interazioni tra i modelli socio-economici di produzione e consumo e le componenti ecologiche. Secondo, tali politiche dovrebbero avere l'obiettivo di raggiungere o mantenere la resilienza ecologica dei sistemi socioecologici marini, in coordinamento con la valutazione e la promozione di transizioni dei sistemi socio-tecnici insostenibili ad essi collegati. Ciò implica una valutazione di sostenibilità dei sistemi socio-tecnici in relazione alle pressioni e agli impatti generati sulla resilienza ecologica dei sistemi socio-ecologici collegati. Terzo, le politiche ambientali e socio-economiche dovrebbero essere articolate seguendo un ciclo iterativo e basato sull'apprendimento e sulla conoscenza scientifica, in maniera tale da favorire un'attuazione maggiormente coordinata delle politiche marine e marittime esistenti. Il quadro teorico proposto presenta tre vantaggi principali. Il primo vantaggio risiede nella possibilità di superare le limitazioni degli approcci di AM e migliorare la comprensione delle complesse dinamiche tra sistemi socio-ecologici e socio-tecnici, attraverso l'inclusione degli aspetti socio-economici di livello micro nella valutazione della resilienza ecologica marina. Il secondo vantaggio risiede nella possibilità di superare le limitazioni degli approcci di TM, relativi alla loro limitata inclusione degli aspetti ambientali nella valutazione del sistema e nello sviluppo del processo di transizione, attraverso l'inclusione degli attori direttamente coinvolti nella gestione dei sistemi socio-ecologici collegati all'interno della cosiddetta arena di transizione. Infine, il terzo vantaggio risiede nella possibilità di ridurre la frammentazione legislativa e gestionale attraverso la creazione di collegamenti diretti tra i cicli delle policy basate sui due approcci.

Nei Capitoli 3 e 4 il quadro teorico proposto è applicato alla valutazione dei quadri legislativi globale ed europeo per la valutazione e gestione dei CAS marini. Il Capitolo 3 presenta la prima valutazione completa mai effettuata dell'intero Acquis comunitario, composto da oltre 12.000 atti normativi, nella prospettiva della valutazione e gestione dei CAS marini. Si conclude come la legislazione europea non fornisca un quadro coerente per la realizzazione di tale obiettivo. Sebbene la Direttiva Quadro "Strategia Marina" (Marine Strategy Framework Directive, MSFD - 2008/56/EC) rappresenti un importante passo in avanti in questa direzione, tuttavia si sottolineano tre limiti principali: (1) la limitata capacità della MSFD di favorire il coordinamento tra Stati Membri all'interno di una stessa regione o sotto-regione marina; (2) l'insufficiente caratterizzazione della resilienza ecologica marina, in particolare in riferimento agli aspetti socio-economici, ai servizi ecosistemici e relativi benefici derivati per le comunità umane e alle interazioni tra scale spaziali; e (3) la limitata capacità della MSFD di ridurre la frammentarietà del quadro normativo europeo e fissare corrette priorità di gestione, basate sull'integrazione della resilienza ecologica all'interno degli obiettivi 
economico-sociali dei settori marittimi.

Il Capitolo 4 passa in rassegna 500 accordi multilaterali globali, per la prima volta analizzati dal punto di vista dei CAS marini. Si mostra come allo stato dell'arte non esistano accordi internazionali aventi l'obiettivo di salvaguardare la resilienza ecologica degli oceani mondiali. Al contrario, si illustra come il sistema normativo internazionale vigente sia frammentato secondo una duplice direzione o prospettiva. Da un lato, gli accordi di natura globale trattano obiettivi specifici per determinate attività economiche, componenti ecologiche o pressioni di tipo antropico. Dall'altro lato, gli accordi relativi a 18 mari regionali mostrano un livello di inclusione della considerazione dei CAS marini e della loro resilienza ecologica mutevole. Si sottolinea quindi l'esigenza di una riforma della governance degli oceani globali, che sia basata su un approccio bio-geografico alla resilienza ecologica degli oceani globali, e che si sviluppi secondo processi e cicli di politiche iterativi, basati sull'apprendimento (learning) e sulla conoscenza scientifica a supporto dei processi di attuazione delle policies.

Il Capitolo 5 analizza lo stato di attuazione dei quadri normativi globali ed europei attraverso l'analisi di un caso di studio di riferimento sul Mare Adriatico. Si mostra come la MSFD rappresenti un passo importante nella costruzione di un approccio alla salvaguardia dell'ambiente marino basato sui principi e sulla visione dei sistemi complessi. Tuttavia, il caso di studio conferma le limitazioni della MSFD in relazione a tre aspetti fondamentali: (1) l'approccio geografico, per cui l'attuazione della MSFD è condotta principalmente a livello nazionale, con deboli riferimenti alla cooperazione transfrontaliera; (2) la vaghezza della descrizione degli elementi di resilienza ecologica, e la relativa limitata capacità di includere gli aspetti socio-economici come parte integrante della valutazione del buono stato ecologico; e (3) la debole capacità di coordinamento con le altre leggi, politiche e programmi a vari livelli di governance. Alla luce di queste limitazioni, si avanzano dei suggerimenti su come rafforzare l'attuazione della MSFD sia a livello del caso di studio Adriatico, che a livello europeo. Questi suggerimenti sono ulteriormente approfonditi nel Capitolo 6, che contiene proposte dettagliate su come favorire l'attuazione di piani di monitoraggio integrato e su larga scala, aventi il potenziale di contribuire allo sviluppo di strategie di attuazione della MSFD a livello europeo efficienti ed efficaci, anche in termini di costi.

Il Capitolo 7 sintetizza i risultati principali della presente tesi. Si derivano lezioni sulla possibilità e utilità di combinare i due approcci scientifici alla sostenibilità presentati in un quadro teorico per la valutazione e gestione dei CAS marini. Si conclude come AM e TM, sebbene possiedano visioni differenti della nozione di sostenibilità e si riferiscano 
a principi teorici differenti, abbiano tuttavia il potenziale di creare sinergie a livello pratico. Si indica come la ricerca scientifica e le pratiche di gestione dovrebbero focalizzarsi sulla necessità per i due approcci di superare il loro relativo isolamento e promuovere sinergie, volte ad una più efficace integrazione delle considerazioni ambientali e di resilienza ecologica marina nelle politiche marittime settoriali. Si avanzano inoltre suggerimenti per promuovere l'introduzione dei principi e obiettivi della resilienza ecologica all'interno dei quadri normativi e di governance esistenti, sia a livello globale che europeo. Tali suggerimenti si basano sulla necessità di: (i) colmare le lacune nell'ambito geografico dei quadri legislativi e promuovere una cooperazione internazionale su scala socio-ecologica; (ii) fornire supporto pratico e gestionale nell'attuazione dei complessi requisiti scientifici propri della concettualizzazione dei CAS marini; (iii) ridurre la frammentazione legislativa e amministrativa attraverso l'introduzione di valutazioni di impatto ambientale e pianificazione dello spazio marittimo basate sulla resilienza ecologica marina. Si suggeriscono infine alcune linee di ricerca scientifica, derivate dalle conclusioni del presente lavoro: l'analisi di ulteriori casi di studio a livello europeo, o di regimi legislativi e di governance esistenti per altri CAS marini a livello globale (es. USA, Canada, Australia, Brasile e Cina); il miglioramento e lo sviluppo di nuovi strumenti scientifici di supporto alla valutazione della resilienza ecologica; e lo sviluppo di strutture e metodologie innovative per rafforzare la govenance degli oceani globali. 



\section{Acknowledgments}

This thesis is the result of a long and complicated route, of a small bit of 'inspiration' followed by a huge amount of years of 'transpiration'. I would like to thank all the people that, in one way or another, contributed to this thesis.

First of all, I would like to thank my supervisors, Arnold and Max, for giving me the opportunity to start my $\mathrm{PhD}$ and for their regular supervision, continuous support and motivation. Thanks to you I had the unique chance to grow as a scientist. I also gratefully acknowledge the Joint Research Centre of the European Commission, for assigning me a 3-year grant that made this research possible. My thanks also to Robin Smith and Regina Babo for the hard work we did on the analysis of legislation, whose great results are at the foundations of the present research.

I would like to thank Nikos Zampoukas for our collaboration on the analysis of the EU legislation, which resulted in a JRC Report and in a scientific article included as a chapter of this thesis. My thanks go to Robin Mahon and Lucia Fanning as well, for their precious advices on the chapter on the global oceans legislation. I am grateful also to the anonymous reviewers and to the editors of the journals I submitted my work to: they showed me that perseverance, tenacity, professionalism and... luck are essential components of both academic and personal life.

I would like to thank all the people I interviewed for the case study, not only in Italy and for the Adriatic Sea, but also from Belgium, Germany, Greece, Portugal and Slovenia where I piloted my questionnaire in the first place. I am also grateful to Camino Liquete for her help in identifying potential case study areas, and to my cousin Valentina for helping me with the translation of the summary of the thesis in Italian.

From Greece, I would like to give a heart-felt thanks to Vangelis Papathanassiou, for giving me the opportunity to collaborate with him in the most challenging period of my $\mathrm{PhD}$, showing me with his example that passion, dedication and hard work will always be rewarded, in one way or another.

The final thanks go to the people that took part in my life during these 6 years. My wife, my children, my parents and my sister, our families, for their patience, understanding, support, fights, smiles and games, and for their continuous stimulus to go forward, face the challenges and do not quit. After all, life is what happens to you while you are busy doing a PhD. 


\section{About the Author}

Emanuele was born on January 2, 1981 in Macerata, Italy. In 2005 he had his M.A. in International and Diplomatic Sciences from the university of Bologna, with a thesis on the Algerian energy policies of the last 30 years. He then had a M.A. in Environmental Law in 2006 from the Italian National Research Council (CNR) in Rome, Italy, with a thesis on the dispute between Argentina and Uruguay on the paper mills along the Uruguay river.

After working in a local NGO to support an orphanage in Mumbai, India, a stage at the Ministry of Foreign Trade in Rome and a period as a consultant on international trade for Small and Medium Enterprises, he moved to the University of Bologna in Ravenna, Italy. There he worked at UniAdrion, the Network of Universities of the Adriatic and Ionian Basin, where he was responsible for the secretariat and to support various crossborder training courses with Western Balkans universities (Albania, BosniaHerzegovina, Montenegro and Serbia).

In 2009, he moved to the European Commission Joint Research Centre (JRC), where he worked on the legal analysis of the monitoring requirements of EU legislation in the context of SEIS (Shared Environmental Information System). There Emanuele started his $\mathrm{PhD}$ as an external student of Wageningen university, sponsored by a 3-year grant from the JRC.

In the period 2014/2015 Emanuele worked as a trainee and a consultant for the Intergovernmental Oceanographic Commission (IOC) of UNESCO, contributing to a study on the risk to human communities from ocean ecosystems degradation.

After a parenthesis in Greece working in the private sector and a collaboration with the Hellenic Centre for Marine Research (HCMR) in the drafting of two proposals for project funding, in 2016 Emanuele collaborated with the JRC in support to the activities of the European Union Location Framework (EULF) Marine Pilot, aiming at fostering the use of INSPIRE to support the e-reporting for the Marine Strategy Framework Directive. 


\section{List of Publications}

\section{Peer-reviewed}

Bigagli, E., 2016. The international legal framework for the management of the global oceans social-ecological system. Marine Policy 68: 155-164.

Bigagli, E., 2015. The EU legal framework for the management of marine complex socialecological systems. Marine Policy 54: 44-51.

Zampoukas N., Piha H., Bigagli E., Hoepffner N., Hanke G. and Cardoso A. C., 2013. Marine Monitoring in the European Union: How to fulfil the requirements for the Marine Strategy Framework Directive in an efficient and integrated way. Marine Policy 39: 349351.

Bigagli, E., 2016. The role of the Marine Strategy Framework Directive for marine integrated management in Europe. Lessons from the Adriatic Sea. Ocean and Coastal Management, submitted.

Abramic, A., Bigagli, E., Barale, V., Assouline, M., Lorenzo-Alonso, A., 2016. Maritime Spatial Planning supported by INSPIRE. Ocean and Coastal Management, submitted.

\section{Conference proceedings}

Bigagli E., 2011. Data and information for an integrated assessment of the marine environment in Europe: theory, legislation and practice. Abstract for oral presentation at the 11th CoastGIS Conference, Ostend, Belgium, 5-8 September 2011. ISBN: 9788889405239.

Bigagli E., 2011. Marine Integrated Assessment. Theory, legislation and practice of marine monitoring in the European Union. Poster presented at the 1st Marine and Coastal Policy Forum, Plymouth, United Kingdom, 22-24 June 2011.

Babo R., Bigagli E., Smith R.S., 2010. Supply and Demand of European Environmental Monitoring in SEIS. Conference presentation for the INSPIRE Conference, June 2010, Krakow, Poland. 
Abramic, A., Bigagli, E.,2016. INSPIRE as a link between marine and maritime planning. INSPIRE Conference, September 2016, Barcelona, Spain.

\section{Other publications}

Zampoukas N., Piha H., Bigagli E., Hoepffner N., Hanke G., Cardoso A.C., 2012. Monitoring for the Marine Strategy Framework Directive: Requirements and Options. JRC Scientific and Technical Report. ISBN: 978-92-79-22811-7. 


\section{PE\&RC Training and Education Statement}

With the training and education activities listed below the $\mathrm{PhD}$ candidate has complied with the requirements set by the C.T. de Wit Graduate School for Production Ecology and Resource Conservation (PE\&RC) which comprises of a minimum total of 32 ECTS (= 22 weeks of activities).

\section{Review of literature (6 ECTS)}

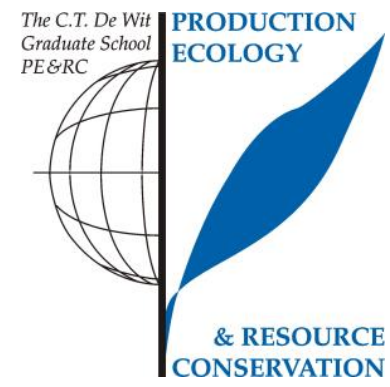

- Sustainability science; sustainability assessment; integrated assessment; marine social-ecological systems; marine environmental assessment and management; data and information requirements for marine assessment and management

\section{Writing of project proposal (4.5 ECTS)}

- Towards an integrated assessment of the marine environment in Europe: theory, legislation and practice

\section{Post-graduate courses (3.3 ECTS)}

- $\quad$ CERES training module on qualitative data analysis for development research; CERES, Den Haag (2011)

- Master class in marine spatial planning; Wageningen Centre for Marine Policy, Leeuwarden (2012)

- Seminar on composite indicators; European Commission Joint Research Centre, Ispra, Italy (2012)

- Workshop on shared approaches to assess costs and benefits of INSPIRE; European Commission Joint Research Centre, Ispra, Italy (2012)

\section{Laboratory training and working visits (4.5 ECTS)}

- Transboundary Waters Assessment Programme - The effects of climate change on coastal communities and the need for global governance; UNESCO, Intergovernmental Oceanographic Commission, Paris, France (2014)

\section{Invited review of (unpublished) journal manuscript (3 ECTS)}

- International Journal of Spatial Data Information and Research: Development of a marine spatial data infrastructure for the Mediterranean (2012) 
- International Journal of Spatial Data Information and Research: Framework for evaluation of marine spatial data infrastructures (2013)

- INSPIRE Conference: Review of six conference papers submitted to the conference (2013)

\section{Competence strengthening / skills courses (1.2 ECTS)}

- Scientific writing; European Commission Joint Research Centre, Ispra, Italy (2011)

- $\quad$ Clear writing; European Commission Joint Research Centre, Ispra, Italy (2012)

\section{PE\&RC Annual meetings, seminars and the PE\&RC weekend (1.2 ECTS)}

- $\quad$ Retreat of the Laboratory of Geo-Information Science and Remote Sensing; WUR (2012)

- $\quad$ PE\&RC Weekend (2013)

\section{Discussion groups / local seminars / other scientific meetings (6.1 ECTS)}

- Workshop on socio-economic benefits from the use of earth observations; European Commission Joint Research Centre, Ispra, Italy (2011)

- ENVIROFI Conference; European Commission Joint Research Centre, Ispra, Italy (2011)

- $\quad$ Scientific support to EU decision-making - Joint JRC-EUROSTAT seminar; European Commission Joint Research Centre, Ispra, Italy (2012)

- Seminars from researchers at European Commission Joint Research Centre, Ispra, Italy (2012-2013)

- JRC-CNECT-RTD Workshop on interoperable data infrastructures and open data; Ispra (2013)

- $\quad$ EUSAIR Stakeholders conference-EU strategy for the Adriatic-Ionian region; DG REGIO and DG MARE; Bruxelles (2013)

- INSPIRE Conference; Barcelona (2016)

\section{International symposia, workshops and conferences (3.5 ECTS)}

- First Marine Coastal and Policy Forum; poster presentation; Plymouth, UK (2011)

- $\quad 11^{\text {th }}$ Edition of CoastGIS; oral presentation; Ostend, Belgium (2011) 
This research was financially supported by the European Commission Joint Research Centre (JRC) through a 3-year grant (Grant number H10114).

Financial support from Wageningen University for printing this thesis is gratefully acknowledged. 